Faculty of Science and Informatics

Doctorate School of Geosciences

Department of Physical Geography and Geoinformatics

\title{
ASSESSMENT OF URBAN VEGETATION CHANGES ON DIFFERENT SCALES IN A SEMI-ARID REGION USING
}

SATELLITE IMAGERIES: A CASE STUDY OF ERBIL CITY, IRAQ

Ph.D. Dissertation

Shwan O. Hussein

Supervisors:

Dr. Ferenc Kovács

Dr. Zalán Tobak

associate professor

assistant professor 


\section{Contents}

CONTENTS 1

LIST OF FIGURES: ...........................................................................................................2

LIST OF TABLES:

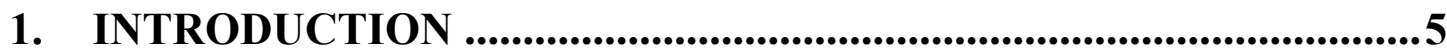

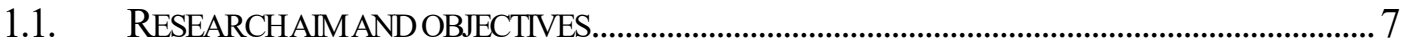

2. LITERATURE REVIEW ..........................................................................9

2.1. VEGETATION AREA AS AN IMPORTANT COMPONENT OF THE URBAN LANDSCAPE...9

2.2. REMOTESENSING INURBANVEGETATION STUDIES ................................................................ 11

2.3. URBAN VEGETATION, LAND USE AND LAND COVER STUDIES IN THE STUDY AREA ....21

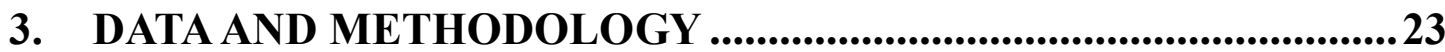

3.1. STUDYAREA..........................................................................................................................2

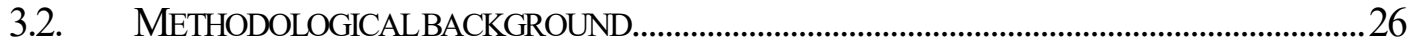

3.3. DATAANDMETHODS...................................................................................................................

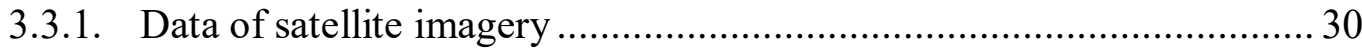

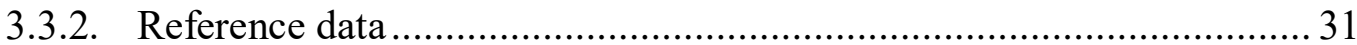

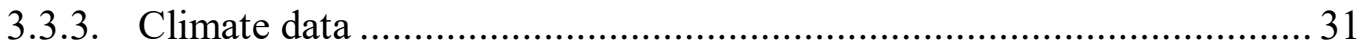

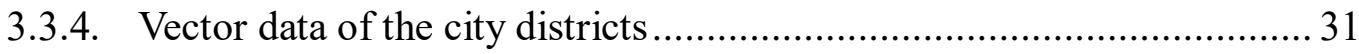

3.3.5. Scale 1: MODIS vegetation indices and land cover ................................. 31

3.3.6. Scale 2: Landsat satellite data and multispectral classification .............. 33

3.3.7. Scale 3: Pleiades very high-resolution imagery and multispectral classification .. 35

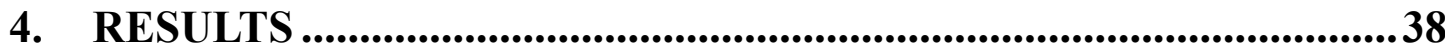

4.1. MONITORING SPATIOTEMPORAL VARIATION OF URBAN VEGETATION COVER USINGMODIS

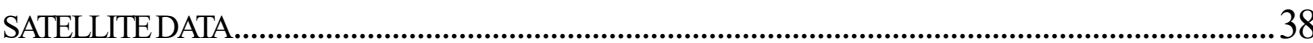

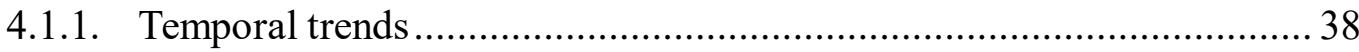

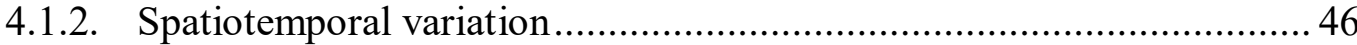

4.2. SPATIOTEMPORAL VARIATION OF URBAN GREENNESS COVER USING LANDSATIMAGERY 51

4.2.1. Results of Linear Spectral Mixture Analysis and Maximum Likelihood Classification 
4.2.2. Spatiotemporal variation of urban vegetation cover derived from

vegetation indices

4.3. SPATIALDISTRIBUTION OF VEGETATION COVER IN ERBIL CITY DISTRICTS USING HIGHRESOLUTION PLEIADES SATELLITE IMAGERY . 62

4.3.1. Results of land use land cover by Pleiades imagery........................... 62

4.3.2. Spatial distribution of vegetation indicator using NDVI ....................... 64

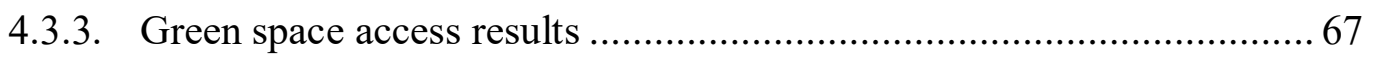

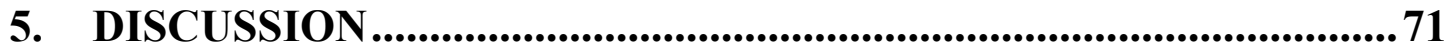

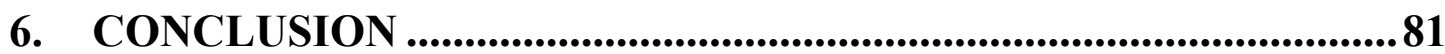

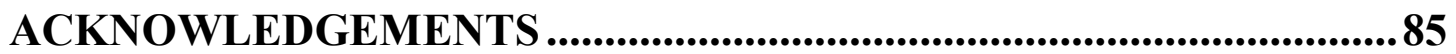

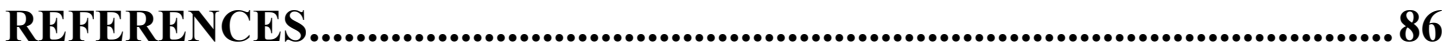

\section{List of Figures:}

Figure 2-1: Represents Relationships among Elements of the Environment- Economy- Society in an Urban Landscape. 9

Figure 2-2: Global Urban and Rural Temperature Difference ......................................... 10

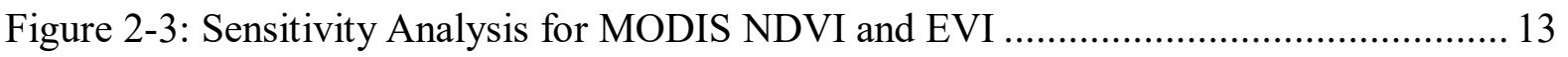

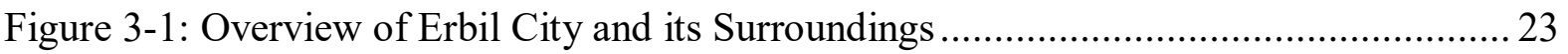

Figure 3-2: Monthly Precipitation 1941-2015, Monthly Air Temperatures, and Monthly

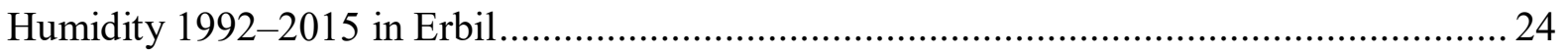

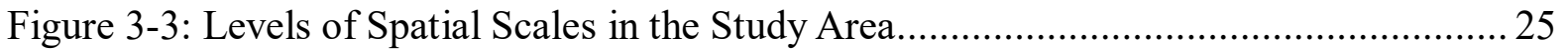

Figure 3-4: Pre-Processing and Processing of MODIS Satellite Imagery Data at Scale 1 ..... 32

Figure 3-5: Pre-Processing and Processing of Landsat Satellite Imagery Data at Scale 2 ..... 34

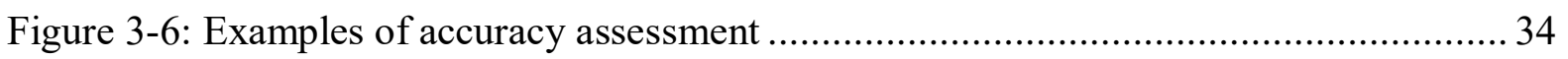

Figure 3-7: Pre-Processing and Processing of Pleiades Satellite Imagery Data at Scale 3..... 36

Figure 4-1: NDVI Monthly Summary Statistics for 2000-2015 ...................................... 40

Figure 4-2: EVI Monthly Summary Statistics for 2000-2015 …................................... 41

Figure 4-3: Monthly plots of NDVI and EVI Summary Statistics for 2000-2015 _............. 42

Figure 4-4: Mean NDVI \& EVI Yearly Values for 2000-2015, Comparing 5 Land Cover Types.. 43

Figure 4-5: Total Annual Rainfall and Average Temperature Time-Series from 2000 - 2015...... 44

Figure 4-6: Annual Mean Humidity Time-Series from 2000 - 2015 ................................ 45

Figure 4-7: Spatiotemporal Distribution of Land Cover Types ......................................... 47 


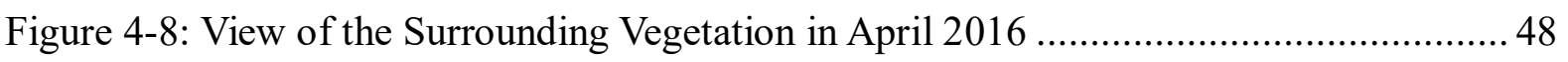

Figure 4-9: April NDVI Raster Time-Series of Erbil from 2000 to 2015 ........................... 49

Figure 4-10: April EVI Raster Time-Series of Erbil from 2000 to 2015 ............................. 50

Figure 4-11: MLC Land Cover Classification (Area, hectares) .......................................... 52

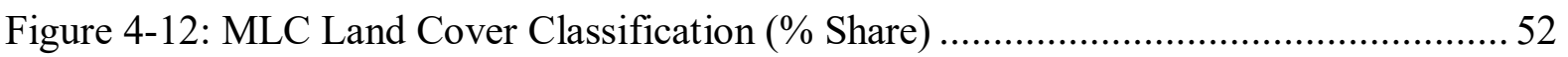

Figure 4-13: LSMA Land Cover Classification (Area, hectares) ........................................ 53

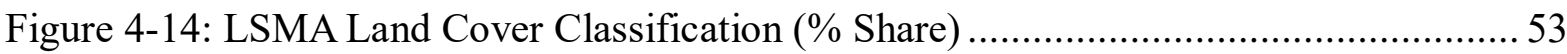

Figure 4-15: A Visual Samples of Landsat Imagery Represent Distribution of Vegetation in Erbil ... 55

Figure 4-16: MLC Spatiotemporal Variation of Land Cover Types .................................... 56

Figure 4-17: LSMA Spatiotemporal Variation of Land Cover Types .................................. 57

Figure 4-18: NDVI Measure from Landsat Imagery ......................................................... 59

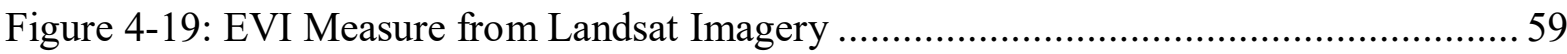

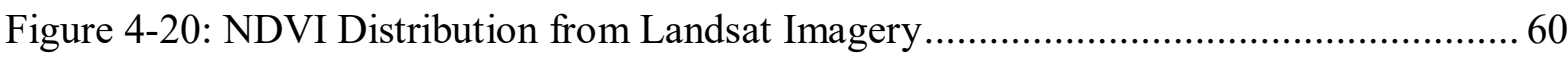

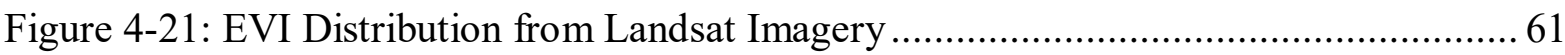

Figure 4-22: Land Cover Classes according to Pleiades Imagery ….................................. 63

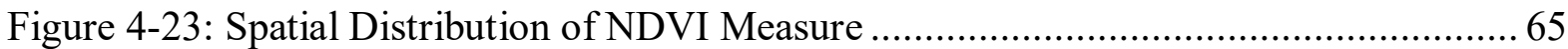

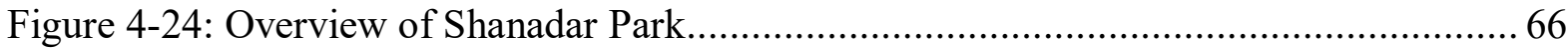

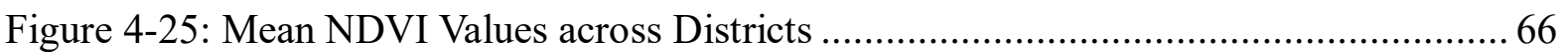

Figure 4-26: A Visual Samples of Pleiades Imagery Represent Distribution of Vegetation in Erbi.... 67

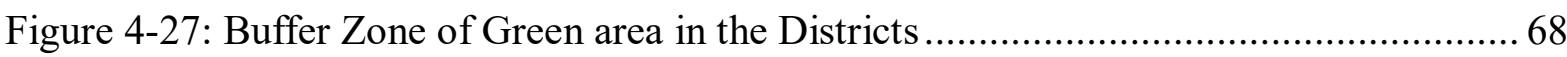

Figure 4-28: Distribution of Districts within the Scales of the Buffer Zones ...................... 69

Figure 5-1: Spatial-Temporal Comparison of MODIS and Landsat land cover from 2000 to 2015 ... 72

Figure 5-2: Statistical Comparison of land uses for MODIS and Landsat from 2000 to 2015..... 73

Figure 5-3: Compares Mean NDVI and EVI Values for MODIS and Landsat from(2000-2015).. 74

Figure 5-4: Spatial-Temporal Comparison of MODIS and Landsat EVI (2000-2015) ......... 75

Figure 5-5: Spatial-Temporal Comparison of MODIS and Landsat NDVI (2000-2015) ...... 76

Figure 5-6: Spatial Comparison of Landsat MLC, LSMA, and Pleiades Land Uses in 2015 ...... 77

Figure 5-7: Land Use Shares across Landsat MLC, LSMA, and the Pleiades in 2015 ......... 78

Figure 5-8: Comparison of MODIS, Landsat, and Pleiades NDVI in 2015 ....................... 78

Figure 5-9: Spatial comparison of MODIS, Landsat and Pleiades NDVI in 2015 ............... 79 


\section{List of Tables:}

Table 3-1: Features of Different Remote Sensing Data ............................................... 27

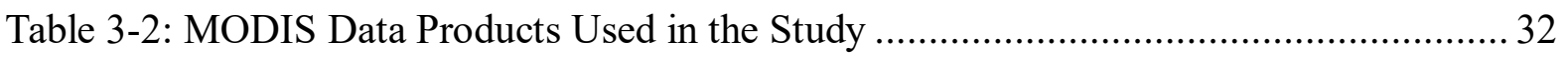

Table 3-3: Description of the Satellite Imagery Used in the Study ................................... 33

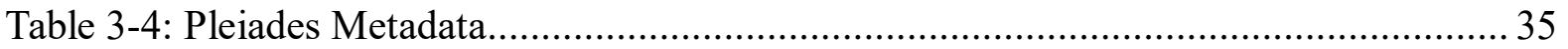

Table 4-1: Correlation Analysis between Monthly Rainfall, Humidity, Temperature and

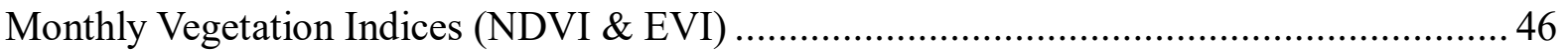

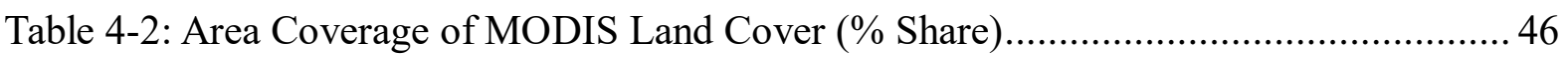

Table 4-3: Classification Accuracy Assessment for LSMA and MLC Methods .................... 55

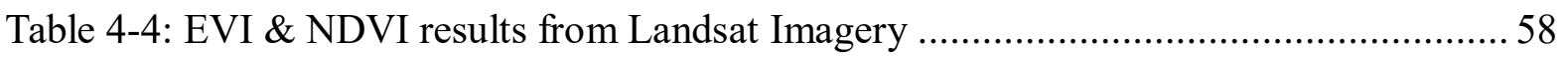

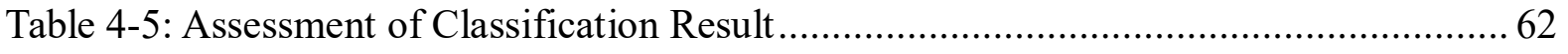

Table 4-6: Percentage of land Use Classes for each District of Pleiades Imagery ................. 64

Table 4-7: Percentage Districts within the Scale of the Buffer Zones ................................. 70 


\section{Introduction}

The rising world population, income levels, and urban density led to increasing demand for all kinds of goods and services, including the land. As a relevant development, a rising share of the world population started living in urban areas and large cities. Urban living is not an old concept. Ritchie and Roser (2018) note that before the seventeenth century, less than $5 \%$ of the population lived in urban settings, and by 1900 this ratio was only $16 \%$. So, it was in the 20th century that the world experienced very high levels of urbanisation. The new capitalist economic system where the production is centralized in the large factories and the relationships economically take place in clustered that considered one of the driving sources of increasing urbanisation. According to the UN World Urbanisation Prospects (2018), the urbanisation level in 2015 was $91.4 \%$ for Japan, $82 \%$ for the US, $70 \%$ for Iraq, $56 \%$ for China, and $33 \%$ for India, with the world average being 56\%. Another development that accompanied the urbanisation trend is the rising urban density. Namely, the established cities generally have limited capacity to grow in terms of their land areas, while the number of people living in these cities tends to increase faster. This process, in return, leads to a higher population density in the urban areas. According to the UN-Habitat Global Observatory (2014), the population density is 44000 persons $/ \mathrm{km}^{2}$ in Dhaka, 32300 persons $/ \mathrm{km}^{2}$ in Mumbai, 11600 persons $/ \mathrm{km}^{2}$ in Delhi, 7100 persons $/ \mathrm{km}^{2}$ in Sao Paulo, 5800 persons $/ \mathrm{km}^{2}$ in London, 3900 persons $/ \mathrm{km}^{2}$ in Paris, 2400 persons $/ \mathrm{km}^{2}$ in Los Angeles, 1800 persons $/ \mathrm{km}^{2}$ in New York, and in Erbil 473 persons $/ \mathrm{km}^{2}$. While urban density rates can vary significantly across cities, the rising trend is evident in most parts of the world. As another essential trend, around $12 \%$ of the world population lives in megacities with sizes larger than 10 million. However, the higher speed of urbanisation and growth of large metropolitan areas, especially in developing countries, come with significant problems as improving infrastructure and maintaining the quality of urban services are difficult with such fast trends. Rakonczai (2018) notes that some of the relevant issues include "not enough main waters," "no hygienic toilets, sewage systems," "problems with transportation, waste removal services," "air pollution," and "excessive urban growth." Then, these problems create high social, political, and economic costs for these developing countries. To give some context to the concentration of human effects on the Earth. Ritchie and Roser (2018) estimate that only $1 \%$ of the global habitable area is useful for urban infrastructures. European Commission (2019) provides more accurate numbers for the EU countries. The report estimates that the share of land area in the EU used for urban centres is $0.9 \%$, and it is $2.9 \%$ for urban clusters, making the total metropolitan area share $3.8 \%$. Another classification in the same report estimates the land share of cities in the EU at $4 \%$. 
Within the above context, one issue that emerges as crucial for the quality of life in urban areas is the vegetation area or green fields. These areas provide relaxation and entertainment opportunities to the citizens as well as they become essential to address climate issues. In terms of economic value, houses/accommodations can be more expensive if they are close to vegetation in the city. In the last decades, the pressures on vital ecosystem functions have increased rapidly due to the expansion in the global population, higher demand for land consumption, and the robust urbanisation process. So, both the rate of urbanisation and the loss of vegetation are two interrelated developments rapidly increasing across the world (Weng et al., 2004; Liu, Y. et al. 2015). The rise of urban areas is one of the factors supporting climate change, and in return, cities can be significantly affected by climate change. More volatile heat and rain patterns can put significant constraints on the city infrastructures as well as the life quality of its citizens, including air pollution. In this setup, green fields emerge as an essential measure to address climate change challenges in the cities. Poor planning and lack of enough vegetation area can lead to the problem of Urban Heat Island (UHI) effects (Arnfield, 2003). Then, it is possible to use vegetation to reduce the impact of UHI. The vegetation cover is also known to affect the social and physical environment in more than one way (van den Bosch \& Ode Sang, 2017). The influence of urban greenery to the quality of human life considered aspects of better air quality, stress reduction, and even social contacts (Grimmond, 2007; Carrus et al., 2015). The lack of vegetation can alter many types of environmental conditions such as climate change, biodiversity, and the quality of water and air. Then, higher levels of vegetation area, as well as its optimal spatial distribution over the city, would balance some of the adverse climate change effects and limit the environmental costs of cities. Therefore, the proper measurement of vegetation area and the assessment of its spatiotemporal distribution are essential inputs in the urban planning and development policies and studies.

The current dissertation focuses in this research field, and it uses satellite imagery technologies to study the spatial and temporal distribution of vegetation area in a semiarid region, such as the city of Erbil in Kurdistan, Iraq has experienced an intense urbanisation process and providing enough infrastructure and maintaining the quality of urban services stand out as essential problems. While covering all dimensions of urbanisation problems is out of scope for the current dissertation, this research project focuses on the urban vegetation dimension. It conducts a detailed analysis of the evolution of surface topology, and especially the vegetation areas, in the city covering the period of 1990-2015. The distribution of green spaces within the city limits is also displayed as it matters for the inhabitants' quality of life. The measurement of vegetation areas involves various parameters like the "frequency, cover, 
density, and biomass" of a specific area (Bonham, 2013). The primary technological tool for this purpose is the use of remote sensing using satellite imagery technologies. Bonham (2013) states that "spectral imagery from aerial and satellite platforms can be used effectively to describe vegetation-environmental systems as a combination within pixels produced by the spectral imagery. These pixels can be ground located within a reasonable precision level, sampled by the use of quadrats, lines, and/or points to obtain a description of species composition, biomass, density, and/or ground cover". Among the remote sensing technologies based on satellite imagery, there are various sensors that differ in terms of coverage and precision. The current dissertation uses data from three different sources, i.e., Moderate Resolution Imaging Spectroradiometer (MODIS) sensor, Landsat satellite, and Pleiades satellite. So, these three data sets provide a mapping from larger to smaller scale, with rising resolution and precision levels. In this way, various indices, statistical measures, and graphical representations produced at different spatial scales.

\subsection{Research aim and objectives}

Based on the above research rationale and motivation, the main aim of this research is to utilise different remote sensing data and sensors at different spatial resolutions (from large to small) to study and analyse the spatial and temporal patterns of the vegetation cover in the city of Erbil. The study further attempts to use these data to characterise and discuss the influence of urbanisation in the city on the spatial distribution and the temporal dynamics of the vegetation cover. Then it evaluates the usefulness and the suitability of the applied land surface data as a means to study vegetation cover from a temporal and spatial perspective. So, the goal of the research project is to provide a comprehensive picture and understanding of the urban vegetation dynamics in the last decades, to examine the factors affecting these dynamics, and to assess the access of citizens to the green areas in the city limits. Within this context, three objectives mentioned as follows:

First objective: To investigate the spatiotemporal variation of urban vegetation cover in the city and its surroundings using the MODIS sensor and examine its relation to climate conditions. In this objective, the following research questions that addressed below:

How did the spatiotemporal variation of urban vegetation cover in the city and its surrounding area measured by the MODIS sensor in the last decades, and how is it related to climate conditions?

How did urbanisation impact the vegetation and quasi-natural (grassland) vegetation in the city and its surroundings? 
Second objective: To study the spatiotemporal variation of urban greenness cover in the city limits and examine the role of urban expansion, using Landsat satellite data. In this objective, the following research question that addressed below:

What is the influence of urbanisation on the temporal dynamics and spatial distribution of vegetation cover in the last decades inside the city limits?

Third objective: To provide a detailed analysis of urban greenness distribution for particular city districts using Pleiades satellite data in the last decades and examine the access of city dwellers to green areas. In this objective, the following research question that addressed at the following:

How the urban greenness distributed within a particular district of the city, and what is the level of greenness access to city dwellers?

One can also construct relevant hypotheses for the three research objectives and questions in the context of the city of Erbil as follow:

The first hypothesis stated as H1: Spatiotemporal variation of urban vegetation cover in the larger city area is related to the climate conditions.

The second hypothesis can be put forward as $\mathrm{H} 2$ : The spatial and temporal changes in the urban vegetation in the city of Erbil have a close association with the urban expansion.

The third hypothesis stated as follows: H3: The spatial distribution of urban vegetation worsened over time in terms of the access of the habitants to green areas within feasible distances.

As the coverage of the research problem and hypotheses is pervasive, complementing imagery data from different satellites becomes valuable to get a comprehensive picture of the relevant issues. Besides, using multiple platforms helps address problems at different scales. In terms of the research concept and methodology, the project follows quantitative research methods based on multispectral content where the raw imagery data pre-processed, processed, and then converted into various surface coverage types and Spectral Vegetation Indices (SVIs). In line with the relevant literature, commonly used SVIs, the Enhanced Vegetation Index (EVI), and the Normalized Difference Vegetation Index (NDVI) constructed for each satellite imagery data. Then, the evolutions of these indices that examined in terms of the spatial and temporal distribution of greenness. With a perspective on their connections to the practical life that could be used for mapping and monitoring the urban vegetation and land cover dynamics for planning purposes to give a clear notion to the city planners and authorities, besides, it is a central issue to the understanding of urban ecosystems and gives the researchers access for further studies, related to the study field. 


\section{Literature Review}

The research topic has two dimensions. The first one is the vegetation cover in urban cities and their relation to the life quality of city habitats, climate change issues, and urban planning. The second one is the use of remote sensing and satellite technologies in the identification of surface cover types, including the vegetation area.

\subsection{Vegetation area as an important component of the urban landscape}

The global area covered by urban land, built-up and impervious surface, were $3 \%$, $0.65 \%$, and $0.45 \%$, respectively, of the world's total land area in 2010 (Liu, Z. et al., 2014). While low, the impacts of urbanisation are essential from the local to the global scale. Urban areas now account for about $60 \%$ of housing water use, $75 \%$ of energy use, and $80 \%$ of human greenhouse gas emissions. Ecosystem processes, biodiversity, ecosystem services, human wellbeing, and their relationship to urban landscape are severely affected by the speed and spatiotemporal pattern of urbanisation that is driven mainly by socio-economic processes (Figure 2-1). As a consequence, this helps to understand the effect of urbanisation on these critical elements (Wu, 2014).

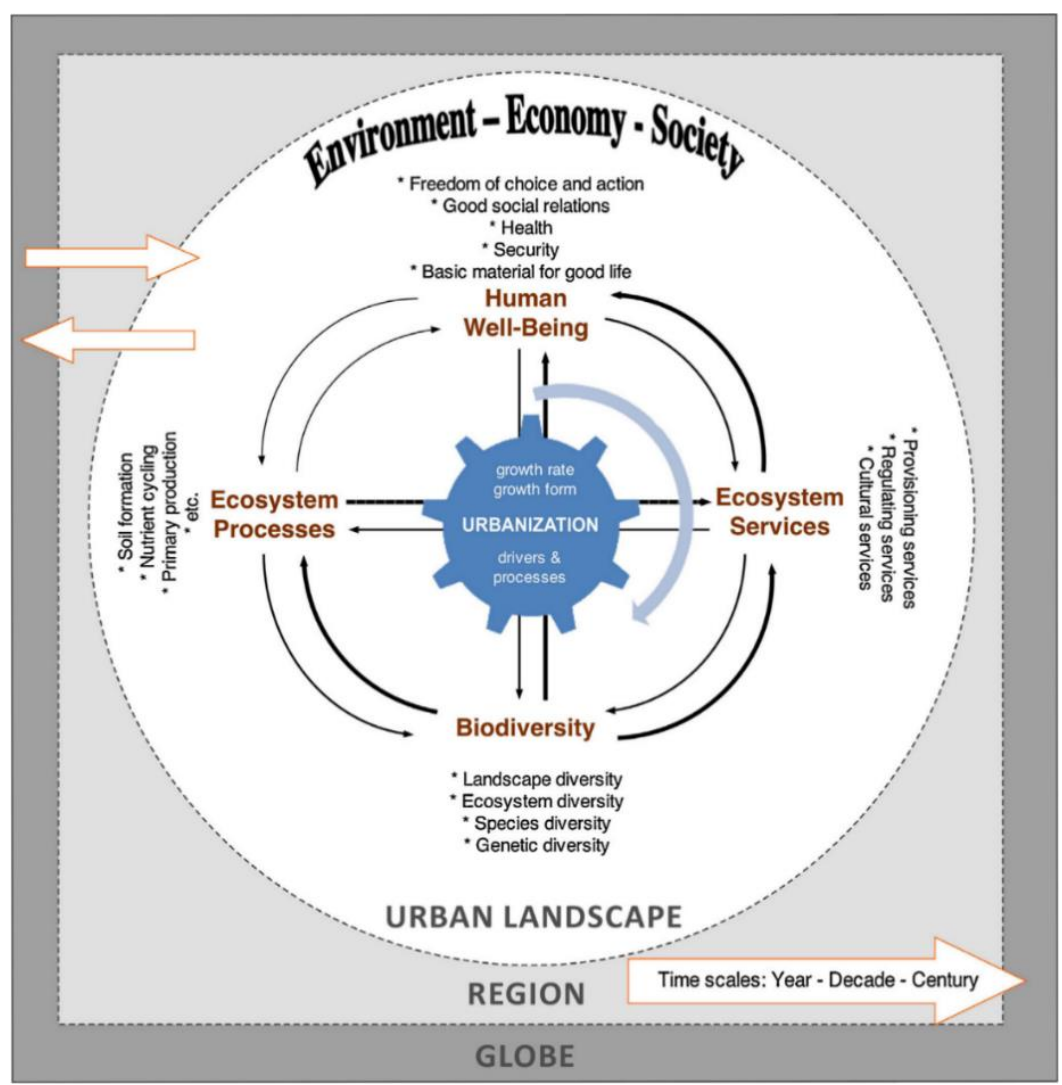

Figure 2-1: Represents Relationships among Elements of the Environment- EconomySociety in an Urban Landscape (Wu, 2014) 
Vegetation area in the urban landscape describes all forms of plant life located within the city environments. These may include pre-existing native plant species to the exotic plants introduced by city dwellers to improve the city landscape and include shrubs, trees, grass, and even flowers. Urban vegetation might be widespread, but, in some instances is concentrated along roadsides, urban parks, and forests, around ponds and streams, or even within urban homesteads and residential plots. Traces of urban vegetation exist at the wastelands and the less built sections of the cities and the aquatic green spaces. These vegetation types fall into three subcategories. (1) The natural plants existed before the construction of the city; (2) the semi-natural exist due to human interference while the (3) introduced plants are those found planted along the roads such as gardens, roadside trees and green belts (Tzoulas et al., 2007; Liu, T. \& Yang, 2013; J. Zhao et al., 2013; Blanusa et al., 2019).

The presence of urban vegetation proves useful in many ways. These include reducing air pollution, moderating the UHI problem, where the statistics show a significant problem worldwide, termed as local climate regulation, absorbing noise, enhancing recreation, and ensuring air quality (Figure 2-2). They also offer aesthetic and while some plant species used in educational services. The scale of importance of urban vegetation depends on the needs of the city residents, but, most importantly, they are responsible for urban ecosystem regulation and improved quality of urban life (Rafiee et al., 2009; Tang et al., 2012; Zhao et al., 2013). Therefore the current model of land use is vital for sustainable ecological preparation, growth, management, and protection.

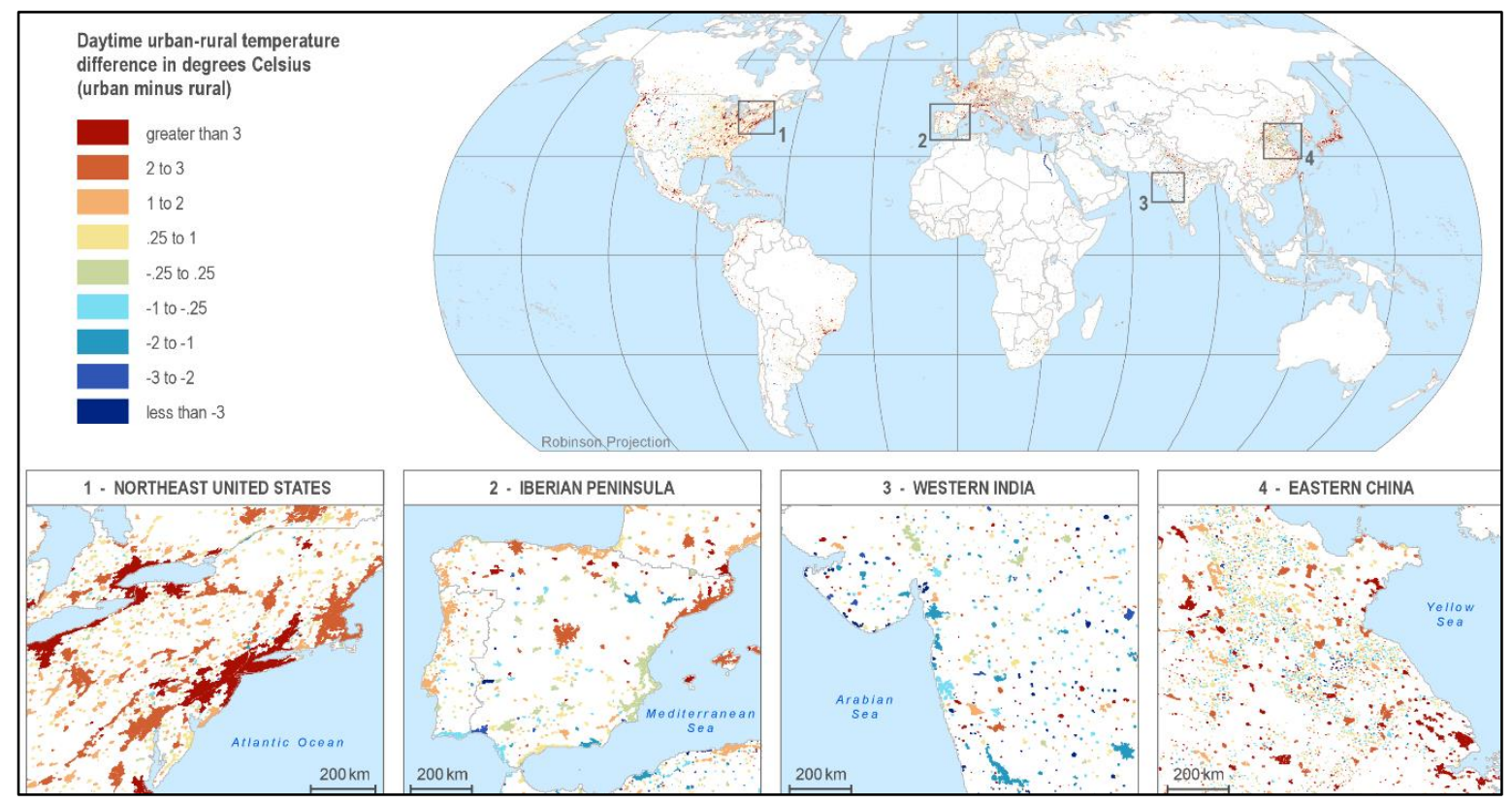

Figure 2-2: Global Urban and Rural Temperature Difference (Center for International Earth Science Information Network, 2013) 
Impervious surfaces have a relation to the density of UHI in urban areas where the concentration of the human activity focused in a small area (Mucsi et al., 2017). The former is very detrimental to the micro-climate of the respective city. The most crucial challenge of vegetation deficiency in the cities is the UHI effect. Here, the high $\mathrm{CO}_{2}$ concentration leads to increased city temperatures, thereby causing discomfort and health complications to the residents (Pataki et al., 2006; Imhoff et al., 2010; Unger et al., 2014). Other than the provision of shadows, the urban greenery mitigates UHI through $\mathrm{CO}_{2}$ balance and evapotranspiration hence the significance of having urban vegetation (Small \& Miller, 2000). It has strongly counted as a significant part of the urban ecosystem. In reinforcing the vital role played by vegetation in UHI mitigation, urban planners are responding by using artificial coverage such as using reflective building surfaces to minimise solar insolation that would otherwise lead to city warming (Bretz et al., 1998; Solecki et al., 2005).

Decision making plans to specialise in the distribution of urban vegetation is already underway. De la Vega-Leinert et al. (2012) looked into UNESCO's plan which seeks to change the land-use patterns in the city. They elaborated that the ongoing conversion of urban settlements into areas of development considered systematically and while paying serious attention to nature. Further, there is a selection of plans to encourage the protection of indigenous species with large biomasses such as forested, green areas, and the ability to adapt it to urban habitats. The conversion of urban centres into developed areas through rapid industrialization and expansion of settlements threaten existence in the city of the urban ecosystem (Tredici, 2010). It is particularly alarming since contact with the natural environment is known to promote health (Tzoulas et al., 2007). A current land use baselines model is essential for sustainable ecological preparation, growth, management, and protection.

\subsection{Remote sensing in urban vegetation studies}

The analysis of urban vegetation change by satellite imagery became an increasingly common and efficient method to study urbanisation impacts on vegetation in urban areas (Yunhao et al., 2006; Rafiee et al., 2009; Tang et al., 2012). Spatial and temporal changes in terrestrial ecosystems can be identified, mapped, and monitored by using multi-temporal data, multi-spectral, and satellite-sensor acquired data. Both natural and anthropogenic generate spatial and temporal changes that identifying the use of remote sensing techniques and satellite imageries (Martínez \& Gilabert, 2009). Therefore, to study urban vegetation change on different scales, this research draws on multi-spatial and multi-temporal resolution remote sensing data literature, including methods of (1) high temporal resolution, (2) moderate 
temporal and spatial resolution and (3) high spatial resolution. The literature review chapter provides a description of SVIs and their applications, then the selected studies grouped according to the satellite sensors, i.e., MODIS, Landsat, and high-resolution data with a particular focus on current approaches. To present a discussion of remote sensing applications in various fields that related to the urban. Finally, highlight the most significant previous studies related to the study area.

The identification of the spatial and temporal analysis of vegetation cover globally identified as a highly urgent need, for assessing the level of threat and for developing strategies to overcome the risks to the living beings (Kong \& Nakagoshi, 2006). The spatial pattern and temporal dynamic analysis hold much significance, where the results of the analysis provide insights into the rate of change of the vegetation cover and the average of changing the urbanisation. Hence, have proven to deliver a pool of benefits such as assessing urban ecological, identify the geographical distribution patterns as well as the time series patterns, simultaneously (Zhou \& Wang, 2011; Wu, 2014).

The centre of this study was the use of Spectral Vegetation Indices (SVIs) such as the NDVI and EVI in extracting patterns of vegetation cover in the area of study. To better differentiate between the individual spectral features separating the various forms of vegetation cover, the study relied on the high-resolution remote sensing satellites to process the images. In the SVIs, NDVI provided adequate sensitivity to vegetation presences and density used in quantifying biomass (Balik et al., 2017). it used solely to predict the natural vegetation cover due to its high highly sensitive to the vegetation existence and dynamics (Zhang, X. et al., 2006). The EVI, is less effective in predicting the actual vegetation but improves the quality of an NDVI product by eradicating the background cover of canopies (Xiao et al., 2009).

Ji and Peters (2007) compared the NVDI and EVI sensitivity to biophysical parameters; statistics show "a high relative sensitivity of NDVI to EVI when NDVI is less than 0.72 and high relative sensitivity of EVI to NDVI when NDVI is greater than 0.72 , and this indicates that NDVI is more sensitive to the low-density canopy, and EVI is more sensitive to the highdensity canopy" (Figure 2-3).

The majority of studies in the literature has focused on the use of different SVIs derived from medium to low spatial resolution data such as; Landsat, and MODIS (Buyantuyev et al., 2007; Martínez \& Gilabert, 2009; Ahmad, 2012; Bhandari et al., 2012; Fatiha et al., 2013; Kovács \& Gulácsi, 2019). Whereas the other studies used spectral and pixel-based classification methods when using high-resolution satellite imagery likes IKONOS, SPOT, Worldview, and Rapid-Eye (Kong \& Nakagoshin, 2005; Hofmann et al., 2011; Noor et al., 
2013). SVIs are spectral transformations of two or more spectral bands developed by algorithms to optimize plant properties to evaluate vegetation distribution, biomass, and dynamics of change in quantitative and qualitative terms (Huete et al., 2002). In the diverse urban environment, green vegetation is comparatively distinct and homogeneous, due to its unique electromagnetic spectral activity during photosynthesis. Thus, even at the pixel level, extracting green vegetation is easier compared to other cover types, using only spectral attributes. Vegetation indices often used to improve image information to promote this process (Anchang et al., 2016).

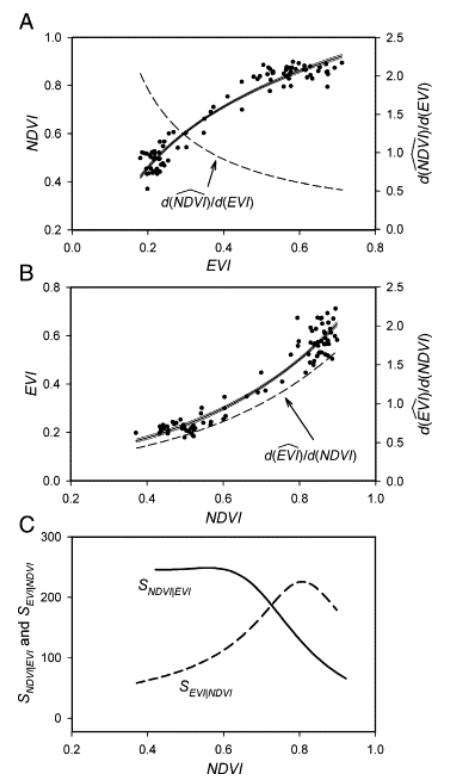

Figure 2-3: Sensitivity Analysis for MODIS NDVI and EVI. “(A) NDVI on EVI regression function (thick solid line), one standard error (thin solid line), and first derivative (dashed line). (B) EVI on NDVI regression function (thick solid line), one standard error (thin solid line), and first derivative (dashed line). (C) Relative sensitivity of NDVI to EVI (sNDVI|EVI) and relative sensitivity of EVI to NDVI (sEVI|NDVI)" (Ji \& Peters, 2007)

For this reason, it has been widely used by researchers to study vegetation cover. On the other hand, because of the variety of different combinations of light spectra, instrumentation, platforms, and resolutions used, there is no single mathematical definition that describes all Spectral Vegetation Indices (SVIs). The advantage of SVIs is that it allows the extraction of long-term data series to be reliable and comparable, which can be low-cost. However, there are two main problems: spatial resolution and revisitation time, particularly on the MODIS and Landsat platforms, revisit time for MODIS is 1-2 days for the same point where it is 16 days for Landsat. Also, passive sensors can't reach the atmosphere, and there is no useful data collection for cloudy days. New satellites, including the Pleiades, have recently increased pixel resolution with potential daily revisit any Earth point within one day. However, the images on this platform may be costly for long-term data series studies (Xue \& Su, 2017). 
As a result, the current study used three different data sources and three different scales combined to construct effective vegetation indices.

It has proved that the MODIS data can provide information necessary for monitoring ecosystem dynamics at adequate spatiotemporal resolution using vegetation indices such as EVI and the NDVI (Schucknecht et al., 2013; Zoran et al., 2013; Esau et al., 2016; Li, F. et al., 2016; Hussein et al., 2017). MODIS NDVI generally has a higher range of values over semiarid sites, and the opposite for more humid forested sites with a lower range (Huete et al., 2002). With the support of satellite imagery time-series data, it became possible for researchers to obtain phenological information at various spatial and temporal intervals. According to the previous studies, the first use of MODIS data in the identification of the key phenological parameters using NDVI described in publications by Zhang, X. et al. (2003). Mertes et al. (2015) demonstrated a methodology over East Asia to monitor urban land expansion at continental to global scales using a multi-temporal composite change detection approach based on MODIS $250 \mathrm{~m}$ annual maximum EVI index data improved. The classification results are capable of distinguishing between landscape changes in the urban environment. Yuan and Bauer (2007) demonstrated a strong correlation between impervious surface and land surface, covering twin cities of Minnesota.

Friedl et al. (2002) noted that: "Advanced very high-resolution radiometer (AVHRR) observations were the only viable source of data for global land cover mapping." MODIS data presented better information on the spectral, spatial, geometric, and radiometric characteristics of the land surfaces for large scale mapping. MODIS was used to construct global land cover maps at 1-km spatial resolution. The initial data mapping trained using information collated from particular sites with high-resolution imagery and supplementary data. They use the International Geosphere-Biosphere Programme Data classification system, with its 17 land surface types ranging from different types of forest to shrubland, savannah, grassland, wetland, cropland, and urban and high-density land. "The quality of the early results presented in this paper, therefore, provides strong evidence supporting the radiometric quality and spectral information content of MODIS data for large-scale land cover mapping applications." This result has further strengthened our confidence in using MODIS to determine the land cover types in the Erbil region.

Zhang, X. et al. (2003) used MODIS to examine the vegetation dynamics for the Northeastern region of the USA. Vegetation phenology is dependent on climate and water conditions. Across a year, vegetation intensities can display high variability depending on major phenological vegetation phases. The authors followed the rate of change in the curvature of the 
fitted logistic models is employed over a 16-day time period and constructed moving EVI indices over a year. They examined the phenological transition dates of vegetation and reflection values. This study shows that MODIS can be used to provide "a flexible means to monitor vegetation dynamics over large areas using remote sensing."

Another relevant point the current study used data from three different sensors to construct SVIs, providing a comparative analysis among them. Lunetta et al. (2006) used 250 m multi-temporal MODIS NDVI 16-day composite data. MODIS cannot capture dynamics within areas of size 1.5 ha. Also, urban areas often have lower accuracy levels.

A series of recent studies have indicated that MODIS SVIs time-series used to carry out surveys of the urban vegetation phenology. Mostly, it uses SVIs to investigate vegetation dynamics and keep them under observation using methodology that is fit for urban areas with a low density of biomass (Zoran et al., 2013; Li, F. et al., 2017).

Zoran et al. (2013) explored the use of time-series MODIS NDVI 16-day composites with a $250 \mathrm{~m}$ spatial resolution (MOD13Q1) between 2002 and 2012, to examine urban vegetation land cover dynamics for the metropolitan area of Bucharest. The vegetation dynamics in urban areas at seasonal and longer timescales reflect large-scale interactions between the terrestrial biosphere and the climate system to understand the urban vegetation dynamic. Also, Li, F. et al. (2017) compared MODIS NDVI with $250 \mathrm{~m}$ spatial resolution (MOD13Q1) and HJ-1A/B NDVI satellite data to analyse urban vegetation phenology using the time-series method in the city of Nanjing in China; their research indicates MODIS NDVI time series reflect better temporal variation because of coarse spatial resolution that shows the trend of vegetation growth and is more appropriate to ascertain the main growth period of vegetation. These underlines demonstrate just how important uses the coarse spatial resolution in our study.

One of the first studies on Landsat imagery to assess the urban greenness areas conducted in 1987; it focused on defining the spatial patterns of urban vegetation and separate woody and herbaceous vegetation (Sadowski et al., 1987). The most relevant studies regarding the use of remotely acquired data are by Small \& Miller (2000), Myint (2006), Tang et al. (2012), Gupta et al. (2012), and Liu, T. \& Yang (2013). They focused on the basic concepts of subpixel classification techniques and endmember extraction. Other studies have used vegetation indices in land-use change analysis, such as Salimi Kouchi et al. (2013), who derived indices like NDVI, Soil Adjusted Vegetation Index (SAVI) and spectral mixture analysis method (SMA). Tooke et al. (2009) used the SMA and decision tree classification methods. Numerous other studies focused on the subject matter and consequently provided 
distinctive results. These include research carried out by Dewan and Yamaguchi (2009), ElKawy et al. (2011), Rawat, and Kumar (2015). Melaas et al. (2016) have examined the impact of elevated temperature in Boston-USA on eco-physiological processes in urban areas and showed the strong coupling between Boston's surface heat island and vegetation phenology at the scale of both individual landscape units and for the region as a whole. The composite nature of pixels is a weakness of remotely sensed data, which led to not being ultimately used. The potential problems of image assessment are therefore considerably affected by the mixed nature of spectral data limiting the accuracy of spectral analyses. One of the methods of image analysis to address mixing problems was the spectral mixture analysis (Somers et al., 2011). One of the disadvantages of Linear Spectral Mixture Analysis (LSMA) is the number of endmembers restricted by the number of available bands provided by image data; also, the reflective values cannot differentiate the features automatically by values alone thus, the selection of end-member images requires higher spatial resolution images (Tang et al., 2012).

Concerning the specifics of the most examined-related studies evaluating urban growth and urban vegetation by applying various remote sensing methods. Rafiee et al. (2009) using ML classification on NDVI in Mashad city based on multispectral and multi-spatial (Landsat TM and IRS LISS-III imagery belonging to 1987 and 2006 respectively) to obtain a detailed change matrix for urban green areas during the 19 years. The study emphasises that the combination of satellite image classification and vegetation indices is a reliable tool to analyse vegetation trends and life quality in urban areas. Consequently, this present study draws on the combination of classifications, vegetation indices, and climatic parameters to evaluate urban greenness changes.

Another study developed by Tang et al. (2012) have combined Maximum Likelihood Classification (MLC) and LSMA as classifications using three Landsat TM datasets to characterise and analyse the urban greenness changes in the Baltimore-Washington corridor area. The research results appear very high in accuracy for both classifications; the LSMA classification has higher efficiency and shows that LSMA extends a better-classified map than the MLC, and also shows that the greenness in the study area has continuously decreased and has impacted the morphology of the urban environment. Rawat \& Kumar (2015) have analysed the dynamics of land use and land cover in Almora District (Uttarakhand, India), using Landsat TM from 1990 to 2010, the MLC used to classify different land use, and land cover shows that agriculture areas have decreased, while built-upon land and vegetation areas have increased over the 20 years, it concluded that multi-temporal satellite imagery has a vital role due to the significant results; highlighting that remote sensing combined with GIS represents a reliable 
approach to quantify spatial phenomena. The study uses the MLC method and Landsat satellite images in urban vegetation mapping. Liu, T., and Yang (2013) employ the multiple endmember SMA method and the stratified classification technique to study the vegetation cover in the Atlanta metropolitan area the authors conduct different analysis with the data, including landscape partition, sub-pixel analysis, and supervised classification and NDVI. Their method is very robust in identifying the vegetation cover density and types. They show the relevance and robustness of Landsat imagery data and relevant techniques in examining vegetation issues.

Elmore et al. (2000) have combined methods like SMA and NDVI in quantifying vegetation variables in the Owens Valley, California, based on fourteen Landsat TM images from 1984 to 1997. This outlines that considered NDVI is a reliable source of data regarding changes of greenness for an area, and SMA is an exact method to measure land cover variables. The results obtained linked with the present study by supporting the use of NDVI and SMA approaches to classify Landsat images in vegetation mapping and land cover variables.

Zhou and Wang (2011), have used supervised classification methods like MLC and also landscape metrics analysis on three different types of satellite imageries; namely Landsat 5 TM from 1992, Landsat 7 ETM+ image from 2000, and SPOT 4 image from 2009 in Kunming city, China, to analyses intensities of green areas and patterns of greenness. The outcomes of the study highlighted that satellite images and methods are helpful to understand how green areas change in urban space and also to clarify how green policies can contribute to the recovery of greenness in the cities, thus confirming the current study that shows that using different types of satellite images and various remote sensing approaches to analyse those images.

Several studies that used pixel-based and multispectral based classification method for studying urban vegetation cover using Landsat-MSS, TM, and OLI imagery. However, these techniques are more accurate when using very high-resolution data. They have explored the benefits of commercial remote sensing data such as IKONOS (Noor et al., 2013; Anchang et al., 2016), Worldview-2 (Mustafa et al., 2015), SPOT, (Kong \& Nakagoshin, 2005), Quickbird (Tooke et al., 2009), GeoEye, (Hofmann et al., 2011), Indian Remote Sensing satellite data IRS P6 LISS IV (Gupta et al., 2012), Pleiades (Balik et al., 2017), to map and detect urban green areas. In an early study, Demetriades-Shah et al. (1990) note that high-resolution methods are beneficial to solve overlapping land surface issues. In particular, these methods are precious "for tackling analogous problems such as interference from soil background reflectance in the remote sensing of vegetation or for resolving complex spectra of several target species within 
individual pixels in remote sensing" (Demetriades-Shah et al., 1990). These methods are successfully used for the assessment of the UHI effect (Lo et al., 1997), the determination of forest species composition (Martin et al., 1998), and the land and water resource monitoring. A recent study analyses and explained the evaluation of urban trees ecosystem services through the use of tree cadastral data to offers a good application for planners due to more economically feasible solutions (Scholz et al., 2018).

Examine and measure the access of city residents to green areas for health, physical activities, and recreation potential. NDVI Landsat imagery in 2010 and the Netherlands national land-use database have been employed by Klompmaker et al. (2018) to evaluate green area distribution, in association with being overweight and the physical activity areas in the city of Utrecht. Based on buffer zones and the distance calculated using NDVI. NDVI is a reliable source obtained from satellite images to study the greenness in urban areas related to different types of demographic data.

McMorris et al. (2015) developed an assessment of greenness in the urban areas in Canada using Landsat images between 1991 and 1995 and buffer zones to describe relationship residential greenness and physical activity based on NDVI. The remarkable result to emerge from the study is that the NDVI method is valuable in terms of obtaining information regarding the spatial distribution of greenness in urban areas. Consequently, physical activity for individuals of different ages, and also the importance of greenness development and maintenance as a significant contribution to improve population health. These relate to the present study by pointing out the importance of urban greenness for population living conditions. A similar study focused on urban greenness mapping using object-based methods in Bishkek and fuzzy class assignments to examine and classify vegetation classes using GeoEye-1 imaging from Hofmann et al. (2011). As a related example of using high-resolution satellite data, Gupta et al. (2012) processed the NDVI in the city of Delhi using Indian Remote Sensing satellite data IRS P6 LISS IV data acquired in 2006 to study vegetation dynamics within the city limits of Delhi. Measures quality of green neighbourhood for Delhi and access of the population to green areas by address combinations of remote sensing and GIS methods used. A similar analysis is conducted in the current study to see the access of Erbil population to green areas in the city limits. The current dissertation uses similar measures such as NDVI and EVI, related to pre-processing and processing procedures, and kind of a similar analysis (such as time-series analysis, correlations, and supervisor classification). Therefore, results produced consistently with the literature. Also, Noor et al. (2013) have utilised multi datasets of SPOT-4, SPOT-2 and IKONOS from 1990, 2001 and 2010 respectively to outline 
changes in vegetation areas in the urban space of the city of Kuala Lumpur, detection analysis approach and implementing MLC as supervised classification was used and having results with very high accuracy for the MLC, thus signaling MLC as a reliable method to be used in the present study.

To our knowledge, the use and the comparison of different spatial resolution data (lowmedium and high) have not yet been investigated all together in the field of the spatial distribution of urban green areas.

The analyses of the relevant remote sensing studies have categorized into various groups such as remote sensing in vegetation researches, remote sensing in urban vegetation researches, remote sensing in urbanisation and urbanisation effects on vegetation, and remote sensing in the urban environment and ecological studies.

Although remotely sensed data/techniques are not the optimal solution for understanding and monitoring urban ecosystem services to understand and improve the quality of work that provided the correct method (Ahmad, 2012; Tavares et al., 2019), such as time of day and year, spatial and temporal resolution (Ayanu et al., 2012). Xie et al. (2008) compare different spectral, spatial, radiometric, and temporal characteristics of remote sensing imagery. Note that remote sensing imageries play an essential role in vegetation researches by examining the global vegetation changes and their classifications, understanding the impact of natural and human-related factors, and providing a basis for restoration and protection. "Traditional methods (e.g., field surveys, literature reviews, map interpretation, and collateral and ancillary data analysis), however, are not effective in acquiring vegetation covers because they are timeconsuming, date lagged, and often too expensive."

Ahmad (2012) used a variety of SVIs (EVI, SAVI, NDVI, and Transformed Normalized Difference Vegetation Index (TNDVI)) from MODIS and Landsat to examine the vegetation dynamics in the Sargodha district of Pakistan, the methods used for image processing and the mainstream classification accuracy assessment. The region is longer than $100 \mathrm{~km}$ in its longest dimension, so the study is large-scale geographic analysis similar to the current research. Then, using the constructed indices, the paper implements a before-and-after analysis like a satisfied percent of surface cover displaying a decrease in SVIs. Multi-temporal and multi-sensor satellite data showed to have great success in the study of biomass. Therefore, environmental monitoring evaluation.

Moreover, the report does not perform a detailed analysis of time series and does not address the relationship with climate influences. Other studies, by contrast, examined this relation. Brown et al. (2012) use remote sensing methods at a global scale to explore the 
dynamics of cropland surface types in the world. The paper constructs NDVI measure and examines its relationship with humidity and temperature. The article shows that the growing period of crops increased in length in the last decades, and it has paper also has time series indicators for various countries. In a similar study, Camberlin et al. (2007) examine the relationship between rainfall and vegetation cover in Africa for the period of 1981-2000. The most significant correlation between rainfall and vegetation indices found for the semi-arid regions in Africa.

In another large-scale analysis, El-Kawy et al. (2011) use remote sensing methods to examine the land cover changes in Nile delta. They analyse data for the 1984-2009 period and find that there were large scale conversions from bare land to agricultural land and some limited conversion from agricultural land to urban areas. In an attempt to evaluate the efficiency of urban green space ecosystem, Senanayake et al. (2013) derive green space areas in Sri Lanka Earth Observation System satellite utilising NDVI. An environmental criticality map based on population density and green space established to classify high-critical areas. The study found that 34 divisions in 55 districts lack the World Health Organization suggested a minimum per capita green living space of $9.5 \mathrm{~m}^{2} /$ person.

According to Anchang et al. (2016), the use of IKONOS imagery data to classify the urban surface types that including vegetation areas in the city of Bamenda in Cameroon. The authors use SAVI measure and apply various pre-processing and processing procedures like pan-sharpening, Fisher Jenks classification and clustering, and data training. However, they argue that unsupervised index results are robust enough to classify land cover types. Given that financial and technical resources might be limited in developing countries to obtain supervised index results. They claim that their method is sufficient for urban vegetation analysis. The study is minimal in terms of robustness analysis, comparative discussion of different methods, and the time series analysis. The current dissertation provides a comprehensive perspective by including these dimensions. Buyantuyev et al. (2007) examine the urban vegetation dynamics for the city of Phoenix in the US. They have used two measures of NDVI and SAVI in their analysis and conducted LSMA. They compared the SMA data to field data and implemented some regression analysis and found that "SMA was a more accurate approach to vegetation quantification in urban and agricultural land uses."SMA is a robust method to study urban and agricultural methods. Buyantuyev et al. (2007) confirm the usefulness and appropriateness of methods in the current research.

A recent study by Henits et al. (2016) employs three long-term Landsat time-series data sets to assess changes in urban land cover by using two data sets each year. The research used 
the classification of maximum likelihood by doing so provided an approach could reduce the problem of classification error between bare lands or forms of impervious surface and vegetation cover. The finding suggests that Landsat multi-temporal data will improve the accuracy of urban land cover. Dewan and Yamaguchi (2009) examine changes in land cover types for the Greater Dhaka in Pakistan for the period of 1975-2003 using three different data sources and asses the accuracy levels. They find significant urban expansion at the expense of vegetation area. Then, as an essential contribution, they conduct multiple regression analyses examining the effects of socio-economic factors on this urbanisation process. Results indicate that Greater Dhaka and the population stand out at the most significant factors driving the urban expansion. This study is also valuable as it conducts a detailed time series analysis of the data and examines substantial determinants. Esau et al. (2016) examine the case of rapid urbanisation in Western Siberia and its impact on vegetation cover using NDVI measure covering the period of 2000-2014. The authors conduct time-series and correlation analyses and find that "Urbanisation destroys the vegetation cover within the developed areas and at about $5-10 \mathrm{~km}$ distance around them. The studied urbanized areas have NDVI values by 15 to $45 \%$ lower than the corresponding areas at 20-40 km distance". The remote sensing methods used for ecological purposes in urban areas.

\subsection{Urban vegetation, land use and land cover studies in the study area}

There have been numerous studies investigating land use, land cover, and vegetation cover in and around the city of Erbil. The first systematic study on remote sensing data was carried out by Kak Ahmed H. A (2006). The study investigated urban land-use changes in the city of Erbil using two data sets; a cadastral map from 1986 and an image of IKONOS data, $1 \mathrm{~m}$ panchromatic, and $4 \mathrm{~m}$ multispectral bands resolution from 2005 . The results indicate that the proportion of green spaces within the city is 5\%. Rasul et al. (2017) measured LST daytime and the effect of swift urban expansion on urban heat and cooling island impacts using Landsat imageries. They also determined land-use and land-cover changes from 1993 to 2013. They used three data sets 1992, 2002, and 2013 in the dry season (July, August, and September), to estimate land use and land cover changes using pixel samples (impervious surface area, LST and NDVI). The results show that $55.3 \mathrm{~km}^{2}$ of city land cover changed from bare soil to urban. Another study assessed the effect of vegetation and moisture on the observed patterns of LST and Surface Urban Cool Island (SUCI) / Surface Urban Heat Island (SUHI) by investigating the relationships of LST with NDVI and the Normalized Multi-band Drought Index (NMDI) (Rasul et al., 2016). The paper employed MODIS NDVI 16-day composite $250 \mathrm{~m}$ resolution 
from 2003 to 2014 to investigate the relationship between NDVI and LST and comparing LST of rural and the city. The results show that: "During the daytime, in summer, autumn and winter, densely built-up areas had lower LST acting as the SUCI compared to the non-urbanised area around the city.

In contrast, at night-time, Erbil experienced higher LST and demonstrated a significant SUHI effect. The relationship between LST and NDVI is affected by seasonality and inverted during spring." Abdullah (2012) used two data sets of Landsat-5 TM imagery in 1998 and 2011 to reveal and assess the urban expansion of the city of Erbil, and its impact on LST between the years. MLC classification and change detection methods used. The results show that a fast and vast expansion took place in the city. Constructed coverage increased from 14\% in 1998 to $30 \%$ in 2011 , and vegetated land decreased from $7 \%$ to $4 \%$. Khalid (2014) investigated urbanisation's impact on the local climate. The study used weather station temperature data, for the city and surrounding areas, and one Landsat 7 ETM+ imagery acquired in September 2011 to estimate LST and NDVI. The research findings showed considerable changes in the local climate of the city's overtime period. In a similar study, Ibrahim (2013) assesses urban expansion in the city, and its surroundings covered an area 32334 ha; (Equilateral square without any mention of criteria), using multi-dated Landsat 5 TM imageries from 1987, 2000 and 2011. Maximum likelihood used to classify land use and change detection methods to identify changes. Significant changes accrued in vegetation and open land classes during the period, also constructed upon areas increased. It is not possible to compare the result with the current study due to the area difference, and the vegetation class includes green areas and agricultural land where we separated them.

Urban vegetation in the study area very effective in influencing the urban environment and climate change due to located in the semi-arid region. The previous studies, also stressed that the rapid change in land uses land cover due to urbanisation. 


\section{Data and Methodology}

\subsection{Study area}

The study area for this research is the city of Erbil and its surroundings. Erbil is the capital of the Iraqi Kurdistan Region, and it is the central city in northern Iraq (Figure 3-1). It lies between longitudes $43^{\circ} 51^{\prime} 20^{\prime \prime}, 44^{\circ} 12^{\prime} 28^{\prime \prime}$ and latitudes $36^{\circ} 05^{\prime} 58^{\prime \prime}, 36^{\circ} 15^{\prime} 54^{\prime \prime}$. It is 412 $\mathrm{m}$ above mean sea level, covering an area around $572 \mathrm{~km}^{2}$. The population of Iraqi Kurdistan is around 5.2 million people, while the population of Erbil city increased by $210 \%$, from 485,968 in 1987 to $1,025,000$ in 2011 (Ministry of Planning, 2014).

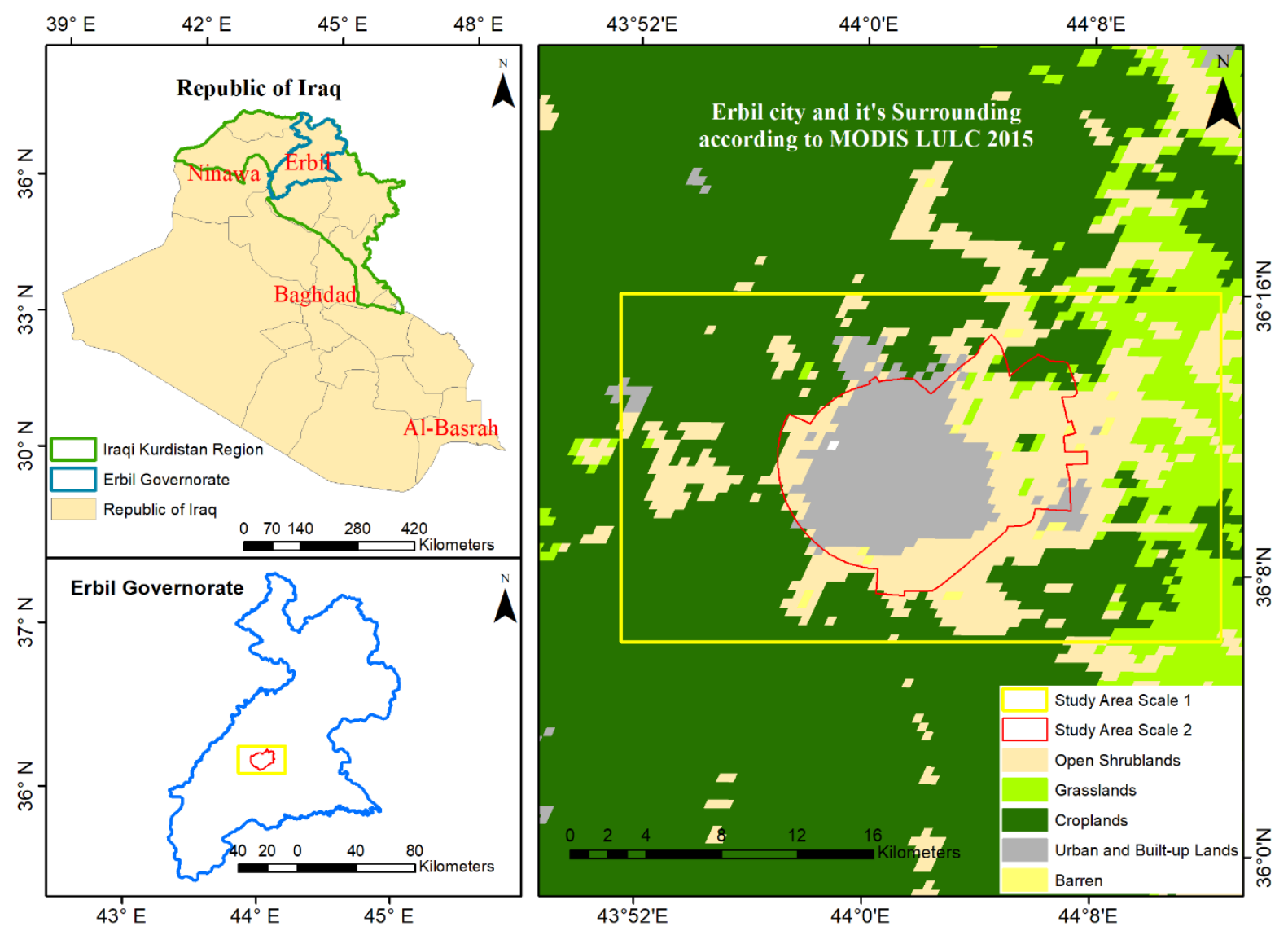

Figure 3-1: Overview of Erbil City and its Surroundings

The area is fertile plains up, hills and mountainous lands. The Zagros Mountains (3600 $\mathrm{m}$ above the sea level) form the main landscape of the northern Kurdistan region. Regarding the vegetation types, agricultural areas form approximately $34 \%$ of Iraqi Kurdistan, while the dominant land cover is composed of grasses and forests. Most of the Kurdistan lands/Iraq use for agricultural purposes (Hameed, 2013). However, during the past two decades, healthy economic development and related political changes have produced an intensive urbanisation 
process on the fertile agricultural lands around the city, which is now one of the most populated cities in this region.

The city of Erbil characterized by a semi-arid, continental, and Mediterranean climates, type BSsh, according to the Koppen classification (Köppen et al., 2011). It has two clear weather patterns; cold and wet in winter and dry and hot in summer. In general, annual precipitation is between $300-500 \mathrm{~mm}$, with the highest rainfall levels taking place between October and May. The annual relative humidity is approximately $47 \%$, and the monthly average air temperature ranges from $9-34{ }^{\circ} \mathrm{C}$. The climate of the study area is typically dry in summer with little-to-no precipitation, while winters are we (Figure 3-2). According to a recent study by Khalid (2014), the minimum temperature increasing at an annual level rate of $0.055^{\circ} \mathrm{C} /$ year.

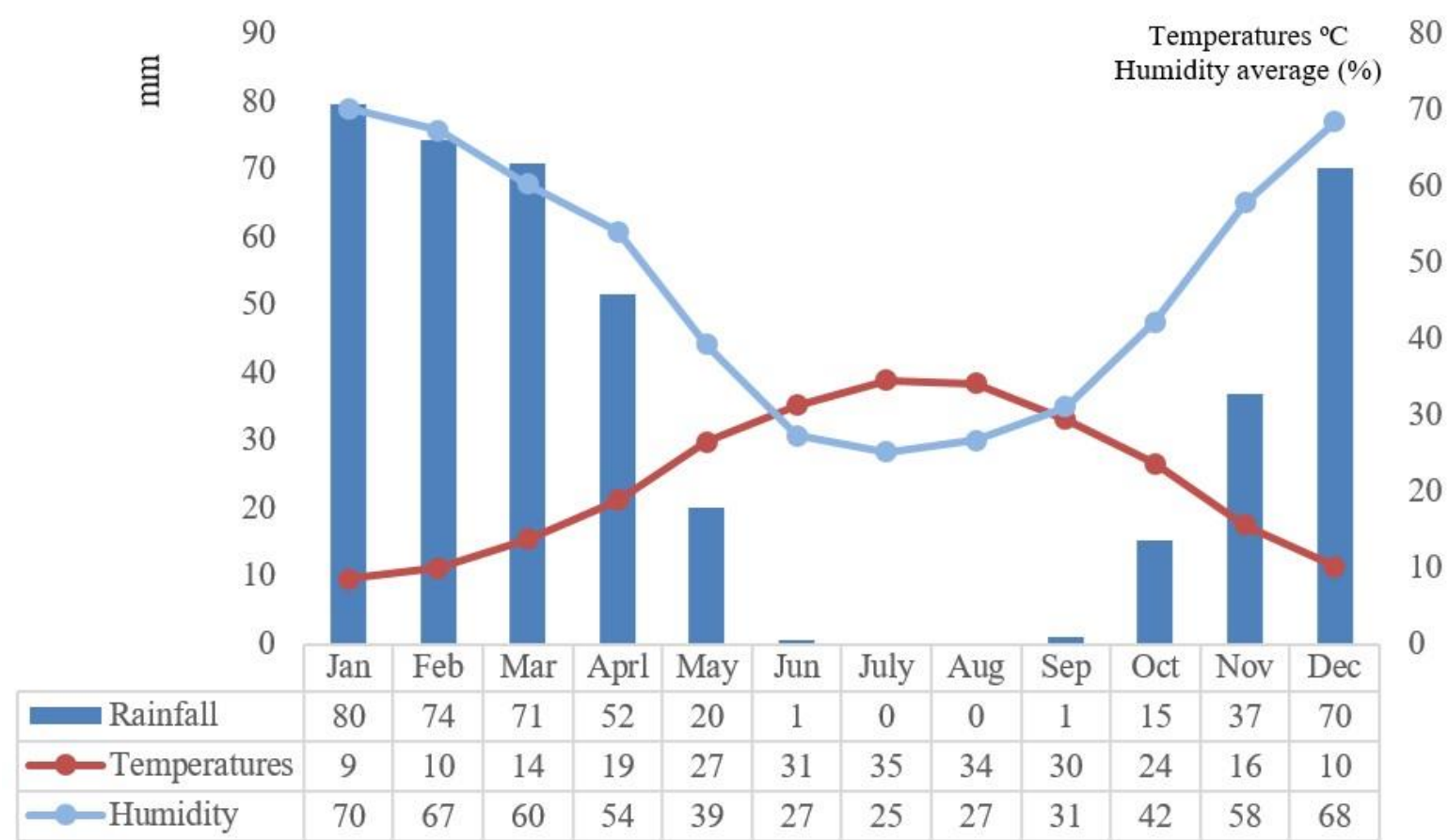

Figure 3-2: Monthly Precipitation 1941-2015, Monthly Air Temperatures, and Monthly Humidity 1992-2015 in Erbil (KRG, 2016)

Regarding the geology of the region, more recent deposits cover the upper Bakhtiari formation. The thickness of deposits ranges around 100-150 m, and the second part of geological formation is Bakhtiari, which dates back to the Pliocene. The thickness of this group is more than $1800 \mathrm{~m}$ (Omer, 1998). Erbil and the surrounding area have three different soil types. The first is lithosolic soil in limestone (sandstone, claystone, and gypsum), while the second is brown soil medium and shallow phase over Bakhtiari gravel (sand, silt, and partly clay). The last type is the brown soil deep phase (sand, clay, and silt) (Hameed, 2013). In terms of surface topology, the region is a plain area. It has low levels of slopes towards the south, 
being less than $3 \%$ in most of Erbil. The south and the south-west regions are flatlands. However, the area is gently sloping to 3-7\% in northern and northeast areas (Hussein, 2008).

In terms of vegetation and green area, the region is characterised by density spring grasses and herbs, while in the summer, soil moisture is poor, and vegetation is scarce in rural areas around the city. The natural vegetation in the area is steppe grass and open shrubland, a transition region between northern mountain vegetation and southern desert vegetation (Hasan, 2006). Winter grains such as wheat and barley are the most frequently grown crops in rural areas, and overall agriculture depends on rainfall rather than on irrigation in the study area. As a result, most croplands are dry during the summer. The green area of the city includes the gardens inside the houses. During the urban expansion in the second half of the twentieth century, homes in newly constructed areas had large frontal garden areas, the later stages of urban development characterized by smaller or no gardens (Rasul, 2016).

The rate of arable land in the governorate of Erbil is $41.3 \%, 92.7 \%$ that rely on rainfall (KRG, 2016). Green areas cover $12 \%$ of the urban area, and the authorities want to raise it to $15 \%$, which is the minimum ratio set by the International Organization for Standardization (ISO) (Hussein, 2018). There are numerous parks and gardens around the city, including Sami Abdulrahman Park, Minare Park, Gllkand Park, and Shanadar Park (Figure 3-3). Sami AbdulRahman Park is in the west of Erbil and is the largest green area (about two $\mathrm{km}^{2}$ ). It divided into gardens and one forest. It consists of lawns, a floral quarter, and a variety of trees and 50,000 trees in the forest (Rasul, 2016).

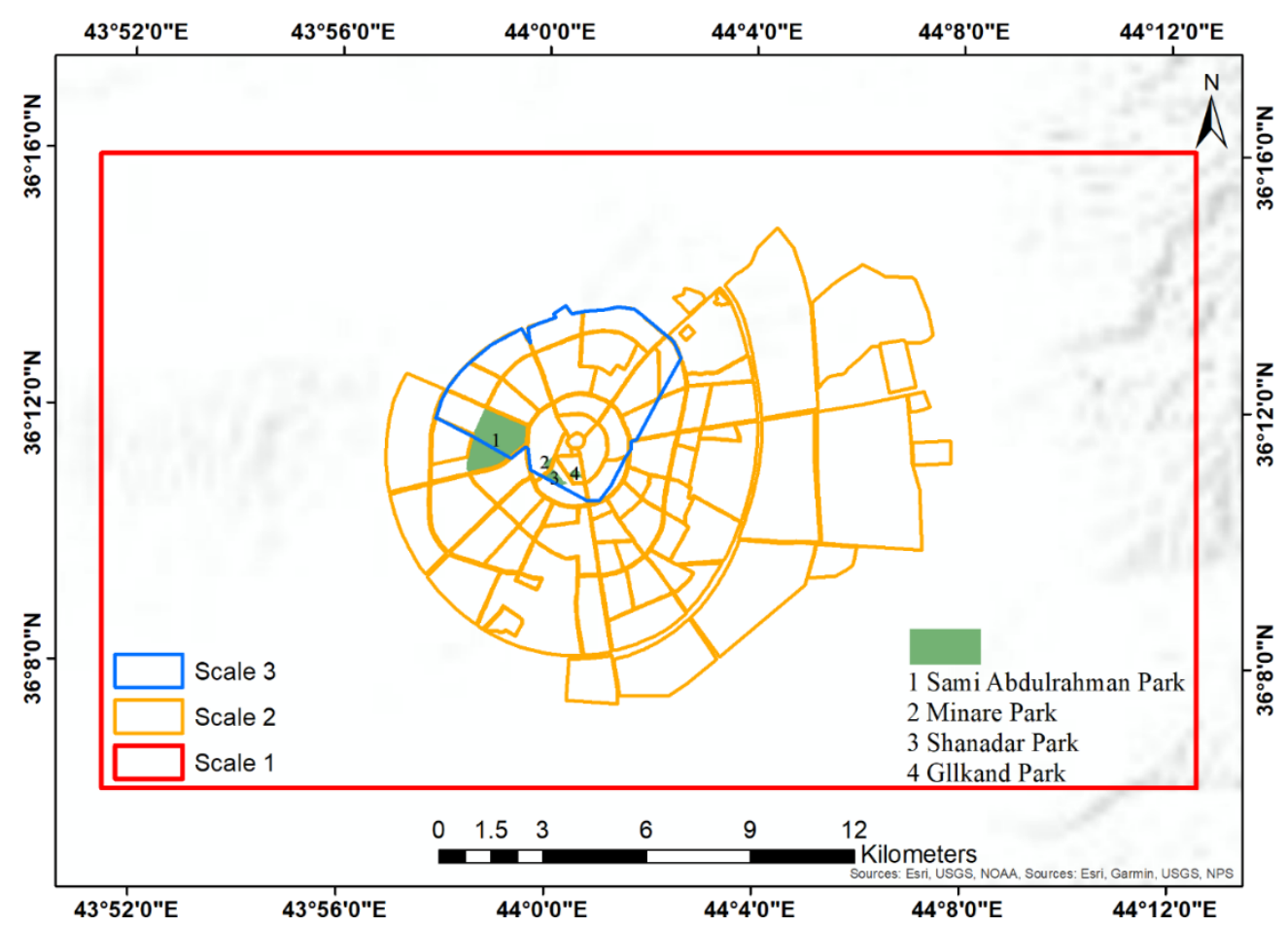

Figure 3-3: Levels of Spatial Scales in the Study Area 


\subsection{Methodological background}

In the remote sensing studies on urban vegetation, the specifications of the platforms and the sensors are significant. The spatial and spectral resolutions of remote sensing data are two essential features. For example, MODIS often has mixed pixels because of their low spatial resolution, and thus they cannot be defined as a specific pure class and can only detect landuse types at the regional level (Bajgiran et al., 2009). As shown in Table 3-1, it is generally more suitable to study mapping at global, regional, or national scales. Still, it can be a good starting point to examine the surface types and vegetation indices at city levels as well.

Time-series methods used to differentiate long-term land coverage change from shortterm variations, mapping of vegetation dynamics, and improved land cover mapping and update. Time series quality is essential concerning these tasks. Data sometimes distorted by several factors, including cloud coverage, high levels of the aerosol, opposing view and illumination angles, sensor defects. These lead to an erroneous interpretation. Therefore, the proper pre-processing and processing of raw data and the generation of relevant vegetation indices are essential steps in the analysis (Colditz et al., 2006).

In particular, MODIS NDVI satellite-based measures have been concentrated by Helbich (2019) because they afford universal coverage in the form of pre-processed time series and involve less computational effort compared to Landsat or other higher-resolution data. The practice of using moderate/coarse resolution data to describe land cover has resulted in the creation of a wide range of methods to exploit satellite data (Borak et al., 2000) Time-series spectral profiles used in a wide range of methods exploiting observations spanning multiple seasons and years. The main reason belongs to the signal is more effectively distinguished from noise and vegetation phenology can be correlated with spectral trajectory based on the multitude of data points (Kennedy et al., 2014), Two methods employed for keeping track of vegetation dynamics and deriving phenological indicators in forest or agricultural landscapes are wavelet transformation (Sakamoto et al., 2007), and curve-fitting (Kennedy et al. 2007).

Temporal compositing benefited by other methods, thus streamlining quantities of data without compromising temporal variability associated with land coverage or phenological conditions (Borak et al., 2000; Clark et al., 2012). Although characterization of time series achieved with any metric, the 'dense time stacks' change detection method lately employed in urban areas. In this method, vegetation phenology approximated based on the yearly mean. Besides, the added seasonal information helped to overcome spectral confusion between fallow cropland and new urban development; monthly mean helps to estimate general trend phenology by year (Schneider, 2012; Hussein, 2017a; Li, F. et al., 2017; Zhang, Y. \& Yang, 2019). 
Table 3-1: Features of Different Remote Sensing Data (Source: (Xie et al., 2008; "Satellite Overview | Geoimage," 2019))

\begin{tabular}{|c|c|c|}
\hline Product (sensors) & Features & Vegetation mapping applications \\
\hline AVHRR & $\begin{array}{l}\text { 1-km Ground Sampling Distance (GSD) with multispectral } \\
\text { data from the NOAA satellite series (1980 to present). 10-bit } \\
\text { radiometric resolution. The approximate scene size } 2400 \times \\
6400 \mathrm{~km} \text {. }\end{array}$ & $\begin{array}{l}\text { Global, continental or national scale } \\
\text { mapping. Suitable for mapping land } \\
\text { cover types (i.e. urban area, classes of } \\
\text { vegetation, water area, etc.). }\end{array}$ \\
\hline MODIS & $\begin{array}{l}\text { Low spatial resolution }(250-1000 \mathrm{~m}) \text { and multispectral data } \\
\text { from the Terra satellite }(2000 \text { to present) and Aqua satellite } \\
\text { ( } 2002 \text { to present). 12-bit radiometric resolution. Revisit interval } \\
\text { is around } 1-2 \text { days. The swath is } 2330 \mathrm{~km} \text { (cross-track) by } 10 \\
\mathrm{~km} \text { (along-track at nadir) }\end{array}$ & $\begin{array}{l}\text { Suitable for vegetarian mapping on a } \\
\text { large or national scale. Also for } \\
\text { mapping land cover types (i.e. urban } \\
\text { area, classes of vegetation, water area, } \\
\text { etc.). }\end{array}$ \\
\hline ASTER & $\begin{array}{l}\text { Medium spatial resolution ( } 15-90 \mathrm{~m}) \text { image with } 14 \text { spectral } \\
\text { bands from the Terra satellite ( } 2000 \text { to present). 8-bit } \\
\text { radiometric resolution. Visible to near-infrared bands have a } \\
\text { spatial resolution of } 15 \mathrm{~m} .30 \mathrm{~m} \text { for short wave infrared bands } \\
\text { and } 90 \mathrm{~m} \text { for thermal infrared bands. }\end{array}$ & $\begin{array}{l}\text { At local, regional to national scale } \\
\text { vegetation mapping at species or } \\
\text { community level. }\end{array}$ \\
\hline Landsat TM & $\begin{array}{l}\text { Medium to coarse spatial resolution with multispectral data } \\
\text { ( } 120 \mathrm{~m} \text { for thermal Infrared band and } 30 \mathrm{~m} \text { for multispectral } \\
\text { band) for Landsat } 4 \text { and } 5 \text { ( } 1980 \text { to } 2011 \text { ). } 8 \text {-bit radiometric } \\
\text { resolution. Each scene covers an area of } 185 \times 185 \mathrm{~km} \text {. } \\
\text { Temporal resolution is } 16 \text { days. }\end{array}$ & \multirow{2}{*}{$\begin{array}{l}\text { Regional scale mapping usually } \\
\text { capable of mapping vegetation at } \\
\text { community level }\end{array}$} \\
\hline $\begin{array}{l}\text { Landsat ETM+ (Landsat } \\
\text { 7) }\end{array}$ & $\begin{array}{l}\text { Medium to coarse spatial resolution with multispectral data ( } 15 \\
\mathrm{~m} \text { for a panchromatic band, } 60 \mathrm{~m} \text { for thermal Infrared band, and } \\
30 \mathrm{~m} \text { for the multispectral band) (1999 to present except after } \\
\text { May } 31,2003 \text {, due to Scan Line Corrector (SLC)-OFF problem } \\
\text { ). 8-bit radiometric resolution. Each scene covers an area of } 185 \\
\times 185 \mathrm{~km} \text {. The temporal resolution is } 16 \text { days. }\end{array}$ & \\
\hline Sentinel-2 & $\begin{array}{l}\text { High spatial resolution }(10-60 \mathrm{~m}) \text { contains } 13 \text { spectral bands } \\
\text { RGB and NIR have } 10 \mathrm{~m} \text { resolution, } 6 \text { bands at } 20 \mathrm{~m} \text {, and } 3 \\
\text { bands at } 60 \mathrm{~m} \text { with a swath width of } 290 \mathrm{~km} .12 \text {-bit radiometric } \\
\text { resolution. Revisit time of } 5 \text { days at the equator and } 2-3 \text { days } \\
\text { at mid-latitudes, launched data on } 23 \text { June } 2015 \text {. }\end{array}$ & $\begin{array}{l}\text { At local to a regional scale capable of } \\
\text { monitoring vegetation during the } \\
\text { growing season, land-cover maps, } \\
\text { land-change detection maps, and } \\
\text { geophysical variables. }\end{array}$ \\
\hline SPOT & $\begin{array}{l}\text { A full range of medium spatial resolution from } 20 \mathrm{~m} \text { down to } \\
2.5 \mathrm{~m} \text {, and SPOT VGT with coarse spatial resolution of } 1 \mathrm{~km} \text {, } \\
8 \text {-bit radiometric resolution. Each scene covers } 60 \times 60 \mathrm{~km} \text { for } \\
\text { HRV/HRVIR/HRG and } 1000 \times 1000 \mathrm{~km} \text { (or } 2000 \times 2000 \mathrm{~km} \text { ) } \\
\text { for VGT. SPOT } 1,2,3,4,5,6,7 \text { were launched in the year of } \\
1986,1990,1993,1998,2002,2012 \text { and } 2014 \text { respectively. } \\
\text { Temporal resolution 1-26 days. SPOT } 1 \text { and } 3 \text { are not providing } \\
\text { data. }\end{array}$ & $\begin{array}{l}\text { Regional-scale usually capable of } \\
\text { mapping vegetation at community } \\
\text { level or species level or } \\
\text { global/national/regional scale (from } \\
\text { VGT) mapping land cover types (i.e. } \\
\text { urban area classes of vegetation, water } \\
\text { area, etc.) but it is quite expensive. }\end{array}$ \\
\hline QuickBird & $\begin{array}{l}\text { High resolution }(0.6-2.4 \mathrm{~m}) \text { panchromatic and multispectral } \\
\text { imagery from a constellation of spacecraft. The single scene } \\
\text { area is } 16.5 \times 16.5 \mathrm{~km}, 11 \text {-bit radiometric resolution. Revisit } \\
\text { frequency is around } 1-3.5 \text { days depending on latitude. Stopped } \\
\text { collecting imagery but has archive from } 2001 \text { to } 2015 \text {. }\end{array}$ & \multirow{4}{*}{$\begin{array}{l}\text { Local to regional scale vegetation } \\
\text { mapping at species or community } \\
\text { level or used to validate vegetation } \\
\text { cover extracted from other images. }\end{array}$} \\
\hline Pleiades & $\begin{array}{l}\text { It collects high-resolution imagery at } 0.5 \mathrm{~m} \text { panchromatic and } \\
2 \mathrm{~m} \text { RGB \& NIR multispectral data. 12-bit radiometric } \\
\text { resolution. Daily acquisition capacity } 700,000 \mathrm{~km}^{2} \text { with a } \\
\text { revisit time of less than one day. }\end{array}$ & \\
\hline WorldView & $\begin{array}{l}\text { WorldView } 2,3 \text { and } 4 \text {, were launched in } 2009,2014 \text {, and } 2016 \\
\text { respectively, with panchromatic } 0.5 \mathrm{~m}, 31 \mathrm{~cm} \text {, and spectral } \\
\text { bands } 8,8,4 \text {, collecting multispectral } 2.0 \mathrm{~m}, 1.24 \mathrm{~m} \text {, and } 1.24 \\
\mathrm{~m} \text {. WorldView } 2,3 \text { and } 4,8 \text {-bit radiometric resolution and have } \\
\text { an average revisit time of } 1.7,2.7,<1,4.5 \text { days, capable of } \\
\text { collecting up to, } 975,000 \mathrm{~km}^{2}, 680,000 \mathrm{~km}^{2}, 680,000 \mathrm{~km}^{2} \text { per } \\
\text { day }\end{array}$ & \\
\hline IKONOS & $\begin{array}{l}\text { Commercial remote sensing data, collects high-resolution } \\
\text { imagery at } 1 \mathrm{~m} \text { panchromatic and } 4 \mathrm{~m} \text { multispectral bands } \\
\text { resolution. } 11 \text {-bit radiometric resolution. The revisit rate is } 3-5 \\
\text { days (off-nadir). Stopped collecting imagery but has archive } \\
\text { from } 2000 \text { to } 2014 \text {. }\end{array}$ & \\
\hline
\end{tabular}


These studies used mean value compositing vegetation indices to assess temporal variations of vegetation. The results of these studies recommend using mean methods to evaluate the temporal dynamics of vegetation and need a high temporal resolution data of remote sensing satellite imagery.

In addition to the MODIS sensor and Landsat satellite data, the current study also uses a very high-resolution sensor from the Pleiades. It delivers high spatial resolution with $0.5 \mathrm{~m}$ panchromatic and four spectral bands image data $2 \mathrm{~m}$ resolution. So, it is precious to make analysis within particular city districts, where identifying the surface type can be more complex and demanding (Koedsin \& Huete, 2015; Anchang et al., 2016). Overall, these three imageries provide complementary data, and the data analysis conducted comparatively.

The EVI is more responsive to the changes in the canopy, while the NDVI is sensitive to chlorophyll (Hussein et al., 2017). The equations for NDVI and EVI described below (Huete et al., 2002).

$$
\begin{gathered}
N D V I=\frac{\rho \mathrm{NIR}-\rho \mathrm{RED}}{\rho \mathrm{NIR}+\rho \mathrm{RED}} \\
E V I=2.5 \frac{\rho N I R-\rho \operatorname{Red}}{\rho N I R+(6 * \rho R E D)-(7.5 \rho B L U E)+1}
\end{gathered}
$$

The purpose of EVI is to improve on a standard NDVI product. They include the enhancement of vegetation signal and sensitivity in abundant biomass regions, the reduction of soil and atmospheric effects, and the reduction of the smoke impact generated as the result of biomass combustion in the tropical areas (Xiao et al., 2009). NDVI is saturated when plants grow well, which will help monitor plant growth status, and EVI improves the sensitivity for well-vegetated areas (Li, H. et al., 2007). The NDVI and EVI products computed from atmospherically corrected bi-directional surface reflectance that masked for water, clouds, heavy aerosols, and cloud shadows (USGS, 2016). A substantial requirement of SVIs science products is that they be accurately validated. Gao et al. (2003) carry out MODIS SVIs product validation at the semiarid, New Mexico, the results show the accuracy, reliability, and science utility of the MODIS SVIs products in arid and semiarid areas.

Remote sensing data based on SVIs widely used in urban areas (Yunhao et al., 2006; Buyantuyev et al., 2007; Rafiee et al., 2009; Zoran et al., 2013; Anchang et al., 2016). These vegetation indices used in various methods, such as the estimation of fractional vegetation cover (Yunhao et al., 2006), a combination of two or more spectral bands using parameters such as radiance, surface reflectance, or apparent reflectance (Zoran et al., 2013), analysis of 
the differences in the histogram of satellite images, and reclassification of these images to obtain a detailed change matrix for urban green areas (Rafiee et al., 2009).

Other approaches use the optimal filter for NDVI time series derivation of vegetation phenology in urban areas (Li, F. et al., 2017). Methods in urban areas with a high amount of background soil include the combination of NDVI and SAVI (Buyantuyev et al., 2007; Anchang et al., 2016). Additionally, NDVI used in a study in combination with radiant surface temperature and multiple-comparison approach. The methods of this study include visual interpretation, GIS zoning categories (Wilson et al., 2003).

In the case of MODIS data, the NDVI and EVI indices generated within the sample years and across the years. Also, five land cover types identified by using MODIS land cover type, and the change of surface types investigated from 2000 to 2015. Then, time series and cross-correlation analyses conducted to see the temporal dynamics of SVIs and their relationship with climate variables. In the case of Landsat data, time series of NDVI, as well as EVI measures produced to conduct some statistical analysis. In this case, the methods of MLC and LSMA also employed in the analysis. A similar analysis also conducted for Pleiades data. Method of MLC performed to classify land use NDVI values extracted using GIS techniques such as zonal statistics. Then, based on these data, mean values and buffer zone criteria are constructed. At this stage, providing some information on the MLC and LSMA techniques would prove useful.

To classify the land cover types at the pixel level, the LSMA and the MLC methods employed. Regarding the MLC method, Sun et al. (2013) state that "MLC is a method for determining a known class of distributions as the maximum for a given statistic. During classification, all unclassified pixels assigned membership based on the relative likelihood (probability) of that pixel occurring within each category's probability density function."

So, MLC provides a robust way of classifying the pixels from the satellite imagery data. Then, using the distribution of these pixels, one can construct different surface cover types and vegetation indices measures. In this analysis, mixed pixels can present difficulty in terms of creating errors with poor classification methods. To address such problems, the LSMA method used in the literature. Chang (2016) states that LSMA is "a widely used theory in hyperspectral data exploration. It first assumes that for a given finite set of basic material substances, a data sample that modelled as a linear admixture of these substances from which the data sample unmixed into their corresponding abundance fractions. In this case, analysis of the data sample performed on these abundance fractions rather than the sample itself'. So, both MLC and LSMA methods are used in the current dissertation to derive robust measures of vegetation. 
Difficulties in urban classifications using satellite data may arise during the establishment of the NDVI thresholds needed to separate dense vegetation by bare soil areas (Belgiu et al., 2014). Another difficulty during classification in urban areas may occur while using only single high-resolution panchromatic data (Benediktsson et al., 2003). Moreover, Sertel \& Akay (2015) posit that pixel-based classification does not rely on spatial, topological, and textural features, and as a result, high-resolution and very high-resolution images can engender challenges for spatial analysis in urban areas. Chanussot et al. (2006) support the notion that, in urban areas, accurate classifications require geometrical information to distinguish between pixels that may be very similar. Spectral separation can present a challenge in urban tree canopies (Walton, 2008; Moskal et al., 2011), as well as bare land in urban areas, due to the similarity of spectral responses (Cai et al., 2019).

Furthermore, shadow boundaries may also cause difficulty in urban area image classification (Dare, 2005). Moreover, the high heterogeneity in urban areas and the similarity of spectral responses of urban land cover may represent other difficulties in remote sensing classifications (Herold et al., 2002). The low spectral variation between different land cover types can also be a challenge in urban area classification if the classification process relies only on spectral information (Salehi et al., 2012).

\subsection{Data and methods}

\subsubsection{Data of satellite imagery}

The research process involves the use of satellite imagery taken from MODIS, Landsat, and the Pleiades. The temporal scale covers 25 years from 1990 to 2015 . The spatial scale involved dividing the study area into three levels, which are looked at in greater detail below, and which reflect different levels of proximity and analysis. These enable a better understanding of distribution and localization in terms of urban change and vegetation cover over time (Figure 3-3). Scale 1 in the below graph is the most significant section of the scale, covering an area of $572 \mathrm{~km}^{2}$, and it is similar to the city in terms of natural characteristics, it selected to identify the impact of urbanisation on vegetation cover. The data extracted to analyse the dynamics of vegetation cover surrounding the city of Erbil and the effects of urbanisation in these areas. Scale 2, which is the most dynamic area affected by human activities, covering an area of $140 \mathrm{~km}^{2}$. The data uses to analyse the spatial-temporal variations of vegetation dynamics and built-up areas. Scale 3 represents a sample of the city that investigates evaluate the spatial distribution of vegetation cover, covering an area $25 \mathrm{~km}^{2}$. All 
analyses performed once by using ENVI ver. 5.3, ERDAS Imagine 2014, and ArcGIS ver. 10.6 to establish supervised classification and producing the final maps, respectively.

\subsubsection{Reference data}

For Landsat based classes 850 ground truth data using handheld GPS, historical maps, images from Google Earth database, QuickBird image from 2005, and SPOT-5 image from 2013 are used in the analysis. For the Pleiades satellite data from 2015, interviews and local knowledge and experience of the study area are employed. Also, for the Pleiades, 550 ground truth data using handheld GPS for each land cover class from the year 2015. Along with images of Google Earth database and maps of the Erbil city master plan, are considered in the study.

\subsubsection{Climate data}

The monthly temperature, humidity, and rainfall data were collected from Erbil station and plotted over the 16 years $(2000-2015)$. Humidity data collected at an altitude of $470 \mathrm{~m}$. All climate data source from the Kurdistan region government, Ministry of Agriculture and Water Resources (2016).

\subsubsection{Vector data of the city districts}

The vector data used in the study are the boundary of Erbil city at scale 1:10000 and the city districts at 1: 5000 that obtained from Erbil Governorate in 2015 (KRG, 2015).

\subsubsection{Scale 1: MODIS vegetation indices and land cover}

1- MODIS vegetation indices (MOD13Q1)

The study uses the 16-day composite, 84 single images for NDVI and the same for EVI, one image for each month, blue, red, and NIR reflectance bands, cantered at $469 \mathrm{~nm}, 645 \mathrm{~nm}$, and $858 \mathrm{~nm}$ respectively, to determine the MODIS vegetation indices. The mean values of NDVI and EVI indices generated to identify temporal variations from 2000 to 2015, using 23-year time intervals, with methods involving NDVI and EVI time series analysis and land use classification in $250 \mathrm{~m}$ spatial resolution (Table 3-2).

2- MODIS $500 \mathrm{~m}$ land cover (MCD12Q1)

The study uses MODIS Land Cover Type Yearly L3 Global 500m resolution (MCD12Q1), Land Cover Type 1 Annual International Geosphere-Biosphere Programme (IGBP) classification (IGBP) global vegetation classification scheme with five global land cover classification systems. Open Shrubland, Grassland, Cropland, Urban/Built-up area, and 
barren or spare vegetation. The 16 single images investigated, for each year into one image. MODIS land cover used to carry out change assessment and distribute NDVI and EVI into land cover classes by using zonal statistical table technique (Table 3-2).

Table 3-2: MODIS Data Products Used in the Study

\begin{tabular}{|c|c|c|c|}
\hline Datasets & Sensor & $\begin{array}{c}\text { Spatial resolution } \\
(\mathrm{m})\end{array}$ & Date of acquisition \\
\hline $\begin{array}{l}\text { MODIS Vegetation Indices 16-Day } \\
\text { L3 Global 250m (MOD13Q1) }\end{array}$ & MODIS-Terra & 250 & 2000-2015 \\
\hline $\begin{array}{l}\text { MODIS Land Cover Type Yearly L3 } \\
\text { Global 500m (MCD12Q1), Land } \\
\text { Cover Type 1: IGBP global } \\
\text { vegetation classification scheme. }\end{array}$ & MODIS-Terra & 500 & 2000-2015 \\
\hline
\end{tabular}

In the case of the MODIS method, the processing flow-chart is given in (Figure 3-4). Data compilation and raster statistics generated in ArcGIS 10.3. Statistical analysis and investigation of possible trends carried in Microsoft Excel. Pre-processing of satellite data was required and conducted in the study. Data pre-processing included checking pixel reliability and vegetation index quality. Bad pixels are omitted from the analysis as they represent clouds, cloud shadows. Mean NDVI and EVI generated to provide an average index over the complete study area, allowing the comparison between years to examine a temporal trend. Plots of monthly NDVI and EVI statistics (mean, minimum, maximum, and standard deviation) are generated from 2000 to 2015 , identifying temporal variations.

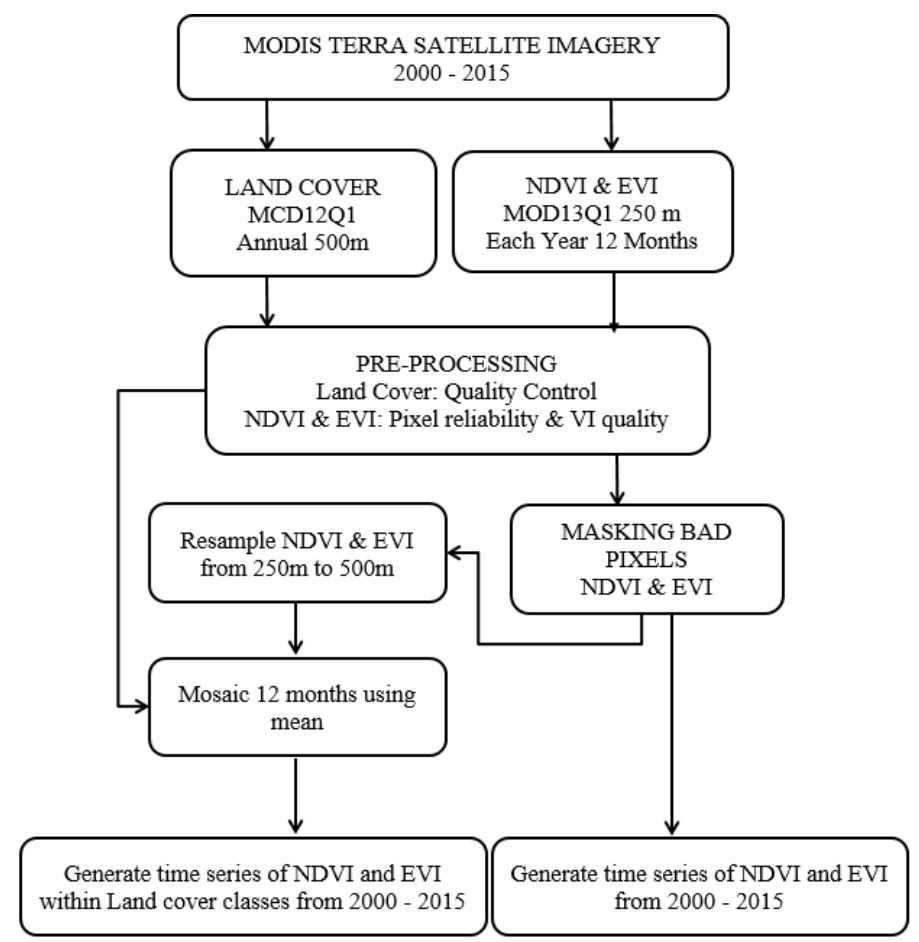

Figure 3-4: Pre-Processing and Processing of MODIS Satellite Imagery Data at Scale 1 


\subsubsection{Scale 2: Landsat satellite data and multispectral classification}

A set of six cloud-free Landsat images used in the analysis. The data ordered in Science Research and Development (LSRD). Pre-progressing such as image enhancement, geometric correction, and atmospheric correction already corrected by LSRD. To avoid seasonally derived errors, to use scenes only in the summer months, which represent the same vegetation condition. Also, the selection of specific periods reflects spatial distributions and temporal changes due to significant economic and urban development (Table 3-3).

Table 3-3: Description of the Satellite Imagery Used in the Study

\begin{tabular}{|c|c|c|c|c|c|c|}
\hline $\begin{array}{l}\text { Characteristics/sensor } \\
\text { Date of acquisition }\end{array}$ & $\begin{array}{c}\text { TM4 } \\
\text { 10-Jul-90 }\end{array}$ & $\begin{array}{c}\text { TM5 } \\
\text { 16-Jul-95 }\end{array}$ & $\begin{array}{c}\text { TM5 } \\
\text { 14-Aug-00 }\end{array}$ & $\begin{array}{c}\text { TM5 } \\
\text { 12-Aug-05 }\end{array}$ & $\begin{array}{c}\text { TM5 } \\
\text { 10-Aug-10 }\end{array}$ & $\begin{array}{c}\text { OLI_TIRS8 } \\
\text { 8-Aug-15 }\end{array}$ \\
\hline Pixel size (m) & & & \multicolumn{4}{|c|}{30} \\
\hline Number of bands & & & \multicolumn{4}{|c|}{6} \\
\hline Path and raw & & & \multicolumn{4}{|c|}{$169 / 35$} \\
\hline Projection / Ellipsoid & & & \multicolumn{4}{|c|}{ UTM Zone 38 / WGS 84} \\
\hline
\end{tabular}

In the case of Landsat imagery data, a four-step framework is used in the analysis, as presented in (Figure 3-5). Step one involved the use of the MLC and the LSMA methods to classify image pixels. In the second step, the results from the LSMA fuzzified to extract the land-use classes, after which both LSMA and MLC results undergo a classification accuracy assessment, which must be greater than $80 \%$ for the classification to use in the analysis. In the third step, the determined magnitude of green vegetation change. Then, in the last step, vegetation indices are extracted to generate statistics (mean, minimum, maximum, and standard deviation) and create maps to determine spatial-temporal variations. These steps are repeated for 5-year intervals starting from 1990 and finishing in 2015.

The accuracy levels for both methods assessed using a series of 50 random validation points for each class; historical maps, field surveys, interviews, and local knowledge and experience of the study area were used as reference data for the assessment, providing a confidence level of $95 \%$ and a confidence interval of $\pm 10 \%$ for both classification methods (Czaplewski, 2003), resulting in an overall accuracy of over 85\% (Figure 3-6). Based on the results from the LSMA, the large type of membership was chosen for the fuzzification process, resulting in a raster file with values ranging from 0 to 1 , where the pixels with values close to 1 have the highest probability of representing that specific land-use class. The trial and error method used to identify the smallest value representing that particular land-use class. After 
multiple trials, the value of 0.92 that identified as the lower limit for each type. The change of urban greenness magnitude determined by considering 1990 as T0, 1995 as T1, 2000 as T2, 2005 as T3, 2010 as T4 and 2015 as T5. Furthermore, All T1, T2, T3, T4, and T5 would be compared with $\mathrm{T} 0$ to assess the magnitude change for each period.

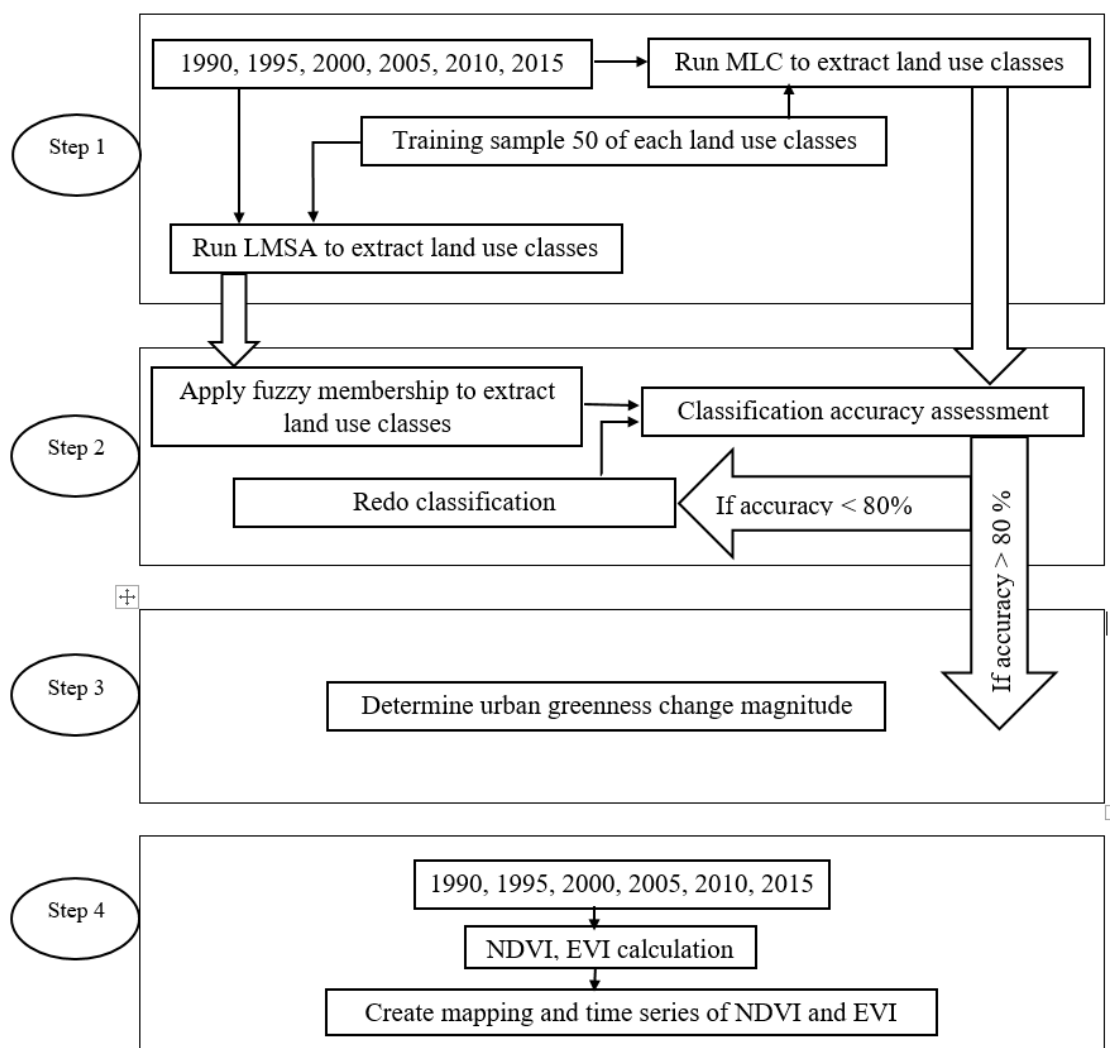

Figure 3-5: Pre-Processing and Processing of Landsat Satellite Imagery Data at Scale 2

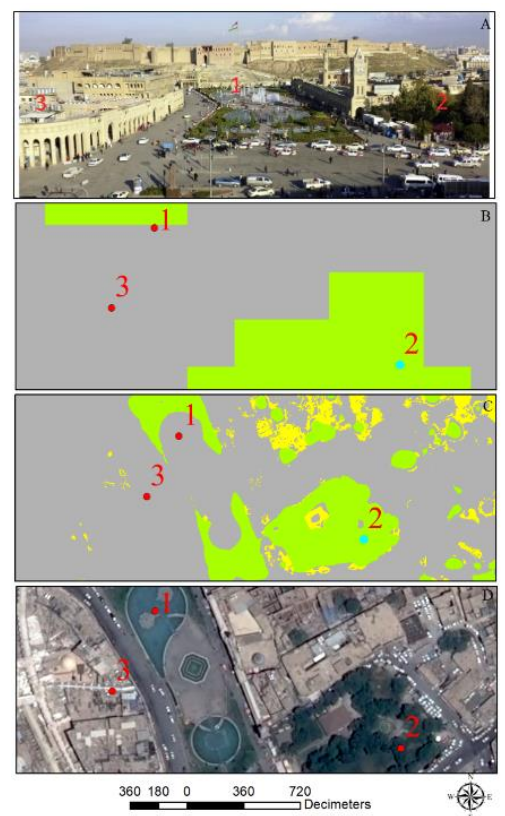

Figure 3-6: Examples of accuracy assessment, three points investigated: (A) view of field measurement. (B) classified of Landsat. (C) classified of Pleiades. (D) Pleiades satellite imagery 


\subsubsection{Scale 3: Pleiades very high-resolution imagery and multispectral classification}

The area of scale 3 selected as a sample representing old and new districts; this study utilised very high resolution and cloud-free multispectral satellite data. Data requested on $21 \mathrm{st}$ June 2015 (Table 3-4). The data delivered in ORTHO form, which means geometrically corrected data in the Universal Transverse Mercator (UTM) coordinate system and matched with sub-pixel accuracy. The Pleiades deliver high spatial resolution $0.5 \mathrm{~m}$ panchromatic and $2 \mathrm{~m}$ multispectral bands (blue, green, red, and infrared (430-550 nm), (490-610 nm), (600-720 $\mathrm{nm}),(750-950 \mathrm{~nm})$ respectively. The satellite images used to produce detailed vegetation maps at a section of Erbil City (Hussein et al., 2019). The year is the same as the last image of MODIS and Landsat (2015).

Table 3-4: Pleiades Metadata

\begin{tabular}{|ccccccc|}
\hline sensor & Date & Projection & Ellipsoid & $\begin{array}{c}\text { Processing } \\
\text { level }\end{array}$ & Spectral Bands & $\begin{array}{c}\text { Spatial } \\
\text { resolution }\end{array}$ \\
\hline Pleiades-L1 & 21- 6- 2015 & UTM Zone 38 & WGS 84 & ORTHO & 4 & $2 \mathrm{~m}$ \\
\hline
\end{tabular}

Lastly, the data from the Pleiades also went under some pre-processing and processing stages. A series of pre-processing steps applied to prepare the satellite images for further analysis (Figure 3-7). First, image radiometric calibration was applied to convert the radiance value to Top-of-Atmosphere (TOA) reflectance. A MODTRAN4-based atmospheric correction software package (FLAASH) used to convert the TOA Reflectance to surface reflectance (Adler-Golden et al., 1999) using ENVI software. Second, the MLC method used to assign the digital pixel values of the satellite images into different land cover classes. There were MLC works based on spectral pattern recognition of each land cover type represented by each pixel in the satellite image (Campbell \& Wynne, 2011; Chuvieco, 2016). In supervised classification, training data collected by drawing boundaries around areas that are representative of the land cover types meant to map in the image. After these steps, the image divided into four classes concerning the main objectives of this study. These classes are bare land, water, vegetation, and built-up land areas.

Finally, to assess the classification accuracy, the error matrix method technique (confusion matrix) is used in the study (Congalton, 1991). A total of 550 ground truth points was collected for the study area as follows; 150 for each urban, vegetation, bare land, and 100 for a body of water. Afterward, the overall user and producer accuracy calculated.

Regarding the NDVI measures, to establish whether the variation between city districts in terms of vegetation cover is significantly different, the analysis of variance (ANOVA) is performed. This statistical method examines whether groups means are different from each 
other in a statistically significant way. Finally, to examine visually how the city districts are different NDVI box plot technique was employed using mean and standard deviation. Furthermore, the percentage of each land cover class was extracted and compared for further analysis, such as comparing with Landsat results.

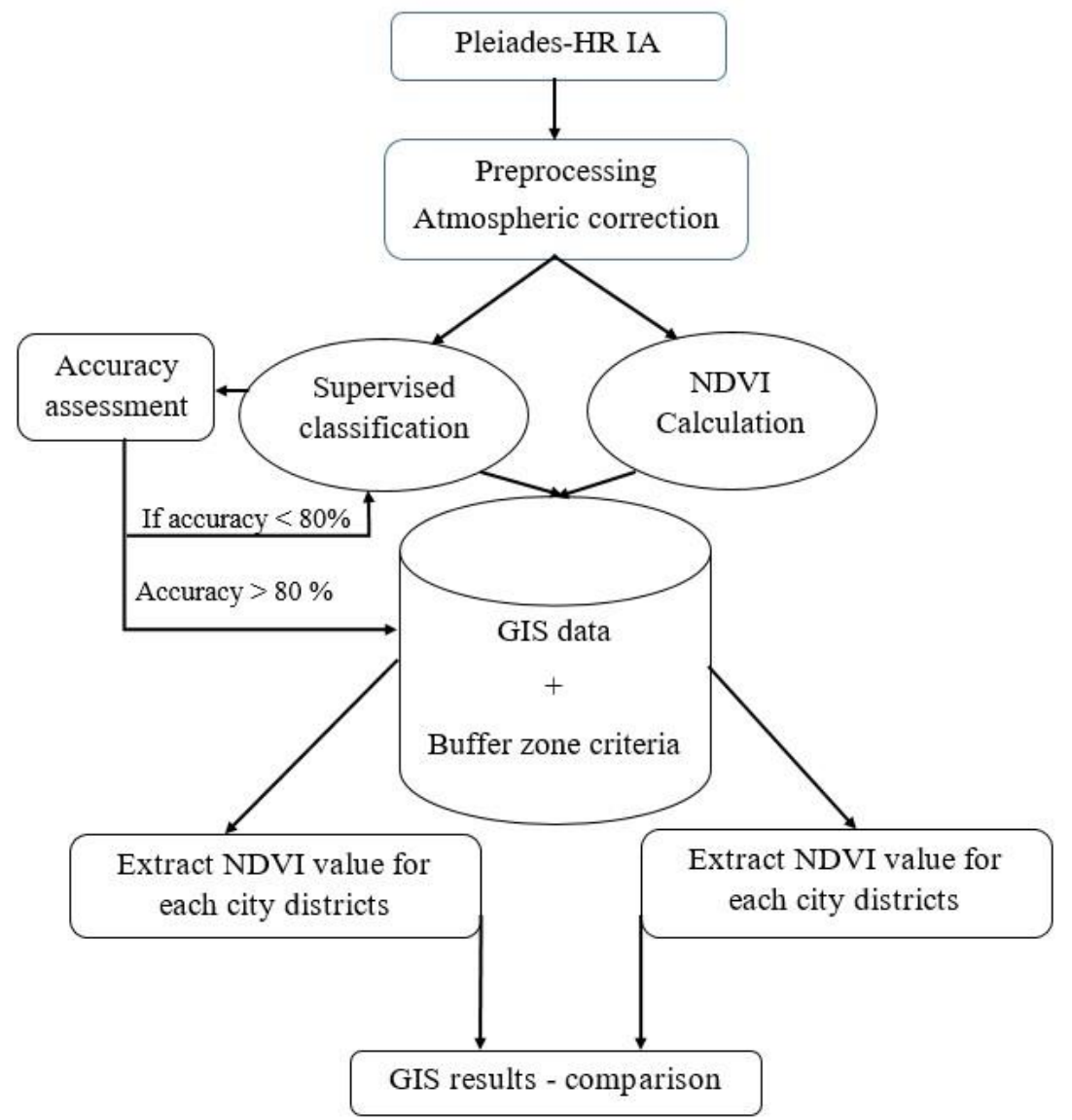

Figure 3-7: Pre-Processing and Processing of Pleiades Satellite Imagery Data at Scale 3

Regarding the conversion of results into the GIS environment, the nature of recorded data in remotely sensed images is pixel values, where each pixel records $\mathrm{X}$, Y information for the ground location. Therefore, this allows remotely derived information that used with other data in spatially distributed modelling efforts, such as with GIS (Lindgren, 1985; Jensen \& Hodgson, 2004). GIS techniques included to analyse and evaluate spatial information. These techniques included the input and conversion of all obtained results into ArcGIS software to facilitate the conversion of data type from raster to polygons. This step has rarely used in literature and, thus, counts as a point of strength for this study. The polygon data of the city used to extract the NDVI value and the classification result based on each district in the city.

Moreover, to determine and explore the accessibility to green spaces within the city districts, buffer zone criteria are used. The most common way to assess exposure to green areas is to determine the greenness within a circular buffer of the residential address (James et al., 
2015). The radius of the buffers used to define surrounding green space varied among studies and ranged from 30 (McMorris et al., 2015) to $2000 \mathrm{~m}$ (Maas et al., 2008). Green space within a buffer can be assessed by using NDVI or by classification of land use for the given area. The current study used the following criteria: 1) $300 \mathrm{~m}$ of buffer was applied to green areas between 2 and 20 ha; 2) A buffer zone of $2 \mathrm{~km}$ applied to green areas more than 20 ha. Subsequently, the total area of each district in those buffer zones was extracted and converted into a percentage of the analysis to determine the accessibility of green space throughout ArcGIS 10.6. 


\section{Results}

\subsection{Monitoring spatiotemporal variation of urban vegetation cover using MODIS satellite data}

Spatiotemporal changes in vegetation cover in and around the city of Erbil investigated by using the NDVI and EVI derived from MODIS satellite imagery. To have high temporal resolution and a long-term perspective on the vegetation dynamics in the city of Erbil, we have constructed an analysis MODIS images covering the period between 2000 and 2015, using time series scatter plots of mean NDVI and EVI values and summary statistics including standard deviation, minimum and maximum. Both indices evaluated within a year for seven separate years between 2000 and 2015 to analyse between the years and the vegetation periods during a year as well. The examined years are 2000, 2003, 2005, 2008, 2010, 2013, and 2015.

\subsubsection{Temporal trends}

One of the striking features from the plots is the monthly pattern within the years. The NDVI and EVI indexes usually starts the year with a value of around 0.2-0.3 and 0.1-0.2 respectively and then reach the highest value of the year during two months of March and April, where the index values can reach the levels of 0.4 to 0.5 for NDVI and 0.3 .5 to 0.4 for EVI (Figure 4-1 and, Figure 4-2). Then, indexes fall to the lowest values within the year during summer and autumn months and stand on the level between 0.1-0.2 for NDVI and 0.5-0.1 for EVI during June and November, while it might experience a slight increase at the end of the year.

The within-month pattern of vegetation index correlated with the humidity NDVI and EVI with values of 0.92 and 0.94 in April and rainfall NDVI and EVI levels with values of 0.64 and 0.62 in April. According to the weather station of Erbil (2016), the average rainfall is highest in January with an average value of $80 \mathrm{~mm}$, followed by $74 \mathrm{~mm}$ in February, and 71 $\mathrm{mm}$ in March. April, along with November and December, also have 37-70 mm rainfall to argue that sustained rise in rains starting from November leads to the highest levels of vegetation during March and April. The high correlation with the rainfall also implies that city policies on irrigation systems for parks and other green fields do not have a sizeable effect on the pattern of vegetation in Erbil. When some broad comparisons made across years for the NDVI and EVI indices, it is seen that 2003 and 2015 stand out as greener years, while 2008 was a notably less green year in the sample. NDVI value started from 0.2 in January 2003 and reached to 0.5 in April, with the values of above 0.3 for February and May of the same year. 
On the other hand, in the same year, EVI started at 0.1 and peaked at 0.4 in April, that is mean the difference is 0.1 value; according to the field data NDVI more represent the environment better than EVI. Similarly, 2015 was also a very green year, with NDVI starting from 0.3 in January and staying above 0.4 in March and April. In contrast, 2008 was a mainly dry year with NDVI values being between 0.1 and 0.2 for the whole year, except the index being slightly above 0.2 in April. The figures also provide information on minimum and maximum values in addition to the mean levels. So, one can analyse the standard deviation in the data. When the most significant values examined, it can be seen that 2015 has the highest levels of maximum values, followed by 2003. 2015 also has the highest NDVI values in 4 of 12 months. Similar to the average value dynamics, 2008 has the lowest values of maximum NDVI and EVI. In terms of minimum values, 2003 stands out again as the year with the highest values. When the standard deviations across the years are examined, it can be seen that 2015 has the highest volatility. Overall, these statistics imply that greener years have high minimum, maximum, and standard deviation values as well.

To see the monthly pattern across the years, Figure 4-3 provides a detailed comparison between the years that shows less green months display limited variation over the years, while more green months display higher variety across the years. For example, June has an average value of close to 0.1. The same can be said for the other less green months of July, August, September, October, November, and December. There was a little variation in these months across years, with average NDVI values being in the vicinity of 0.1 ; the only small temporal difference observed in some of these months is that 2003 had slightly higher NDVI value, while 2008 had slightly lower NDVI value. Based on these observations, it was clear that there is no obvious upward or downward trend in NDVI values for these months over the sample years from 2000 to 2015, as confirmed by the near-constant linear fit lines in (Figure 4-3).

In contrast to the stable course of NDVI values for months from June to December, the first five months displayed some variation as well as trends across years. In the sample years, 2008 stands out as the least green year in the first five months of the year. NDVI graphs make a thorough in 2008, while the peak year is observed in 2003 for April and May, in 2005 for March and 2015 for January and February. In terms of long-term trends, according to the figure, January, February, and especially March have clear upward trends, while April has a stable course, and May has a downward trend. For example, in the case of March observations, the last three sample years (i.e., 2010, 2013, and 2015) have larger NDVI values than the first three sample years (i.e., 2000, 2003, and 2005). So, the vegetation indices display some temporal variation, especially in the first five months of the year. 


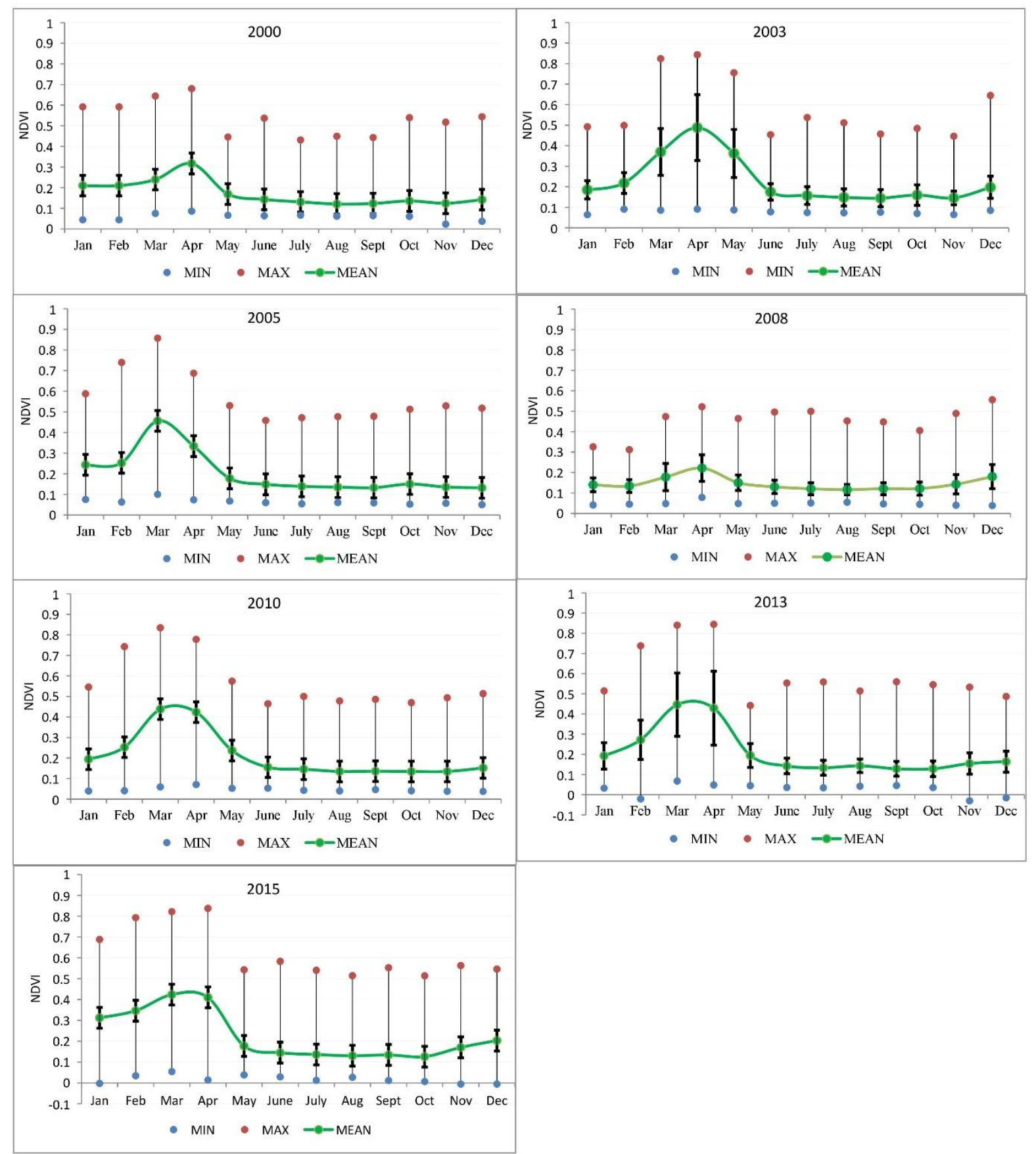

Figure 4-1: NDVI Monthly Summary Statistics for 2000-2015

Graphs for EVI dynamics in Figure 4-3 also display similar properties, as in the case of NDVI. From June to December, there is limited variation across the sample years. Besides, EVI dynamics in the first five months also display similar trends and volatilities. Overall, two measures of vegetation indices produce very similar findings on the evolution of vegetation area in the city of Erbil. The figure also presents information on min, maximum, and standard deviation across months in different years. For example, December is the driest month in terms of NDVI and EVI values. December also has the lowest minimum and maximum values. 


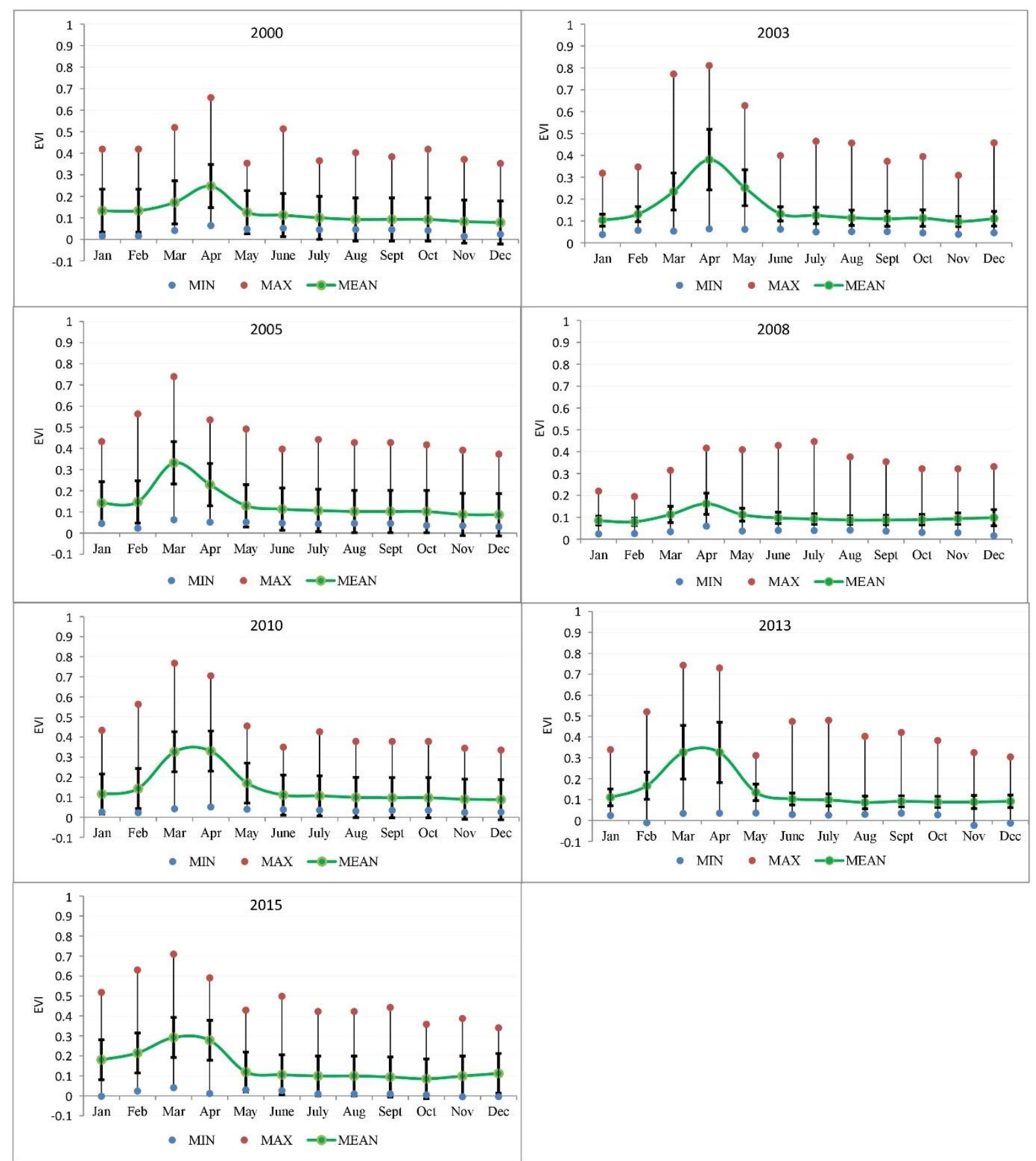

Figure 4-2: EVI Monthly Summary Statistics for 2000-2015

Similarly, April is the greenest month in terms of average NDVI and EVI. April also has the highest minimum and maximum values. So, the minimum and maximum values are positively associated with the average vegetation indices. Also, the standard deviation is highest in the greenest month, so being green comes with some volatility in the data. In contrast, dry months like December and July have very low standard deviations in NDVI and EVI values. 

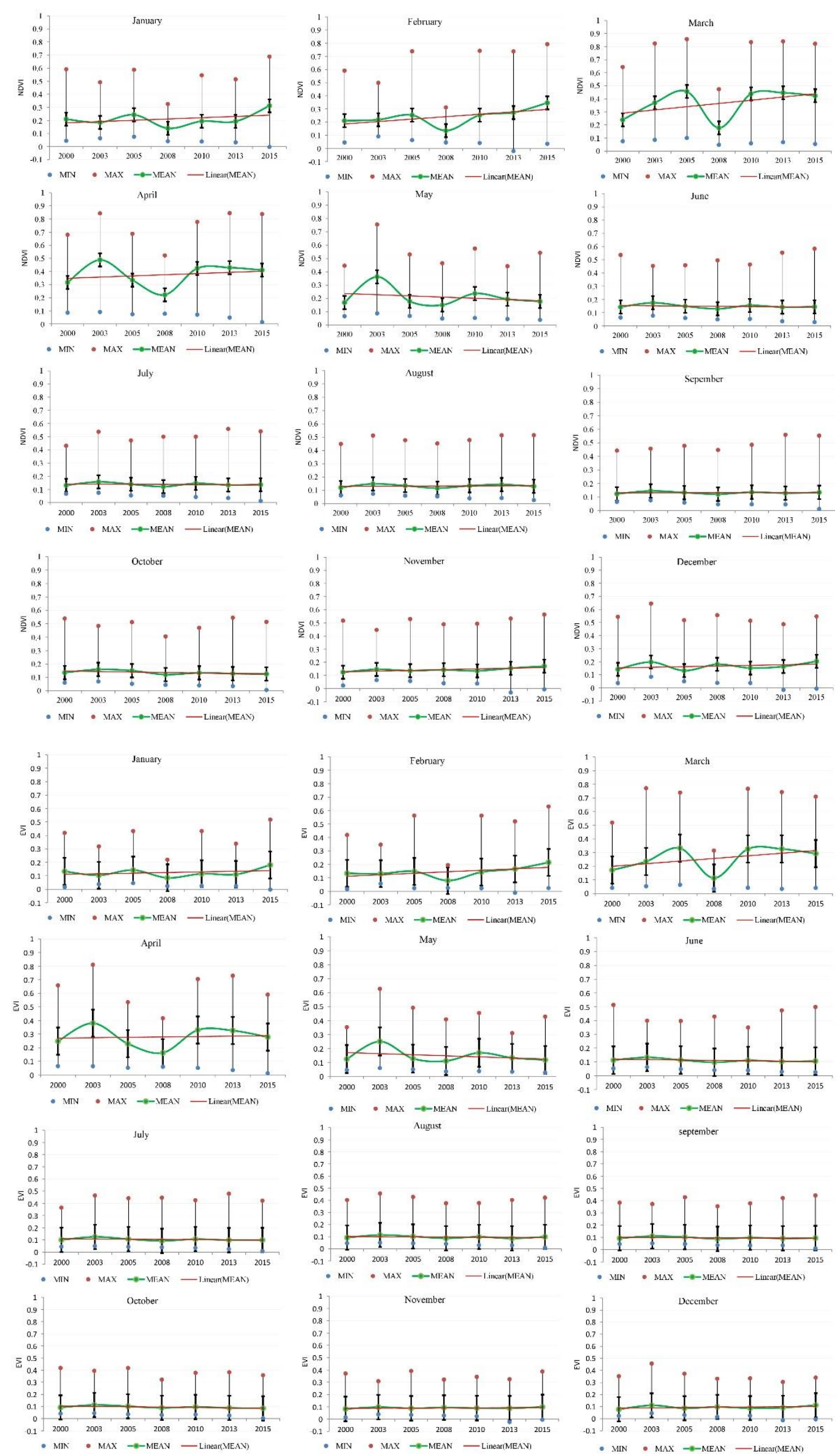

Figure 4-3: Monthly plots of NDVI and EVI Summary Statistics for 2000-2015 
Moreover, the result examines the distribution of NDVI and EVI into a map of land cover/land use. Annual MODIS was used to calculate land cover statistics for time series for both indices, which showed in (Figure 4-4). Most of the sample years contain SVIs values with variation, except for both SVIs values in 2008. NDVI shows a higher variety than EVI. Abrupt climatic explained that changes were resulting in vegetation growth or decline. The cropland class had the highest NDVI values over any other class during the 16 years, which expected as healthy green crops would exhibit a higher NDVI value compared to open shrub and grassland ecosystems that contain various plant species with varying foliage colours and types. Barren/sparsely vegetated and urban areas displayed the lowest mean NDVI values for the study area over the 16 years, except grassland; the mean values showed the lowest in 2010 .
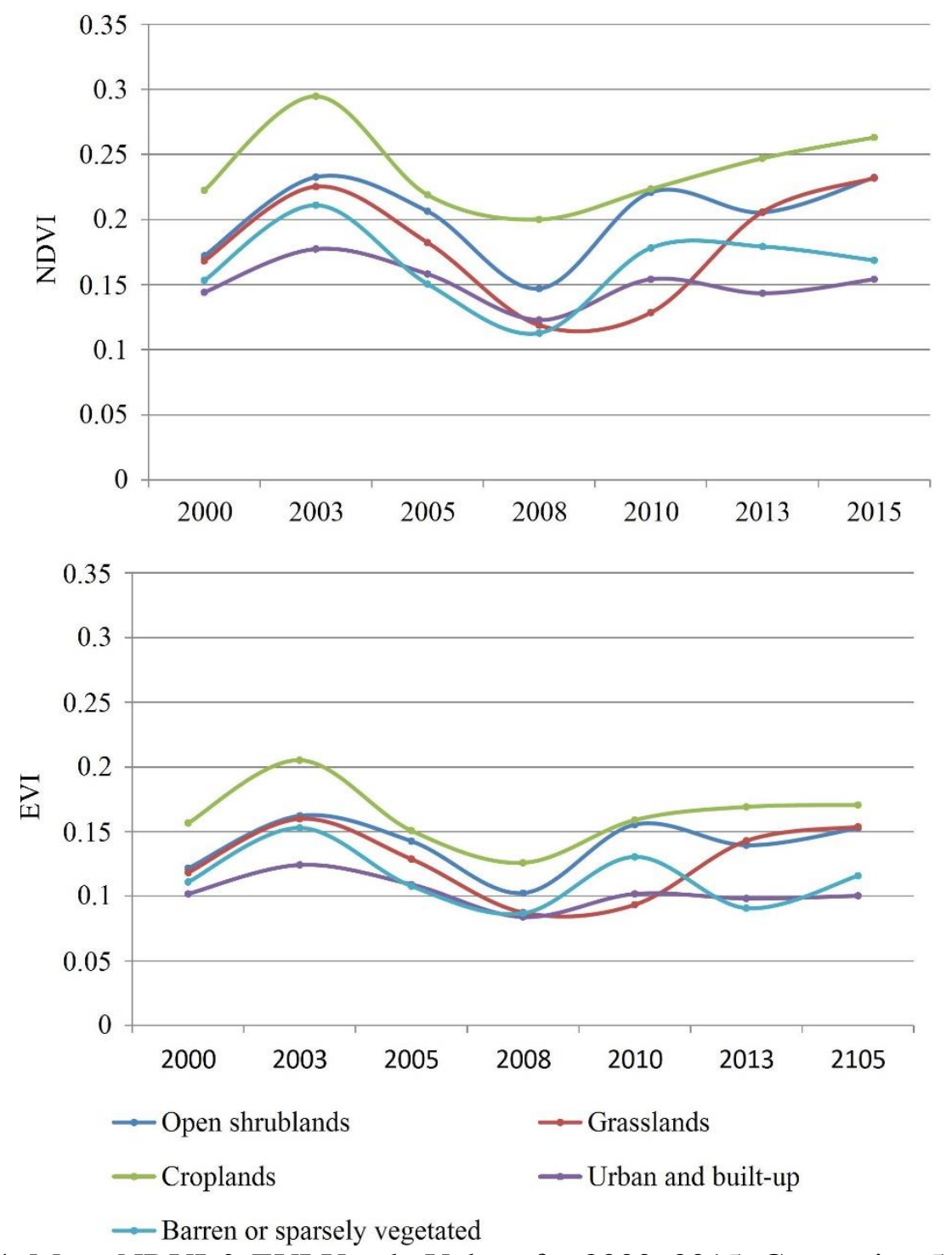

Figure 4-4: Mean NDVI \& EVI Yearly Values for 2000-2015, Comparing 5 Land Cover Types 
The EVI time series presents a similar trend, as cropland appears to generally have higher biomass over grasslands and open shrublands over the 16 years. Cropland EVI exceeds grassland due to additional crop irrigation for those years. As expected, EVI in urban areas remains relatively low over the study period; however, EVI in barren/sparsely vegetated classes seems to spike in 2003 and 2015 (Figure 4-4). The spikes explained by an increase in sparse vegetation species and opportunistic species such as weeds. Based on Figure 4-1, Figure 4-2 and, Figure 4-4, it suggested that NDVI is more sensitive than EVI for fluctuations in vegetation health and biomass in the study area.

When the literature examines the dynamics of vegetation indices, the relevant studies also look at the possible factors associated with the given dynamics (Lanorte et al., 2014; Fernández-Martinez et al., 2015). Some of the leading variables that the literature examines are the rainfall (Nicholson et al., 1990; Davenport \& Nicholson, 1993; Santos \& Negri, 1997), humidity (Stabler et al., 2005; Brown et al., 2012), and temperature (Sandholt et al., 2002; Kustas et al., 2003). Annual rainfall, average temperature, average humidity, and covering the 16 years presented (Figure 4-5, and Figure 4-6). Total rainfall was higher in 2003 and 2006, followed by low rainfall years in 2004, 2010, and 2007. After 2007 total rainfall has remained more constant with less variation between years, with a positive increasing trend towards 2015 .

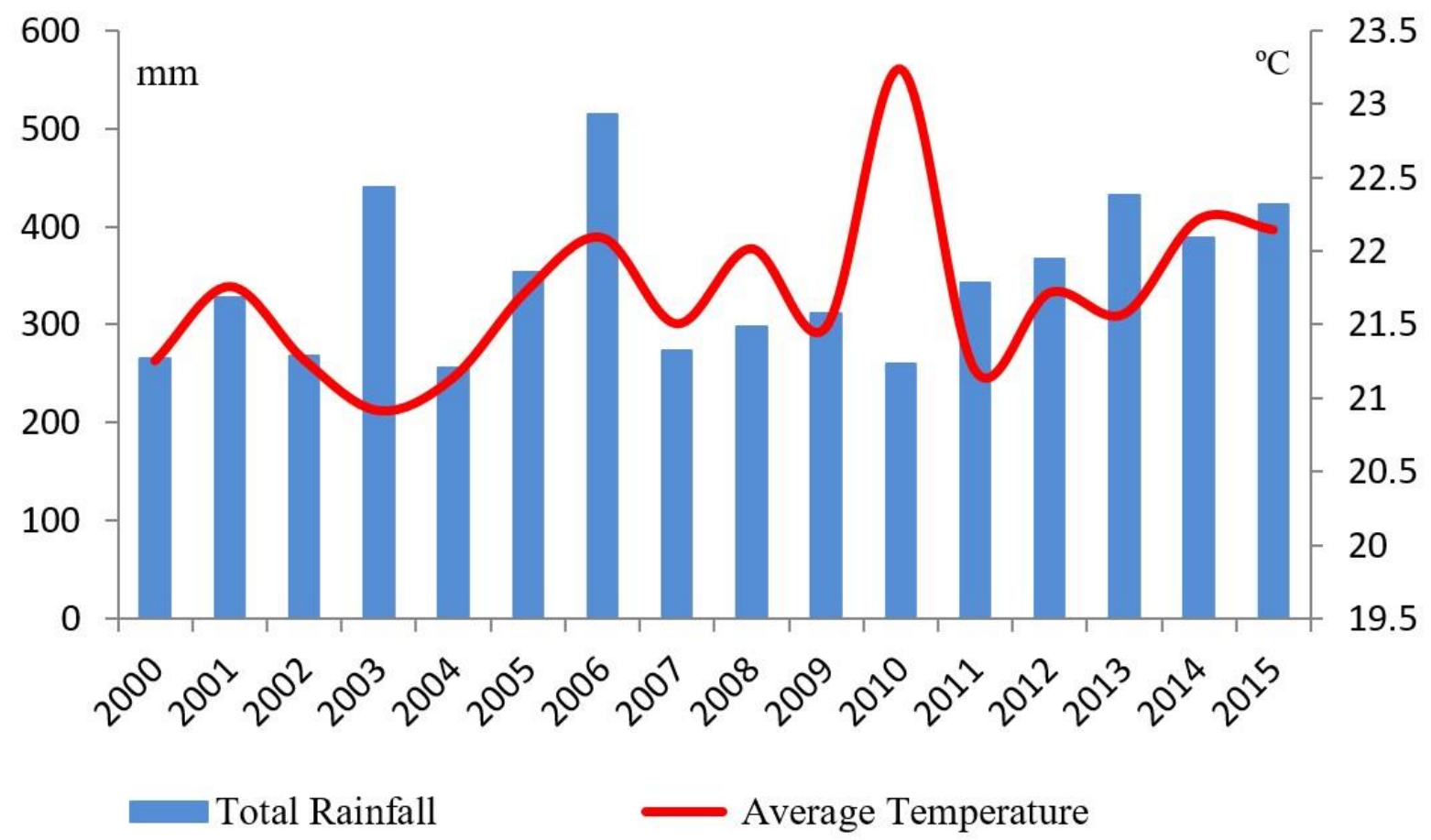

Figure 4-5: Total Annual Rainfall and Average Temperature Time-Series from 2000 - 2015 (KRG, 2016) 


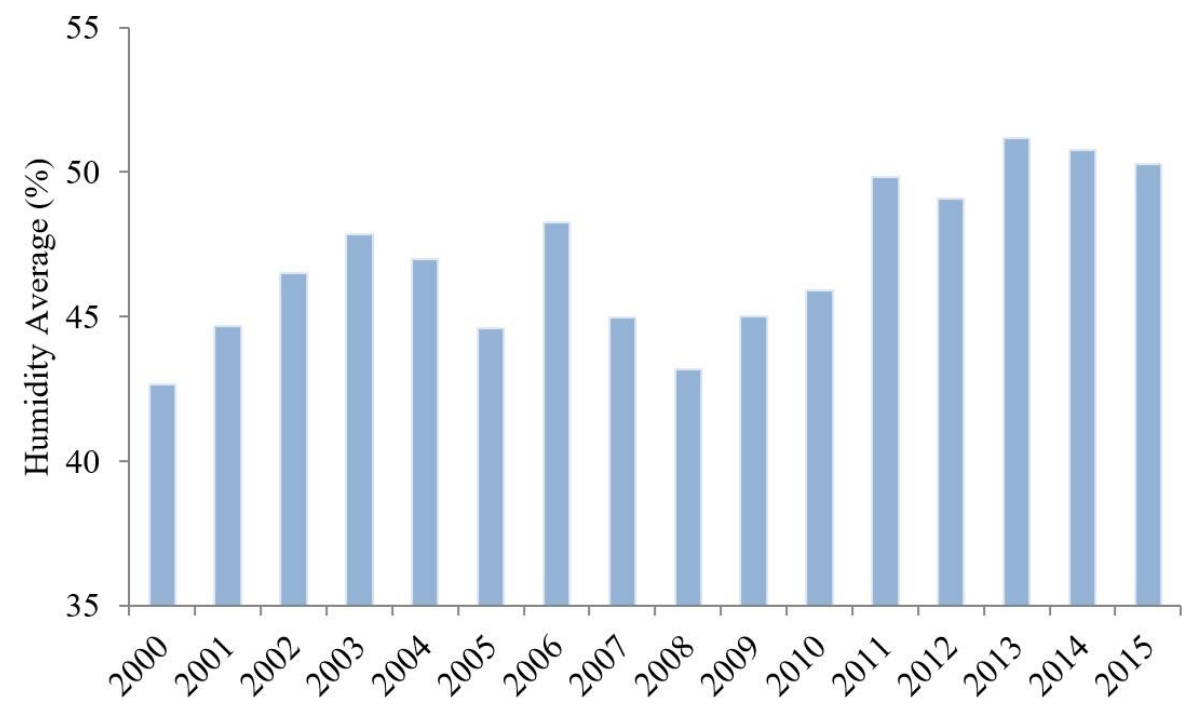

Figure 4-6: Annual Mean Humidity Time-Series from 2000 - 2015 (KRG, 2016)

Humidity shares a similar pattern to rainfall, with high averages in 2003 and 2006, followed by lows and then a gradually increasing trend towards (Figure 4-6). Interestingly to note, the average temperature for 2003 was the lowest over the 16 years, while in 2006, the temperature was relatively high for that period (Figure 4-5). In 2010 average temperature spiked at $23^{\circ} \mathrm{C}$, the highest average temperature over the 16 years. By comparison, total rainfall was deficient in 2010 with average humidity. Average rainfall, humidity, and temperature all appear to have generally increased between 2000 and 2015 with various positive and navigate fluctuations in-between.

The relationship of MODIS vegetation indices with climate factors presents in Table 4-1.The correlation between three climate variables and two SVIs from 2000 to 2015 measures. The table shows that humidity has a very high positive correlation to SVIs in April with a value of 0.94 and 0.92 for EVI and NDVI, respectively, followed by March with a value of 0.78 and 0.86 . The positive impact of humidity on vegetation also begins in November and continues until April. Rainfall measures indicate a significant correlation in April in the case of EVI with a value of 0.82 and the months of April, November, and December positively associated with SVIs.

Regarding the temperatures, the months of January, February, and October have a weakly positive relationship, and the rest of the months have a negative correlation. So, humidity and rainfall have positive associations with the SVIs measures in the city of Erbil. However, the relationship of SVIs with temperature is negative in general. Consequently, the results from climatic conditions analysis show that humidity and rainfall are parameters more important in vegetation evolution. 
Table 4-1: Correlation Analysis between Monthly Rainfall, Humidity, Temperature and Monthly Vegetation Indices (NDVI \& EVI), Green Highlighted Refers to a Correlation

\begin{tabular}{|lcccccc|}
\hline & \multicolumn{3}{c}{ Rainfall } & \multicolumn{2}{c|}{ Temperatures } & \multicolumn{2}{c|}{ Humidity } \\
\cline { 2 - 7 } Months & NDVI & EVI & EVI & NDVI & EVI & NDVI \\
\hline Jan & -0.13 & -0.11 & 0.22 & 0.27 & 0.58 & 0.57 \\
Feb & 0.06 & -0.06 & 0.40 & 0.45 & 0.52 & 0.55 \\
Mar & 0.05 & 0.03 & -0.12 & -0.17 & 0.78 & 0.86 \\
Apr & 0.64 & 0.62 & -0.88 & -0.93 & 0.92 & 0.94 \\
May & 0.24 & 0.22 & -0.23 & -0.23 & 0.08 & 0.11 \\
Jun & 0.00 & 0.00 & -0.32 & -0.05 & -0.48 & -0.26 \\
Jul & 0.00 & 0.00 & -0.37 & -0.33 & 0.05 & 0.21 \\
Aug & 0.00 & 0.00 & 0.26 & -0.29 & -0.13 & 0.22 \\
Sep & 0.00 & 0.00 & -0.25 & 0.08 & -0.16 & 0.06 \\
Oct & 0.00 & 0.00 & 0.37 & 0.31 & -0.48 & -0.58 \\
Nov & 0.74 & 0.82 & -0.35 & -0.23 & 0.52 & 0.90 \\
Dec & 0.53 & 0.65 & -0.51 & -0.69 & 0.28 & 0.42 \\
\hline
\end{tabular}

\subsubsection{Spatiotemporal variation}

Figure 4-7 and Table 4-2 clarify the distribution of land cover types from 2000 to 2015. The table that urban and built-up areas remained relatively similar at this resolution over time, except for 2015. While vegetation areas experienced a volatile pattern. Especially, cropland and grassland displayed some ups and downs in the sample period. As a result, the plants around the city are seasonal vegetation, seasonal crops associated with precipitation, hence indicate to the weak interaction between urban ecosystem and suburban and rural environments.

Table 4-2: Area Coverage of MODIS Land Cover (\% Share)

\begin{tabular}{|cccccccc|}
\hline Land Covers & $\mathbf{2 0 0 0}$ & $\mathbf{2 0 0 3}$ & $\mathbf{2 0 0 5}$ & $\mathbf{2 0 0 8}$ & $\mathbf{2 0 1 0}$ & $\mathbf{2 0 1 3}$ & $\mathbf{2 0 1 5}$ \\
\hline Open shrublands & 62 & 64 & 52 & 86 & 84 & 59 & 28 \\
Grasslands & 6 & 8 & 1 & 1 & 2 & 19 & 12 \\
Croplands & 12 & 11 & 36 & 2 & 2 & 10 & 45 \\
Urban and built-up & 11 & 11 & 11 & 11 & 11 & 11 & 15 \\
Barren or sparsely vegetated & 9 & 6 & 1 & 1 & 2 & 1 & 1 \\
\hline
\end{tabular}

Figure 4-9, and Figure 4-10 present visualize the spatiotemporal variation of vegetation from April 2000 to April 2015 for NDVI and EVI measures, respectively. April is chosen as the comparison month as it had the highest vegetation growth, and as a result, it would best represent differences in true vegetation coverage extent (Figure 4-8). 

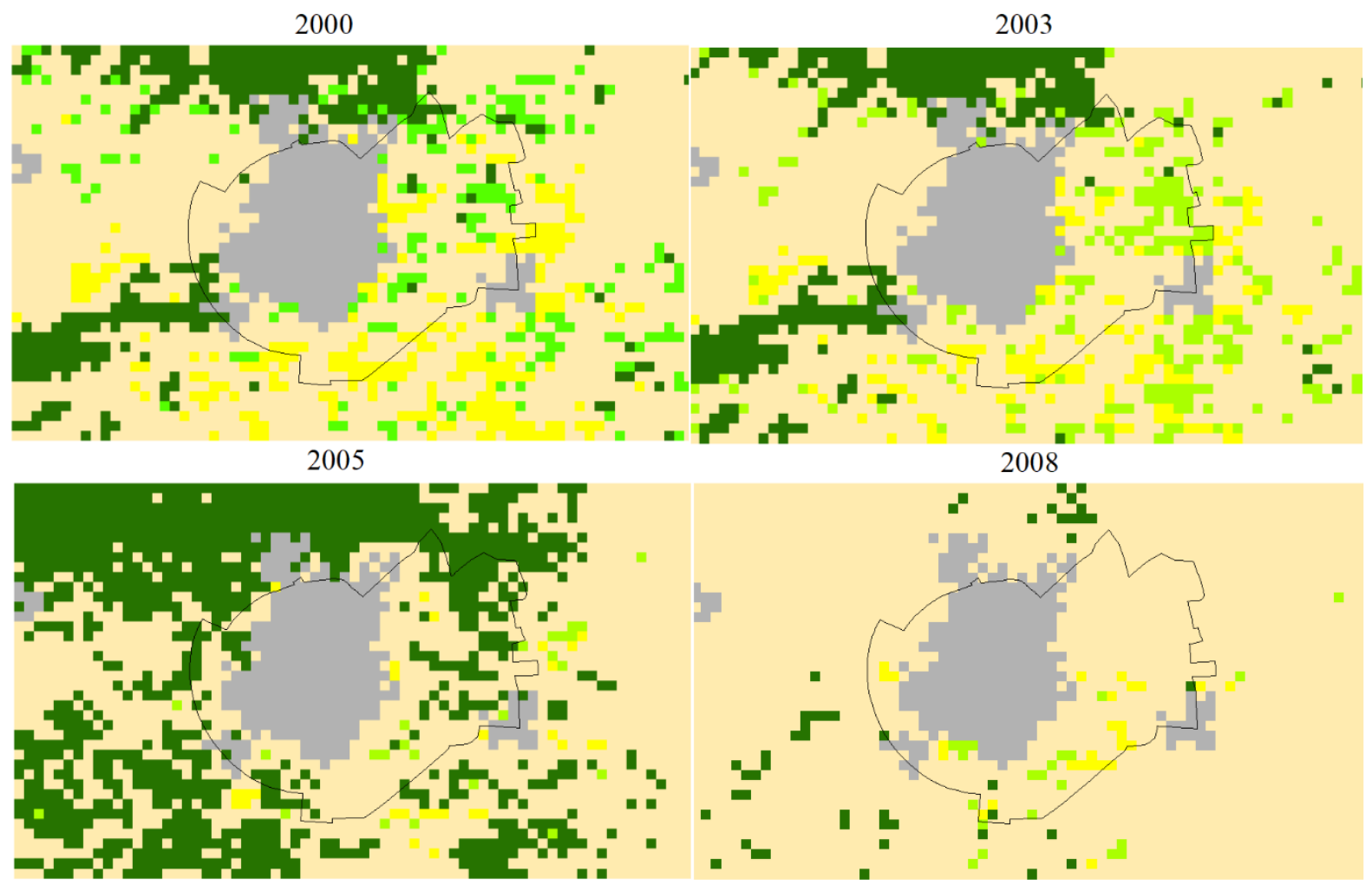

2010

2013
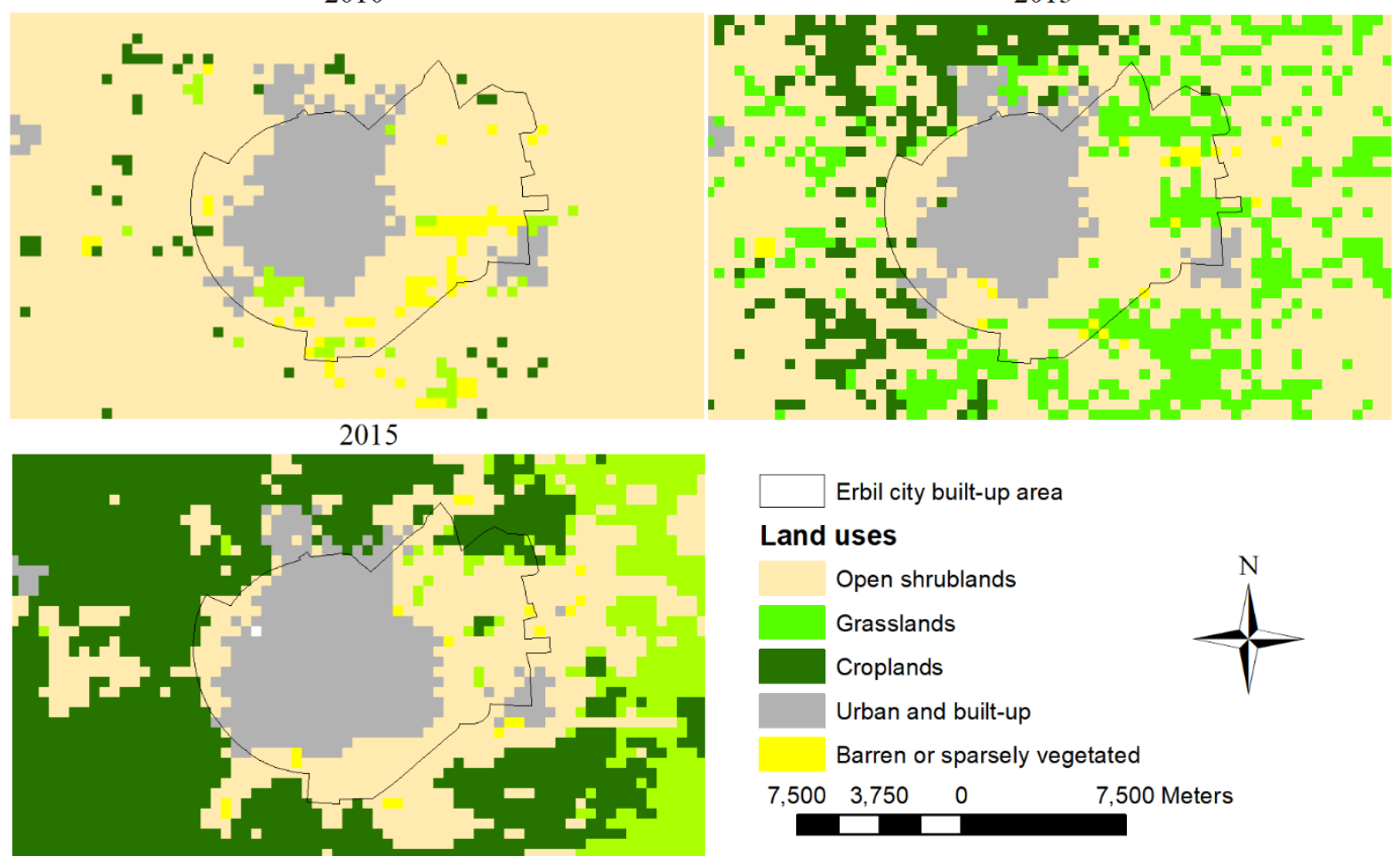

Land uses

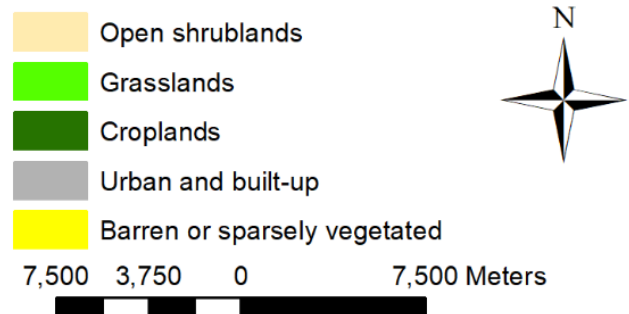

Figure 4-7: Spatiotemporal Distribution of Land Cover Types 


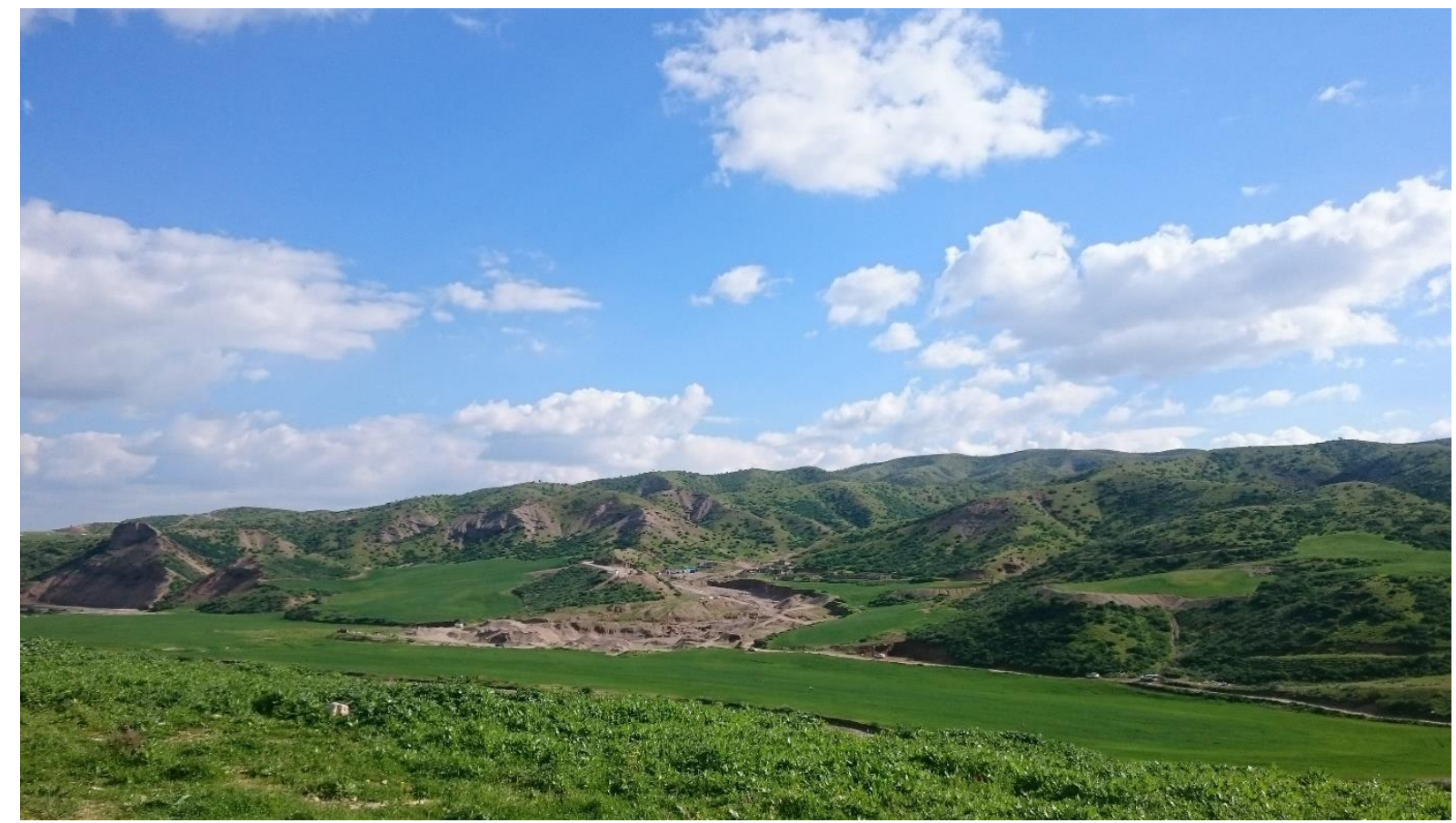

Figure 4-8: View of the Surrounding Vegetation in April 2016 ("Wikimedia Commons," 2020)

It is evident from the maps that the spatial distribution of urban areas and/or barren or sparsely vegetated areas with values less than 0.25 has expanded over the past 16 years. However, this growth did not happen in a linear way (Figure 4-4). From 2000 to 2003, there was a significant increase in the vegetation areas with the index values of higher than 0.4 . The situation worsened in 2005 and reached its lowest vegetation level in 2008. As seen from both Figure 4-9, and Figure 4-10, there was almost no area with higher than 0.4 SVIs levels in the study area. Then the situation slightly improved. These observations are consistent with the previous findings that the sample years of 2003 and 2015 were relatively green years, while 2008 was the least green year. When the initial year of 2000 and the final year of 2015 compared in Figure 4-9, and Figure 4-10, showed that there is a decrease in the SVIs measures, especially within the city limits.

Consequently, vegetation surrounding the urban centre replaced by urban growth. The EVI imagery has displayed a large area of poor vegetation health, which is more likely in the semi-arid regions of Iraq. The variation in vegetation distribution in the city of Erbil and its surrounding areas is a consequence of the following factors: the significant increase in builtup land, the constructions of green spaces such as parks; reducing vacant land; reducing agricultural land until almost to zero value. 


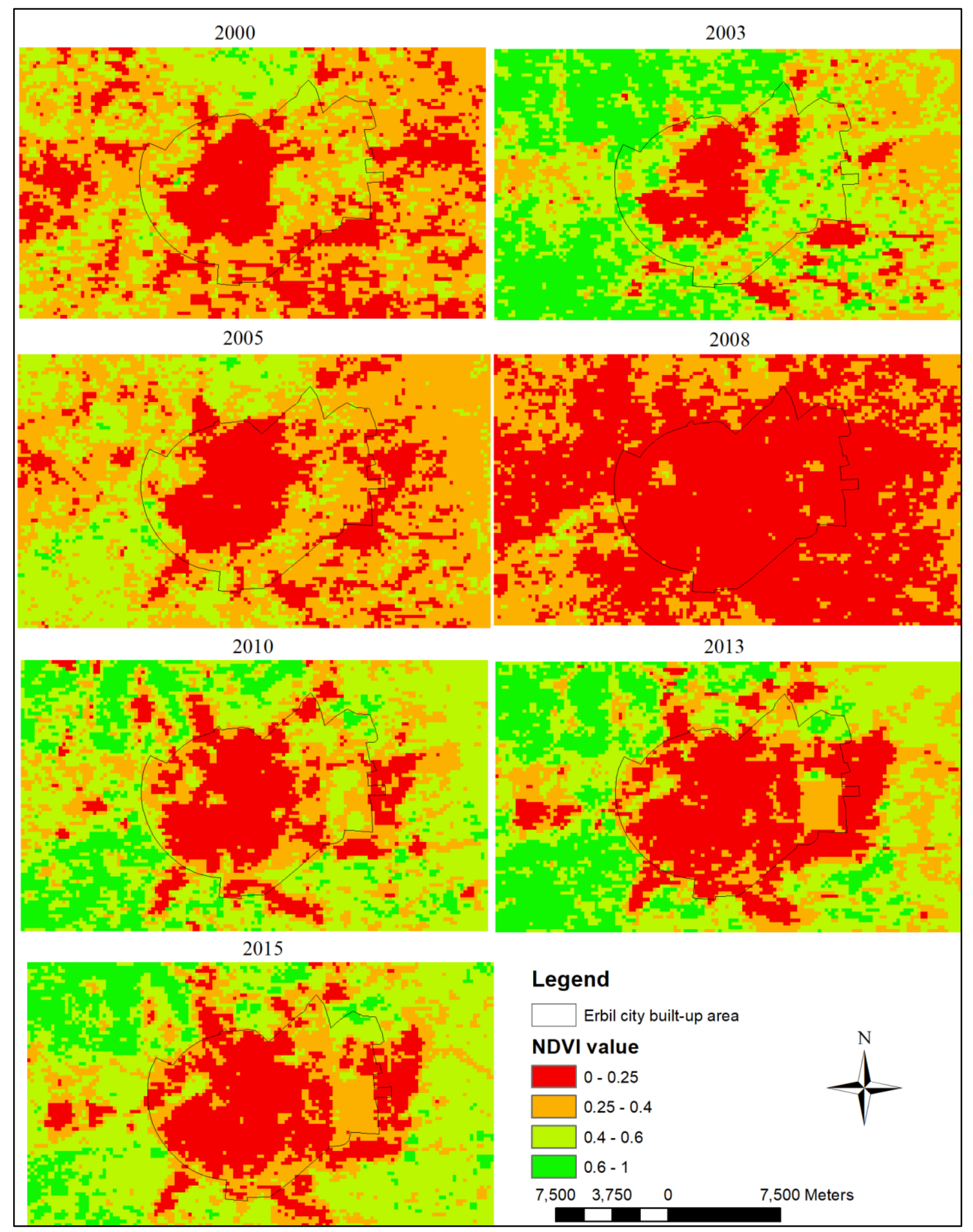

Figure 4-9: April NDVI Raster Time-Series of Erbil from 2000 to 2015 


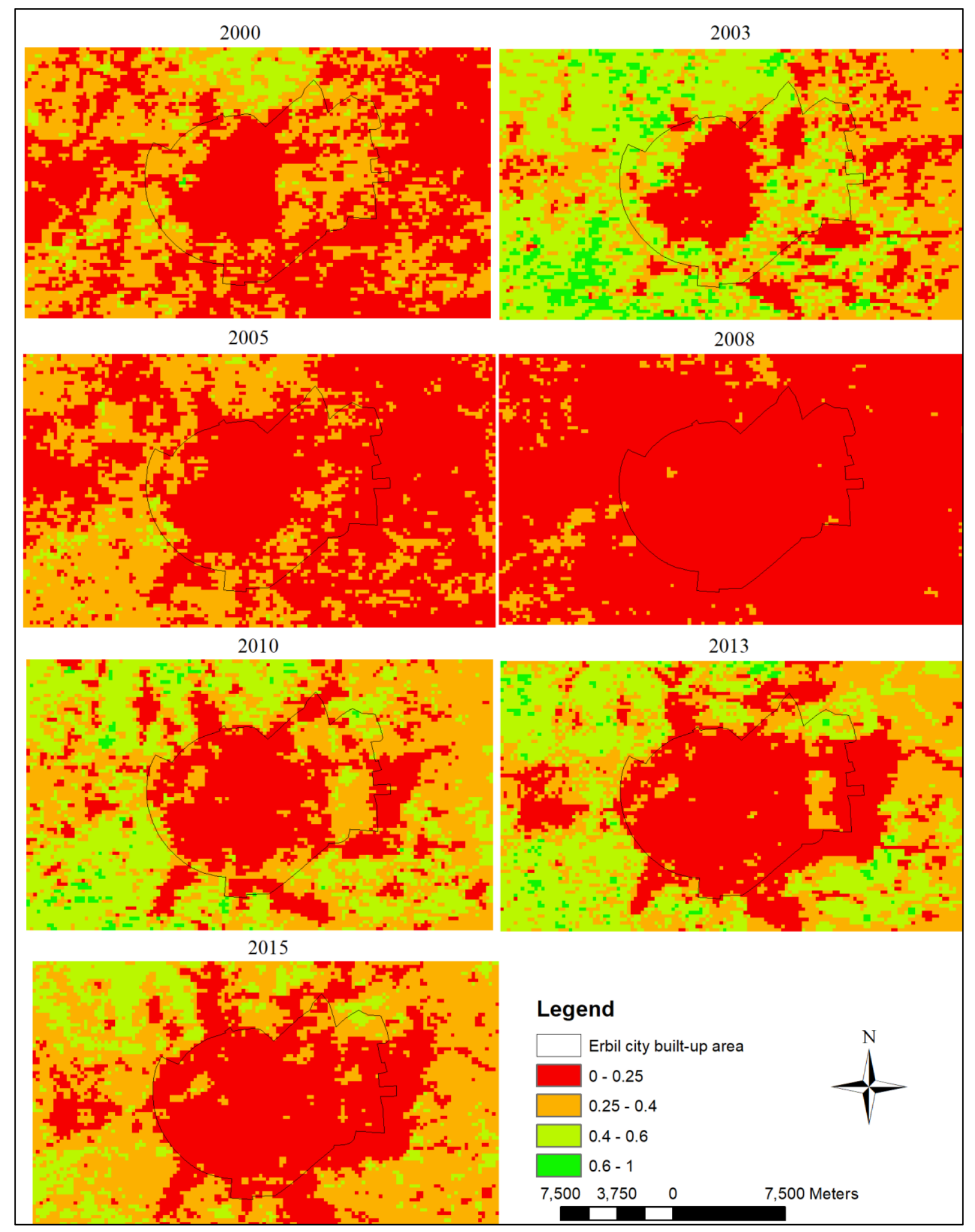

Figure 4-10: April EVI Raster Time-Series of Erbil from 2000 to 2015 


\subsection{Spatiotemporal variation of urban greenness cover using Landsat imagery}

\subsubsection{Results of Linear Spectral Mixture Analysis and Maximum Likelihood Classification}

This section presents the results achieved from urban greenness cover and urban land use land cover that covered an area 14032 ha, derived from LSMA and MLC classification. The spatiotemporal variation of urban greenness cover specifically presents a summary of LULC classification statistics and the results of LSMA and MLC for 1990, 2000, 2005, 2010, and 2015 images presented. Based on a Landsat image classification, four major land use land cover identified and verified.

The results of the MLC classification showed that land cover types displayed a significant change in the sample years covering the period of 1990-2015 (

Figure 4-11, Figure 4-12, and Figure 4-16). As an important finding, the share of builtup land increased significantly from $24 \%$ in 1990 to $58 \%$ in 2015 . This development is closely related to the rising population and the increasing urbanisation rates in the city of Erbil (KRG, 2015). Figure 4-12 shows that the rising share of build-up land happened at the expense of bare land and agricultural land. The share of the built-up area increased by $34 \%$ points, while the share of bare land decreased by $24 \%$ points, and the share of agricultural land decreased by $8 \%$ points between 1990 and 2010. The agricultural land had a share of $8 \%$ as of 1990 and decreased gradually to 2005, while its share disappeared totally as of 2010 .

Regarding the green vegetation area, it displayed little difference between 1990 and 2015, as the total green vegetation area was 889 ha in 1990 and 815 ha in 2015 . That means that the area remained unchanged and did not keep pace with other levels of land use growth. However, its share first declined to $2.7 \%$ in 2005, and its share increased back to $6 \%$ in 2015 . So, the urban expansion affected the green vegetation area negatively in the 1990-2005 period, while with the construction of green areas by the local administration government (KRG, 2015), the green vegetation area recovered back in the 2005-2015 period.

A similar analysis also presented using the LSMA method Figure 4-13, along with Figure 4-14, and Figure 4-17. The figures show that green vegetation had a lower share of $4.2 \%$ in 1990, while build-up land and agricultural land had higher shares compared to the MLC method. The LSMA method also showed that the share of built-up land increased significantly from $25.6 \%$ in 1990 to $61.2 \%$ in 2015 (i.e., a rise of $35.6 \%$ points that happened at the expense of agricultural land, which lost $9.3 \%$ points in share, and bare land, which lost $29.3 \%$ points. 


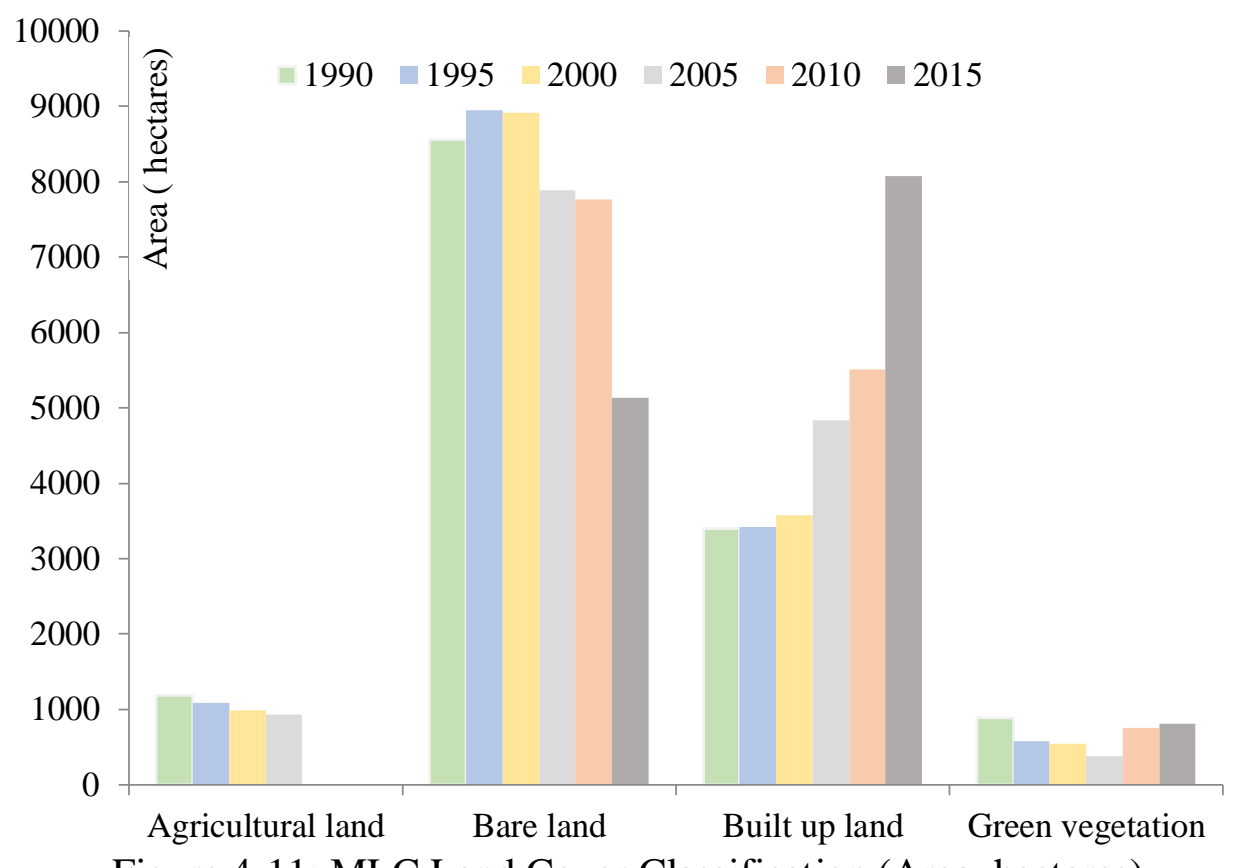

Figure 4-11: MLC Land Cover Classification (Area, hectares)
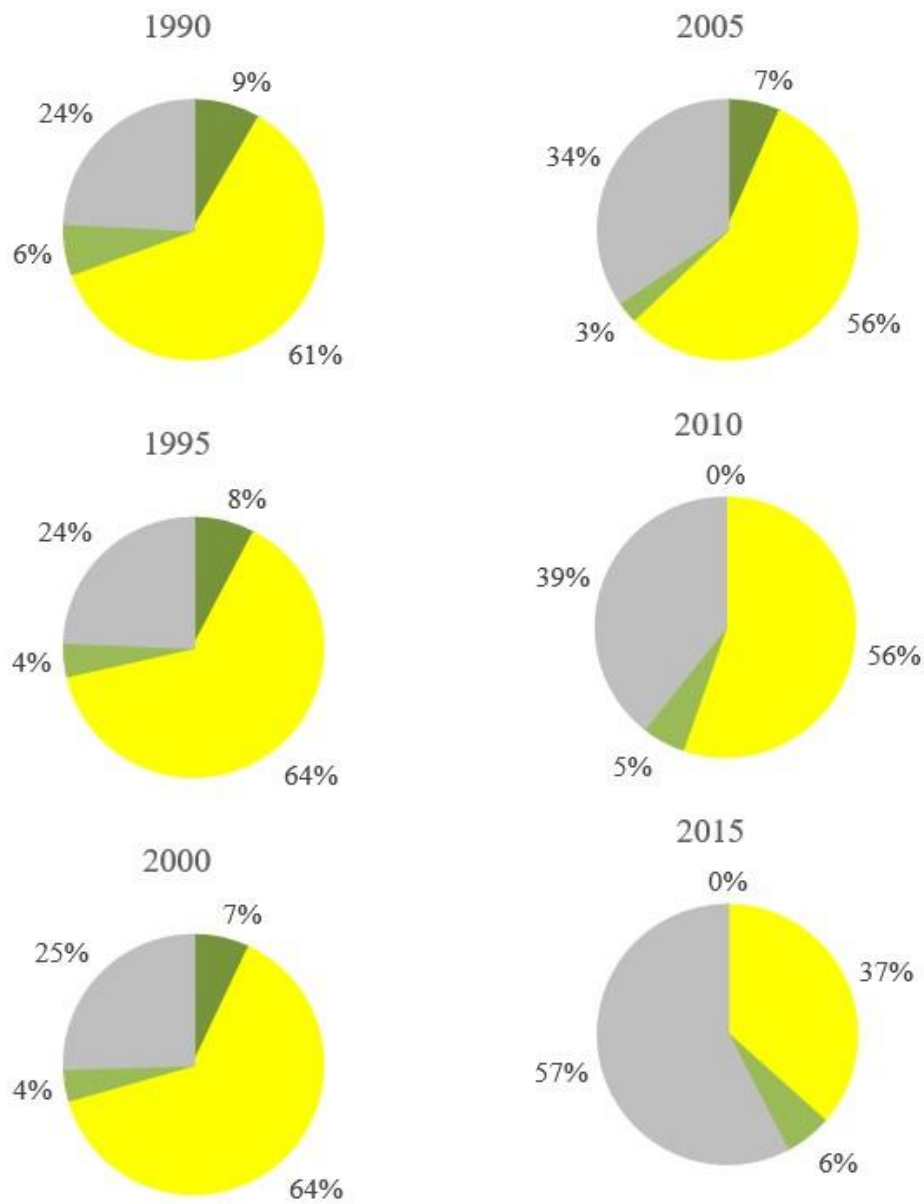

घgricultural land $\quad$ Bare land $\quad$ Green vegetation $\square$ Built up land

Figure 4-12: MLC Land Cover Classification (\% Share) 


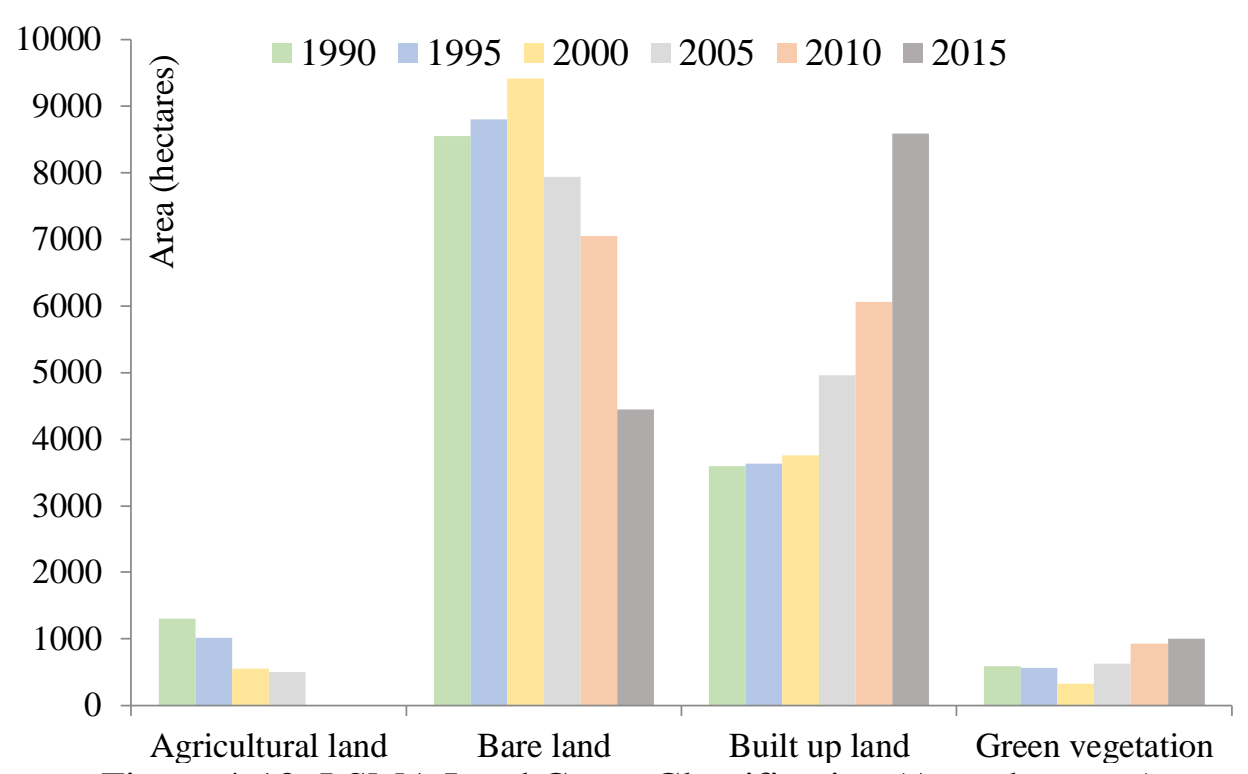

Figure 4-13: LSMA Land Cover Classification (Area, hectares)
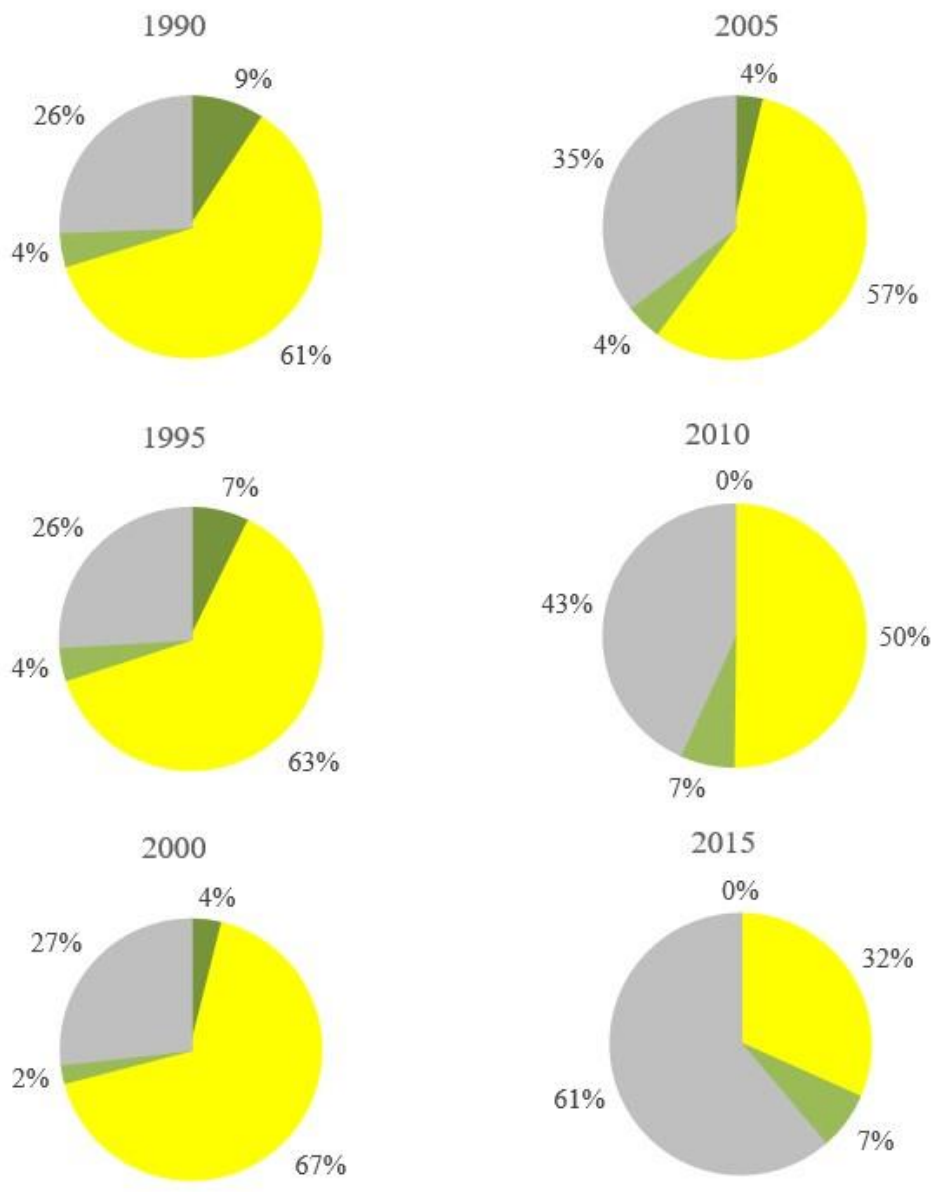

agricultural land Bare land $\quad$ Green vegetation $\quad$ Built up land Figure 4-14: LSMA Land Cover Classification (\% Share)

The result in the case of the LSMA method is different from MLC's results; the share of green vegetation increased in the sample period. The relevant share was $4.2 \%$ in 1990 , and 
it declined to $2.3 \%$ in 2000 . However, it displayed strong growth in the following years, and the share of green vegetation increased to $7.1 \%$ in 2015 .

The above parts provide general temporal characteristics of different land cover types. Figure 4-16, and Figure 4-17 display the spatiotemporal variation of land cover types in the city of Erbil for MLC and LSMA methods, respectively.

Both MLC and LSMA spatiotemporal distribution of land cover types display very similar dynamics. Significant changes have taken place in the land use classes. Built-up land grew slowly from 1990 to 2000 and extended from the north-east to the south-west. According to KRG (2015), this is due to low internal migration, whether rural to urban or urban to urban, due to economic and political crises. Then it increased rapidly to 2015, and the city expanded in different directions. The reasons were the lifting of UN sanctions after 2003 and a stable security situation, which stimulated economic growth and expansion in construction (KRG, 2015). Evidently, as of 1990, there existed dispersed green vegetation areas within the city limits as well as sizeable agricultural land in the surroundings of the city. However, over time, agricultural land disappeared totally, and the green vegetation became more concentrated in certain parts of the city. The most noticeable change in vegetation land occurs around the urban centre and main roads in 2000 and 2005, which can be explained by the subsequent increase in spatial extension and seasonal drought. As discussed by Hussein (2018), the construction of Sami Abdulrahman Park, covering around 200 ha or close to $50 \%$ of green vegetation as of 2010 in LSMA method, was instrumental in the concentrated increase in the share of green vegetation in the city.

Assessed the scale of urban ecology throughout the city in 2015 by evaluating satellite images or using ground-survey data. Three types of vegetation areas monitored: the presence of built environments without vegetation; built environments lacking vegetation; vegetation abundance areas (Figure 4-15).

The accuracy levels for both methods were assessed using a series of 50 random trust points for each class. Feld surveys and the validation datasets were used as reference data for the assessment. The research uses overall accuracy, user's, and producer's for land use/cover classes. LSMA table showed very high accuracy rates, with values being above $90 \%$ for all sample years. In the case of the MLC method, it also has enough accuracy levels expect for the sample year of 2000 (Table 4-3). 
Table 4-3: Classification Accuracy Assessment for LSMA and MLC Methods

\begin{tabular}{|ccccccc|}
\hline \% & $\mathbf{1 9 9 0}$ & $\mathbf{1 9 9 5}$ & $\mathbf{2 0 0 0}$ & $\mathbf{2 0 0 5}$ & $\mathbf{2 0 1 0}$ & $\mathbf{2 0 1 5}$ \\
\hline LMSA Overall accuracy & 92 & 96 & 95 & 90 & 91 & 92 \\
MLC Overall accuracy & 96 & 93 & 81 & 87 & 89 & 87 \\
\hline
\end{tabular}
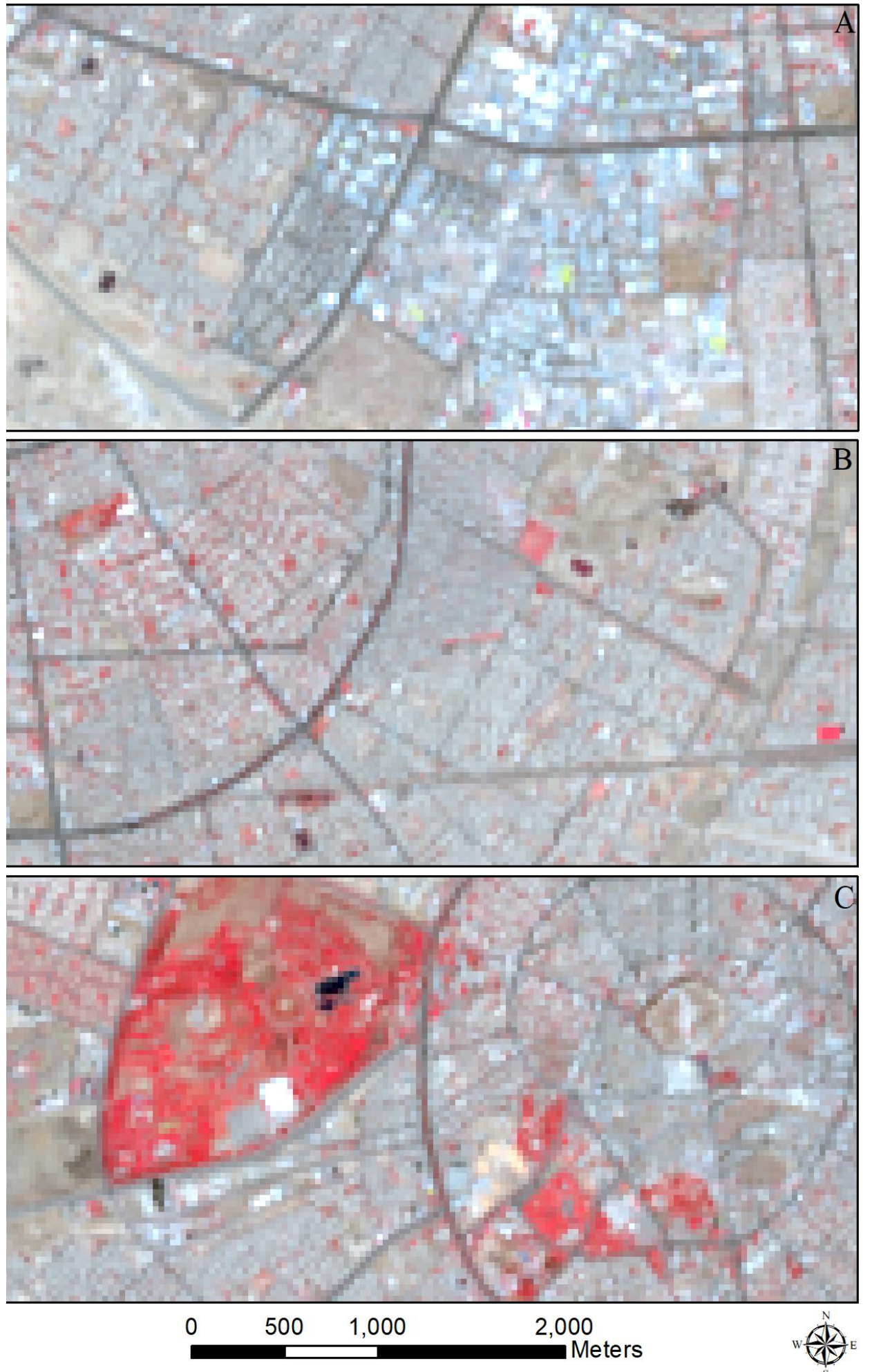

Figure 4-15: A Visual Samples of Landsat Imagery Represent Distribution of Vegetation in Erbil: (A) Built environments without vegetation, (B) built environments lacking vegetation, and $(\mathrm{C})$ vegetation abundance areas. 


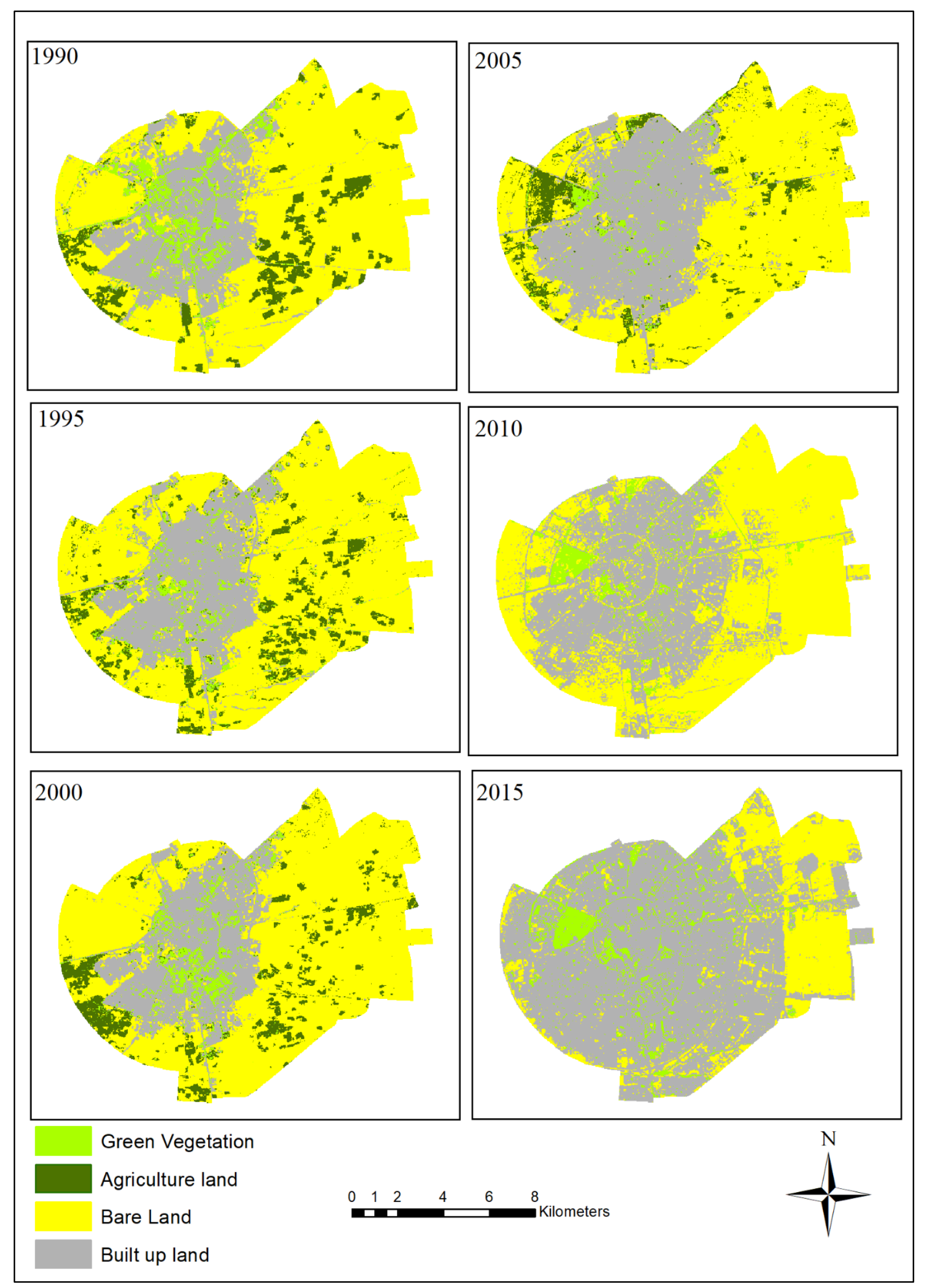

Figure 4-16: MLC Spatiotemporal Variation of Land Cover Types 


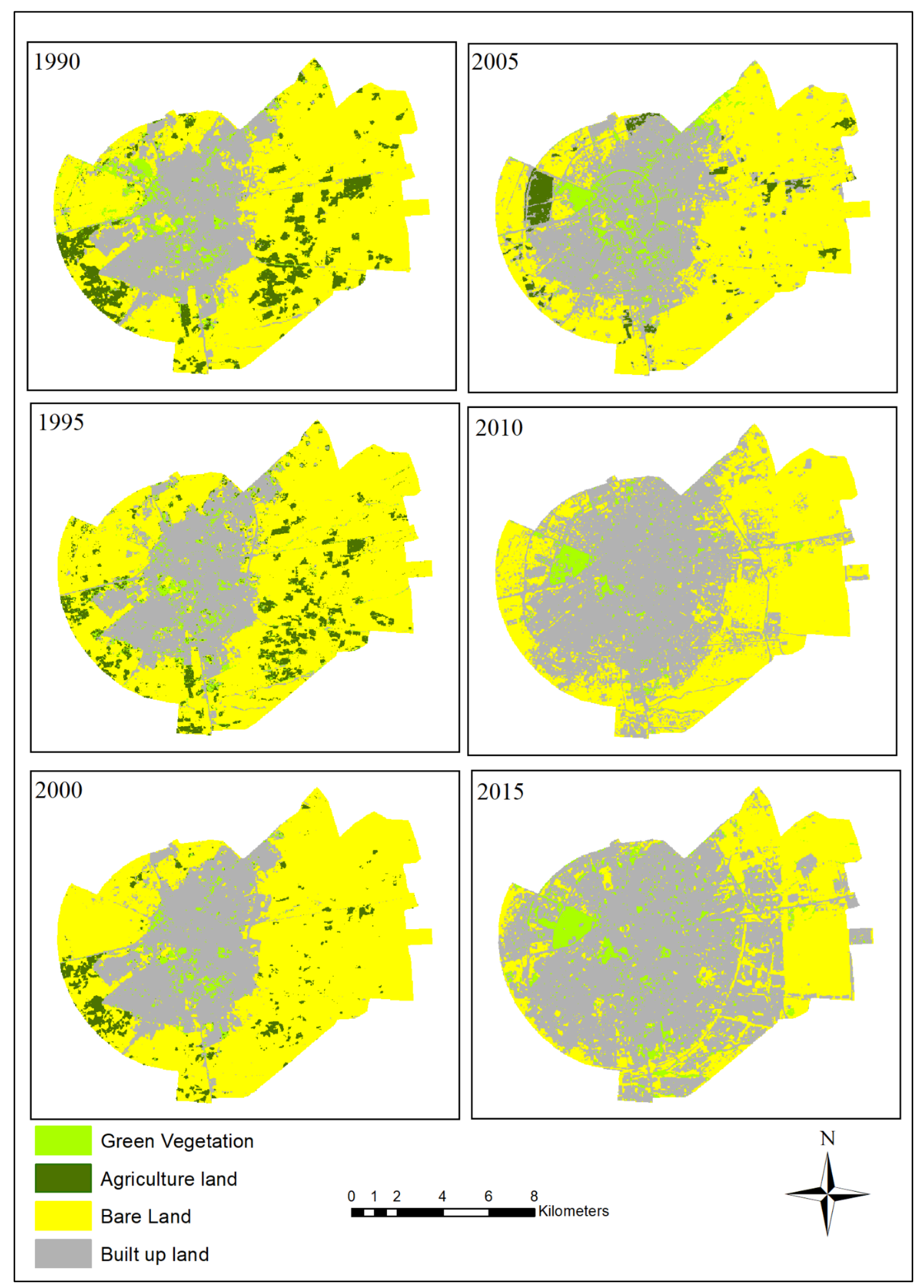

Figure 4-17: LSMA Spatiotemporal Variation of Land Cover Types 


\subsubsection{Spatiotemporal variation of urban vegetation cover derived from vegetation indices}

Landsat imagery data used to construct the EVI and NDVI, similar to MODIS imagery data. Table 4-4 presents the estimated values for both indices covering the period of 1990-2015 at five-year intervals. The table indicates that the mean EVI measure declined from 0.114 in 1990 to 0.080 in 2015 , and the mean NDVI measure declined from 0.137 to 0.113 in the same period.

Figure 4-18, and Figure 4-19 also, show that the biomass of vegetation remains low with a value of less than 0.2 according to Landsat SVIs data. The mean of EVI and NDVI started at the highest value in 1990 and decreased gradually to dip in 2005, then increased gradually to 2015. Overall, vegetation indices showed a gradually decreasing trend from 1990 to 2015. Besides the mean levels, the figure also provides information on min, maximum, and standard deviation values. When evaluating the most critical values, 2015 has the highest NDVI, and EVI maximum, and standard deviation values, followed by 1995 and 1990. Similar to the average value dynamics 1990, 1995, 2015, have the highest NDVI, EVI, and standard deviation values. 2005 has the lowest maximum and standard deviation values as well. Same to the average value dynamics, 2005 has the smallest standard deviation, NDVI, and EVI maximum values. Generally, such statistics indicate that greener year also has high, maximum, and standard deviation values, and the opposite is exact for the least green years.

Table 4-4: EVI \& NDVI results from Landsat Imagery

\begin{tabular}{|ccccc|}
\hline SVIs year & Min & Max & Mean & STD \\
\hline EVI 1990 & 0.007 & 0.605 & 0.114 & 0.048 \\
EVI 1995 & 0.074 & 0.632 & 0.102 & 0.048 \\
EVI 2000 & 0.015 & 0.461 & 0.076 & 0.027 \\
EVI 2005 & 0.076 & 0.425 & 0.060 & 0.025 \\
EVI 2010 & 0.095 & 0.489 & 0.088 & 0.045 \\
EVI 2015 & 0.147 & 0.802 & 0.080 & 0.051 \\
NDVI 1990 & 0.008 & 0.673 & 0.137 & 0.059 \\
NDVI 1995 & 0.130 & 0.682 & 0.132 & 0.059 \\
NDVI 2000 & 0.020 & 0.472 & 0.090 & 0.030 \\
NDVI 2005 & 0.082 & 0.435 & 0.070 & 0.028 \\
NDVI 2010 & 0.180 & 0.523 & 0.112 & 0.052 \\
NDVI 2015 & 0.452 & 0.857 & 0.113 & 0.072 \\
\hline
\end{tabular}

So, the vegetation indices show that the biomass of green vegetation and agricultural lands has significantly declined. This outcome also confirmed by the spatiotemporal 
distributions given in (Figure 4-20, and Figure 4-21). The figures confirm that some vegetation areas scattered around the city, as pointed in 1990. The green areas were mostly on the surroundings of the city, implying agricultural land held an essential share in them. However, over time, the green vegetation in the surrounding areas disappeared, and some concentrated green areas emerged in the city limits. The new green areas included the construction of parks, especially the massive Sami Abdulrahman Park.

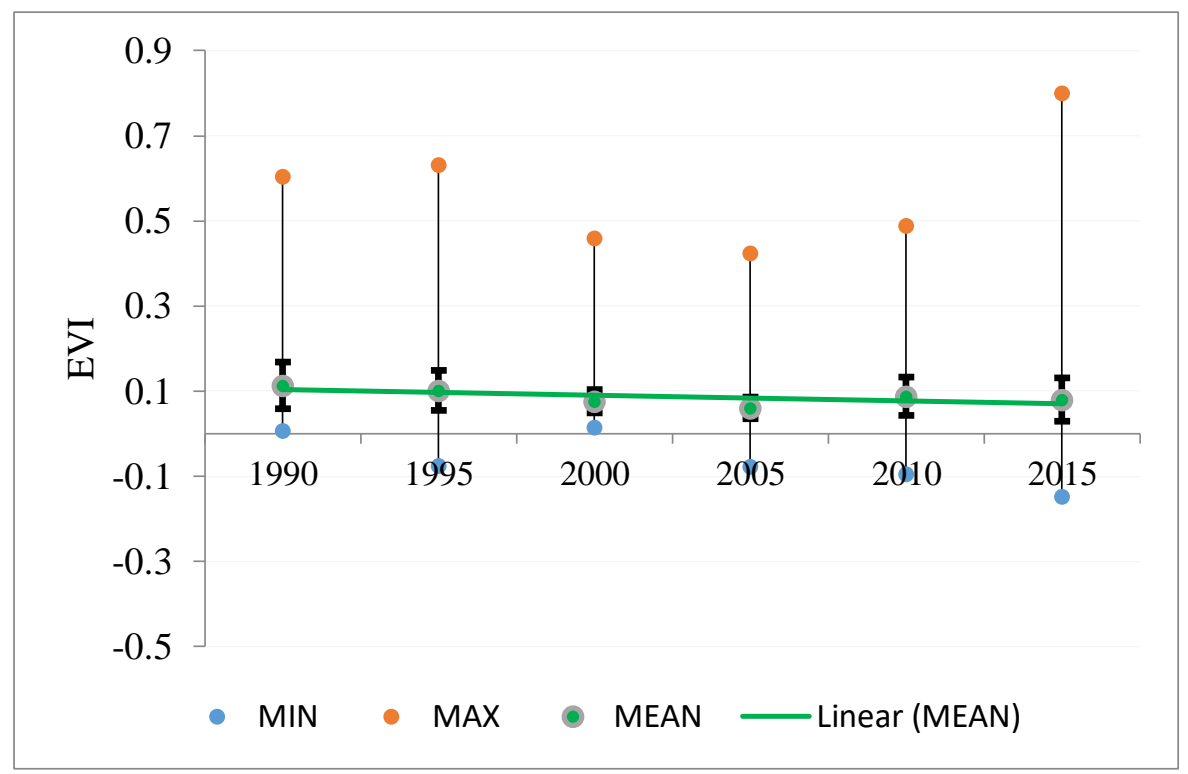

Figure 4-18: NDVI Measure from Landsat Imagery

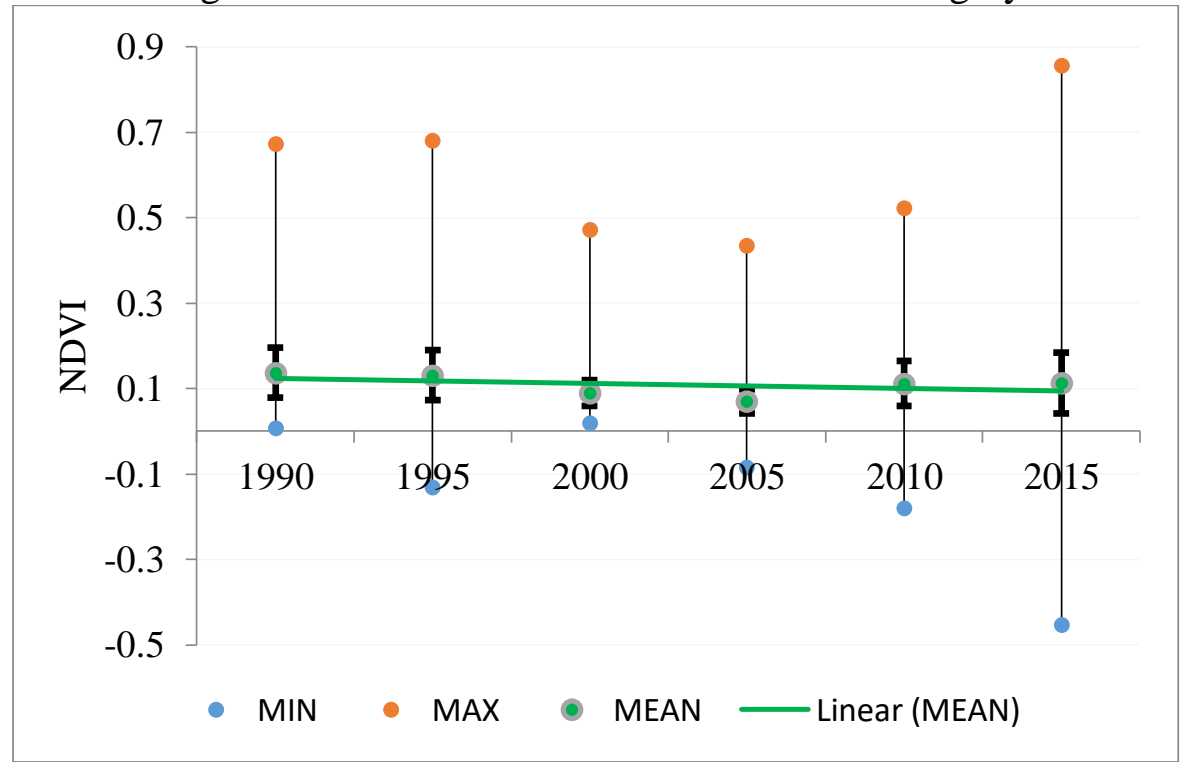

Figure 4-19: EVI Measure from Landsat Imagery

Overall, the Landsat imagery data indicates a significant change in the level and composition of vegetation areas in the city of Erbil. EVI and NDVI values gradually decreased from 1990 to 2015. 

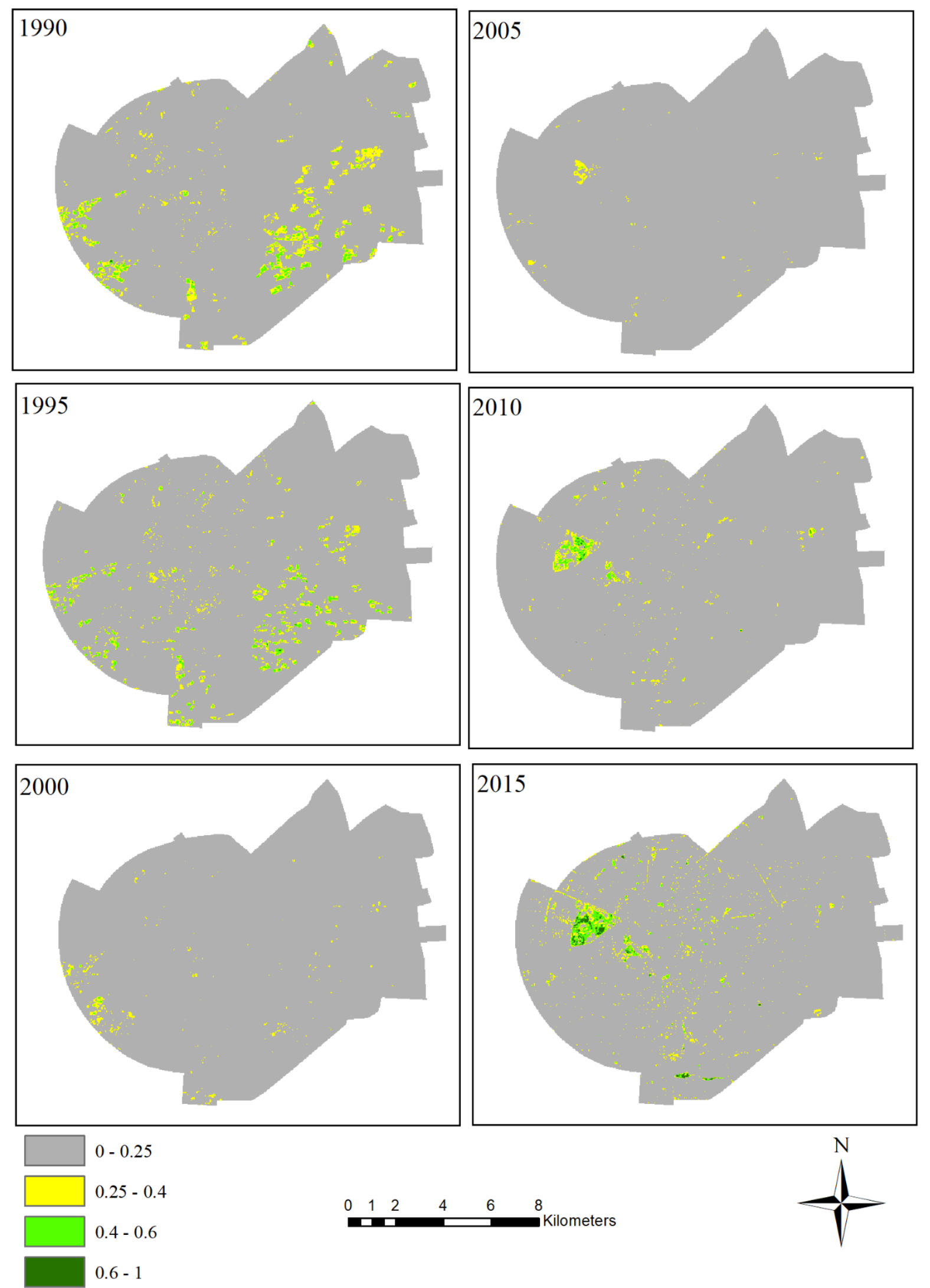

Figure 4-20: NDVI Distribution from Landsat Imagery 

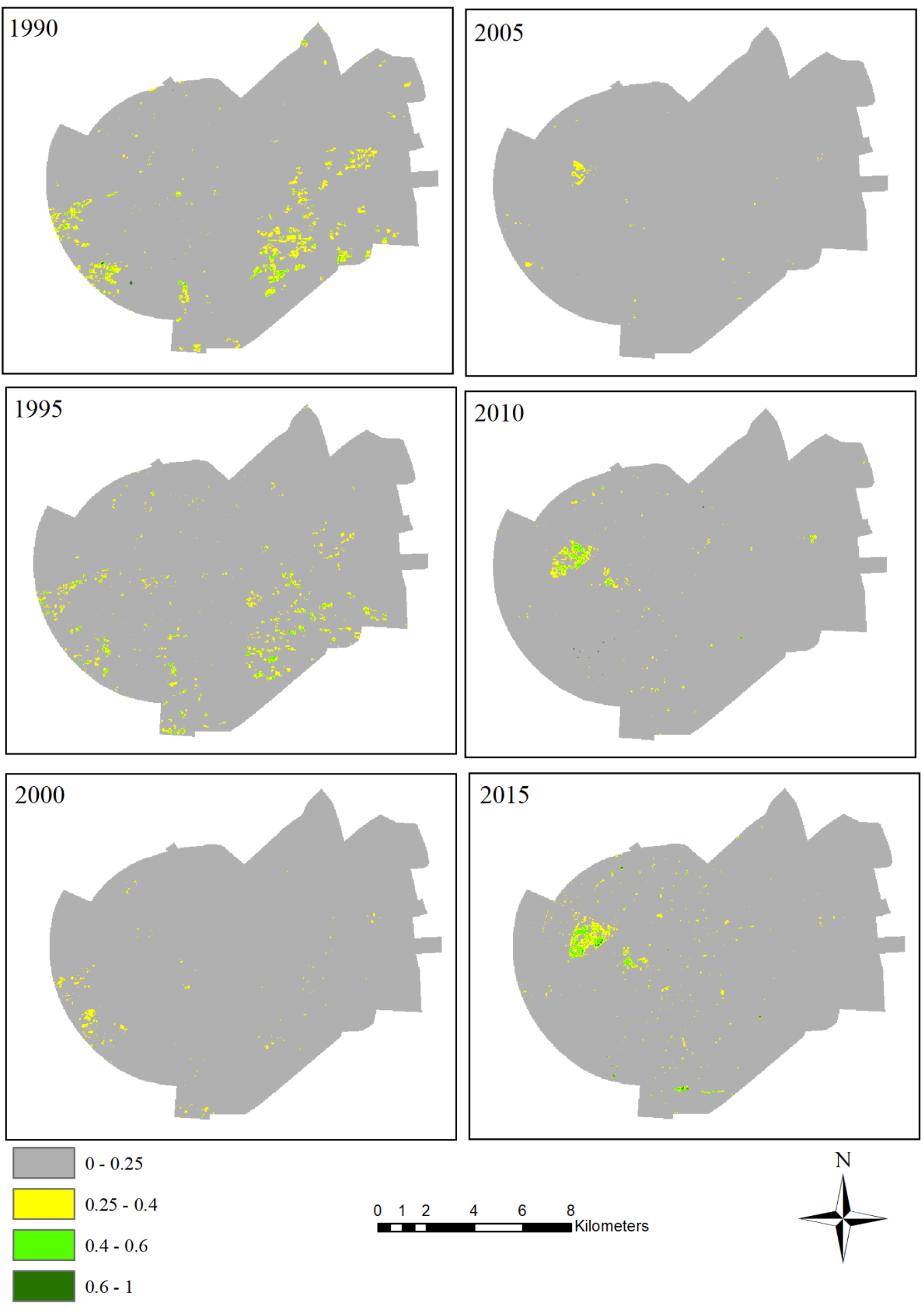

Figure 4-21: EVI Distribution from Landsat Imagery 


\subsection{Spatial distribution of vegetation cover in Erbil city districts using high- resolution Pleiades satellite imagery}

The section subdivided into three major sections that correspond to the supervised classification and presented in the study design. As the study herein has adopted a predominantly interpretive approach, the only statistical evaluation is in the description of the classifications (not totally statistical as the figures presented as percentages). The statistical figures help identify the levels of vegetation cover for the various classifications of the research, which is built-up land, vegetation cover, water body, and bare land. The main headlined sections include and are limited to one, the spatial distribution of vegetation indicator using NDVI and two, green spaces access in the city of Erbil. These two form a platform from which to base the interpretation of the results and produce a detailed vegetation map for the optimization of the urban ecosystem services (Ahern et al., 2014).

\subsubsection{Results of land use land cover by Pleiades imagery}

Pleiades satellite imagery used to construct in a particular land surface types and vegetation indices. This part of the city comprises of 24 Districts and coverage of 2371 hectare. Establishing the percentage of vegetation cover in each district to subcategorized the land surface into four classes, including the body of water, built-up land, bare land, and vegetation cover, considered as land use and land cover. The results of the supervised classification highlighted that most of the districts, which are $69 \%$ urban land, following this, bare land covers an area of $17 \%$. However, the ratio of the vegetation land cover is only $14 \%$ (Figure $4-22$ ).

The overall accuracy of the LULC image was determined to be $96 \%$ following the comparison of user's and producer's accuracies of particular classes were continuously high, ranging from $92 \%$ to $99 \%$ (Table $4-5$ ).

Table 4-5: Assessment of Classification Result

\begin{tabular}{|c|c|c|}
\hline Categories & $\begin{array}{c}\text { Producer's accuracy } \\
{[\%]}\end{array}$ & $\begin{array}{c}\text { User's accuracy } \\
{[\%]}\end{array}$ \\
\hline Urban & 92 & 96 \\
\hline Vegetation & 96 & 94 \\
\hline Water & 99 & 99 \\
\hline Bare land & 95 & 97 \\
\hline Overall accuracy & 96 & \\
\hline
\end{tabular}




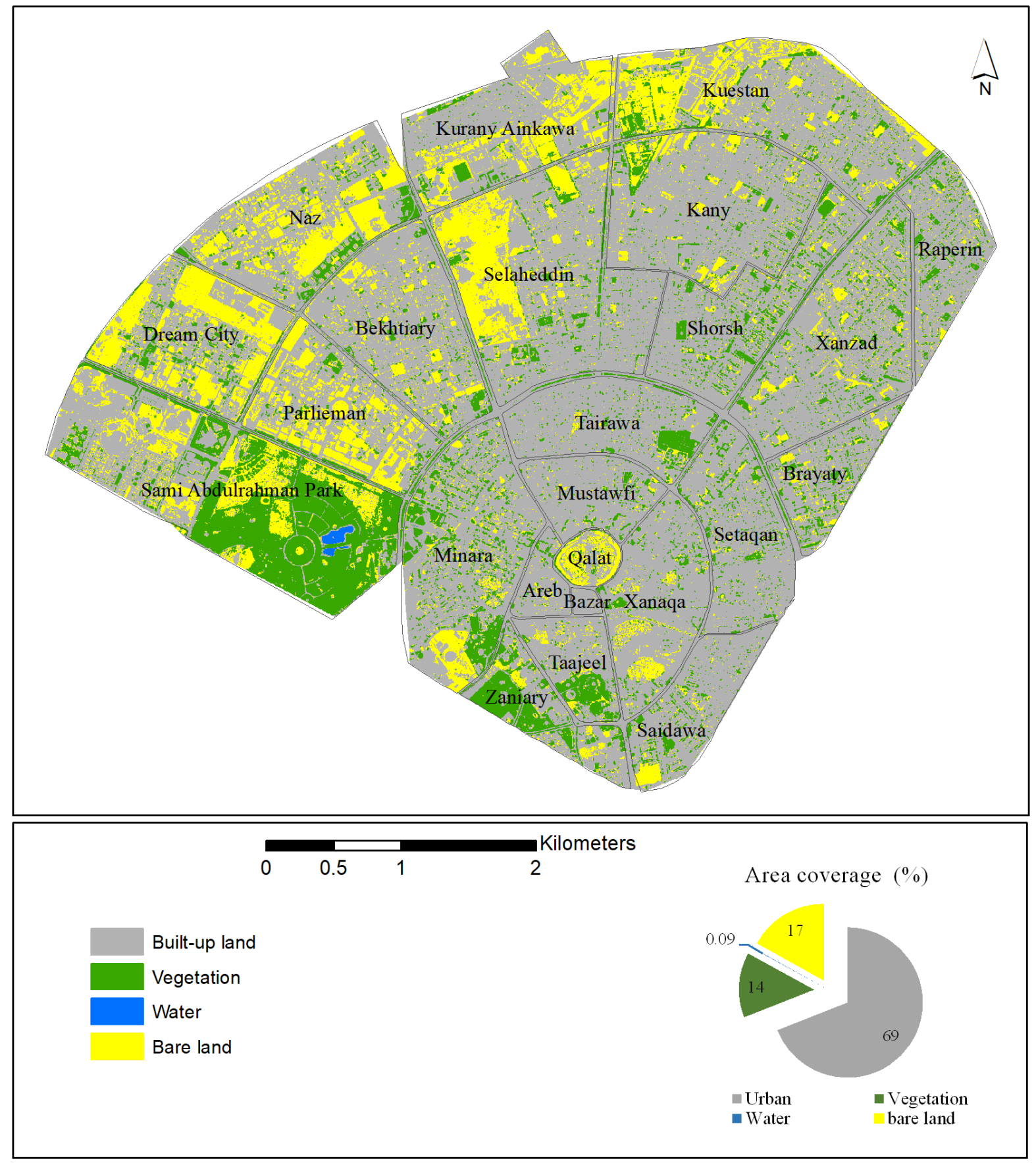

Figure 4-22: Land Cover Classes according to Pleiades Imagery

Table 4-6 indicates that some districts have very high vegetation areas, such as Sami Abdulrahman Park having 44\% vegetation share, Zaniary with 38\% vegetation share, Taajeel with a $22 \%$ share and Brayaty $21 \%$ vegetation share. However, half of the districts have less than $10 \%$ vegetation area. 
Table 4-6: Percentage of land Use Classes for each District of Pleiades Imagery

\begin{tabular}{|c|c|c|c|c|c|}
\hline \multirow{2}{*}{ Name of District } & \multicolumn{4}{|c|}{ Land Use Land Cover Classes (\%) } & \multirow[b]{2}{*}{ etation } \\
\hline & Urban & Water & Bare land & $\mathrm{Ve}$ & \\
\hline $\begin{array}{l}\text { Sami Abdulrahman } \\
\text { Park }\end{array}$ & 34 & 1 & 21 & 44 & \multirow{4}{*}{$\underset{20 \%}{\geq}$} \\
\hline Zaniary & 53 & 0 & 9 & 38 & \\
\hline Taajeel & 70 & 0 & 8 & 22 & \\
\hline Brayaty & 70 & 0 & 9 & 21 & \\
\hline Minara & 70 & 0 & 11 & 18 & \multirow{7}{*}{$\begin{array}{c}10- \\
20 \%\end{array}$} \\
\hline Shorsh & 79 & 0 & 5 & 15 & \\
\hline Raperin & 81 & 0 & 6 & 13 & \\
\hline Tairawa & 86 & 0 & 3 & 11 & \\
\hline Setaqan & 86 & 0 & 3 & 11 & \\
\hline Xanzad & 81 & 0 & 8 & 11 & \\
\hline Saidawa & 82 & 0 & 8 & 10 & \\
\hline Kuestan & 64 & 0 & 27 & 9 & \multirow{13}{*}{$\stackrel{<}{10 \%}$} \\
\hline $\mathrm{Naz}$ & 59 & 0 & 32 & 9 & \\
\hline Dream City & 48 & 0 & 43 & 9 & \\
\hline Kany & 81 & 0 & 11 & 8 & \\
\hline Xanaqa & 83 & 0 & 9 & 8 & \\
\hline Mustawfi & 89 & 0 & 3 & 7 & \\
\hline Selaheddin & 68 & 0 & 25 & 7 & \\
\hline Bekhtiary & 81 & 0 & 13 & 7 & \\
\hline Areb & 90 & 0 & 4 & 6 & \\
\hline Qalat & 42 & 0 & 51 & 6 & \\
\hline Parlieman & 58 & 0 & 36 & 6 & \\
\hline Kurany Ainkawa & 68 & 0 & 27 & 6 & \\
\hline Bazar & 99 & 0 & 1 & 0 & \\
\hline
\end{tabular}

\subsubsection{Spatial distribution of vegetation indicator using NDVI}

Pleiades satellite imagery data also used to construct vegetation indices such as NDVI measure; therefore, a quantitative indicator obtained to compare different districts within the city. In general, the mean value of NDVI less than 0.3 , and high NDVI values clustered in the districts of Sami Abdulrahman Park, Zaniary, Taajeel, and Minara, 0.35, 0.25, 0.22 and 0.18, while the areas that covered by tall trees, dense bushes and shrubs as well as grasses, while NDVI is less than 0.1 in the city centre areas as constructed areas dominate it (Figure 4-23). 


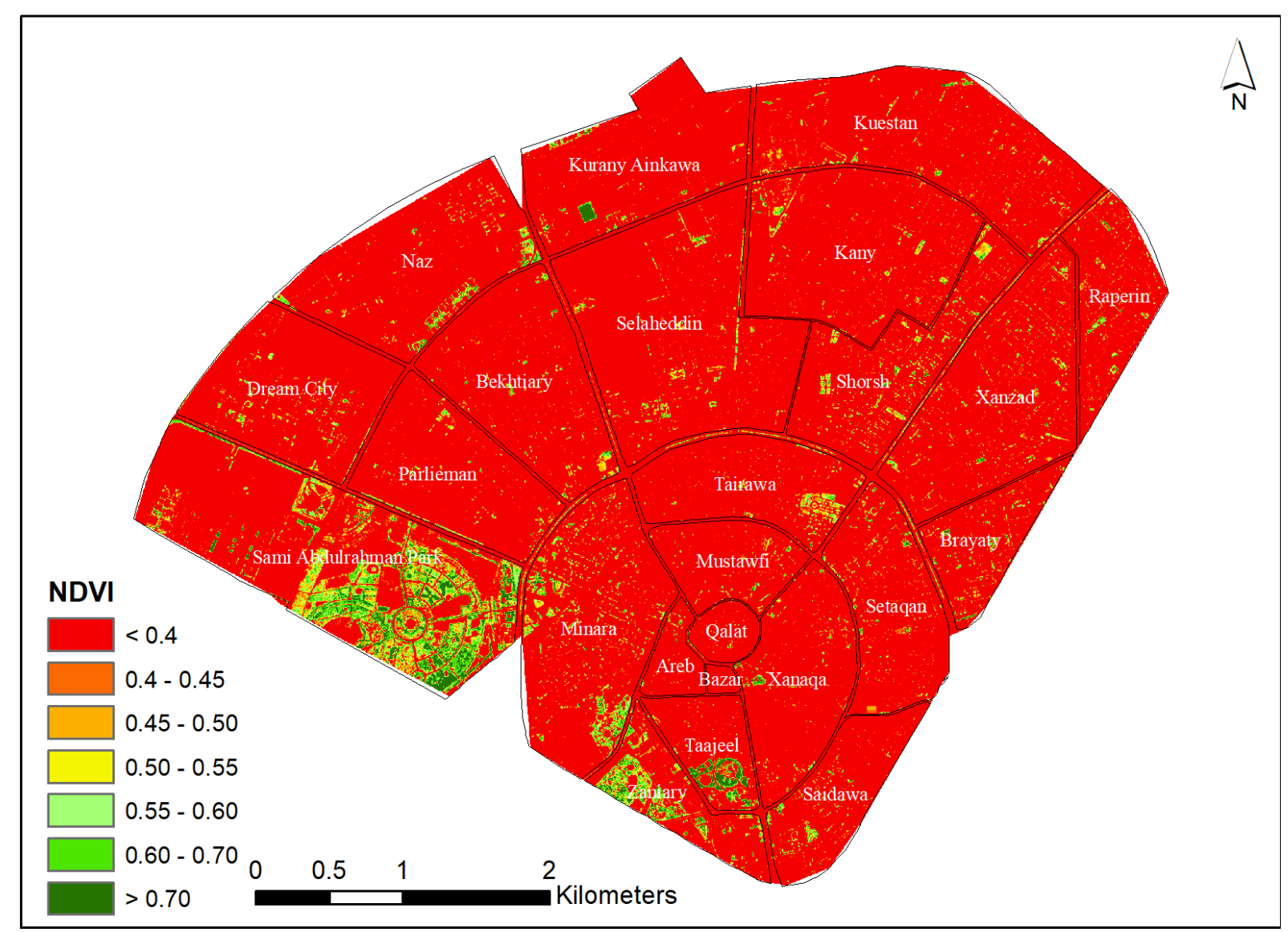

Figure 4-23: Spatial Distribution of NDVI Measure

On the other hand, some districts have low vegetation covers, such as Setaqan, Xanzad, Raperin, Xanaqa, Mustawfi, Tairawa, and Qalat (Figure 4-23, and Figure 4-25). This result counts as a significant point in terms of justifying the study objectives (Figure 4-26). Because insufficient vegetation cover in those districts may have impacted the ecosystem function, biodiversity, and climatic variables. In addition, the lack of greenery in those districts is negatively affected regarding the process of the observation of solar radiation by particular ground surfaces (Mallick et al., 2008). Thus, the other climatic indicators, such as surface temperature, evaporation, and storage of heat, will also change (Figure 4-24).

Similarly, the districts located close to the city centre, such as Mustawfi, Tairawa, Setaqan, and Bazar show the lowest green space compared to the other city districts. The possible reason for this finding might be related to the history of these areas because Erbil is one of the oldest cities in the northern part of Iraq due to having an ancient castle at its centre. Over its history, the city has expanded in a circular shape around the castle. Therefore, the older districts, which are close to the castle, have a very low proportion of green space due to the lack of available land. Built-in or built-up areas have low values of mean NDVI 0.16 and 0.074. In the new build districts like Dream city and Naz, still, NDVI values are low (Figure 4-23, and Figure 4-25). This result is in line with our classification result, as it shows that those new 
build districts have more bare lands compared to other places in the city. This spatial distribution confirms the previous finding that green vegetation is distributed very unevenly across districts.

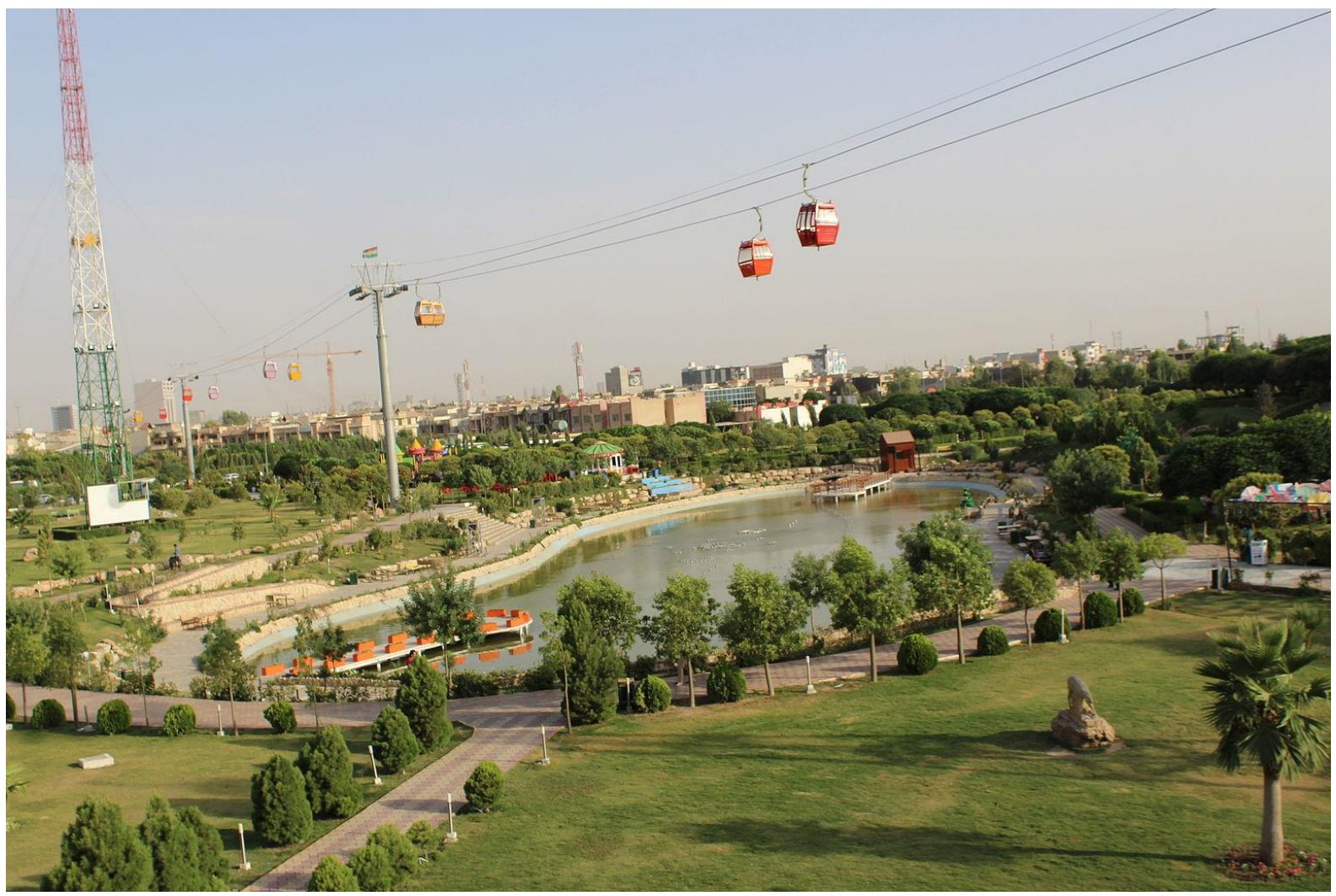

Figure 4-24: Overview of Shanadar Park ("Wikimedia Commons," 2020)

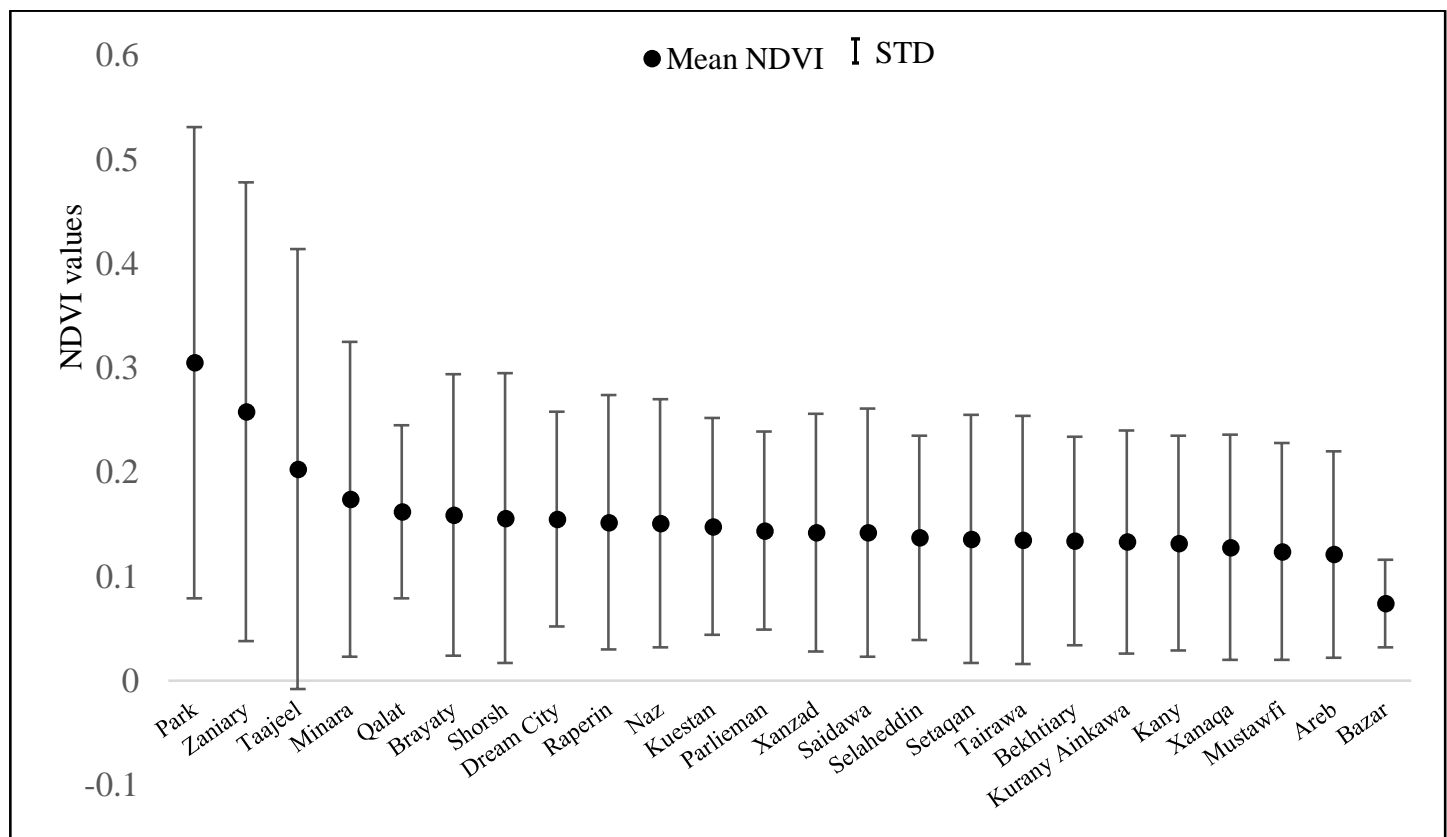

Figure 4-25: Mean NDVI Values across Districts 


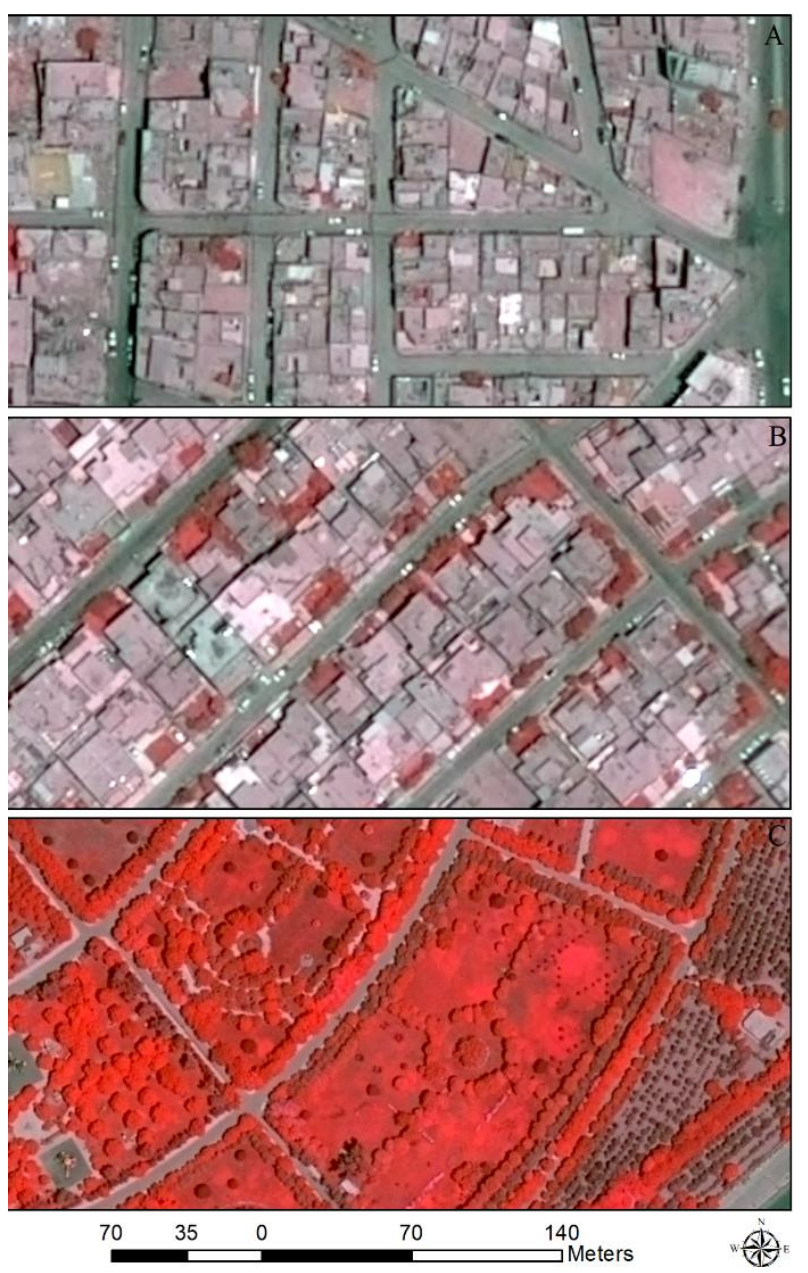

Figure 4-26: A Visual Samples of Pleiades Imagery Represent Distribution of Vegetation in Erbil: (A) Built-up area with no vegetation, (B) Built-up area with limited vegetation, and (C) General view of the park.

\subsubsection{Green space access results}

Assessing the accessibility of green spaces based on each city district by applying the buffer zone technique. The study area divided using six different scales (A-E). The 'A' scale shows the district is not in any buffer zone. The ' $\mathrm{B}$ ' scale shows the area located within one buffer zone of $300 \mathrm{~m}$. The ' $\mathrm{C}$ ' scale shows the areas situated in two and above buffer zones of $300 \mathrm{~m}$. The 'D' scale shows the areas are within $2 \mathrm{~km}$, and one $300 \mathrm{~m}$ buffer zone, and finally, the 'E' scale shows the areas that have access to green spaces with $2 \mathrm{~km}$ and more than one 300 buffer zones (Figure 4-27). The graph refers that green access within $300 \mathrm{~m}$ is minimal in most districts except the surroundings of Sami Abdulrahman Park. Moreover, 4 districts have zero access within the $300 \mathrm{~m}$ buffer zone, while four of these also have zero green access within a $2 \mathrm{~km}$ buffer zone. These values imply that green vegetation areas unevenly distributed within the city limits. Districts such as Bazar, Qalat, Mustawfi, Tairawa, and Dream city have 100\% access to one $300 \mathrm{~m}$ and $2 \mathrm{~km}$ buffer zone around the biggest green area of the city, the Sami Abdulrahman Park as well, representing $21 \%$ of districts (Table 4-7). However, some of the 
parks and green areas located in the northeast of the city were small, such as small playgrounds or public gardens. They have access to a $300 \mathrm{~m}$ buffer zone (Figure 4-27).

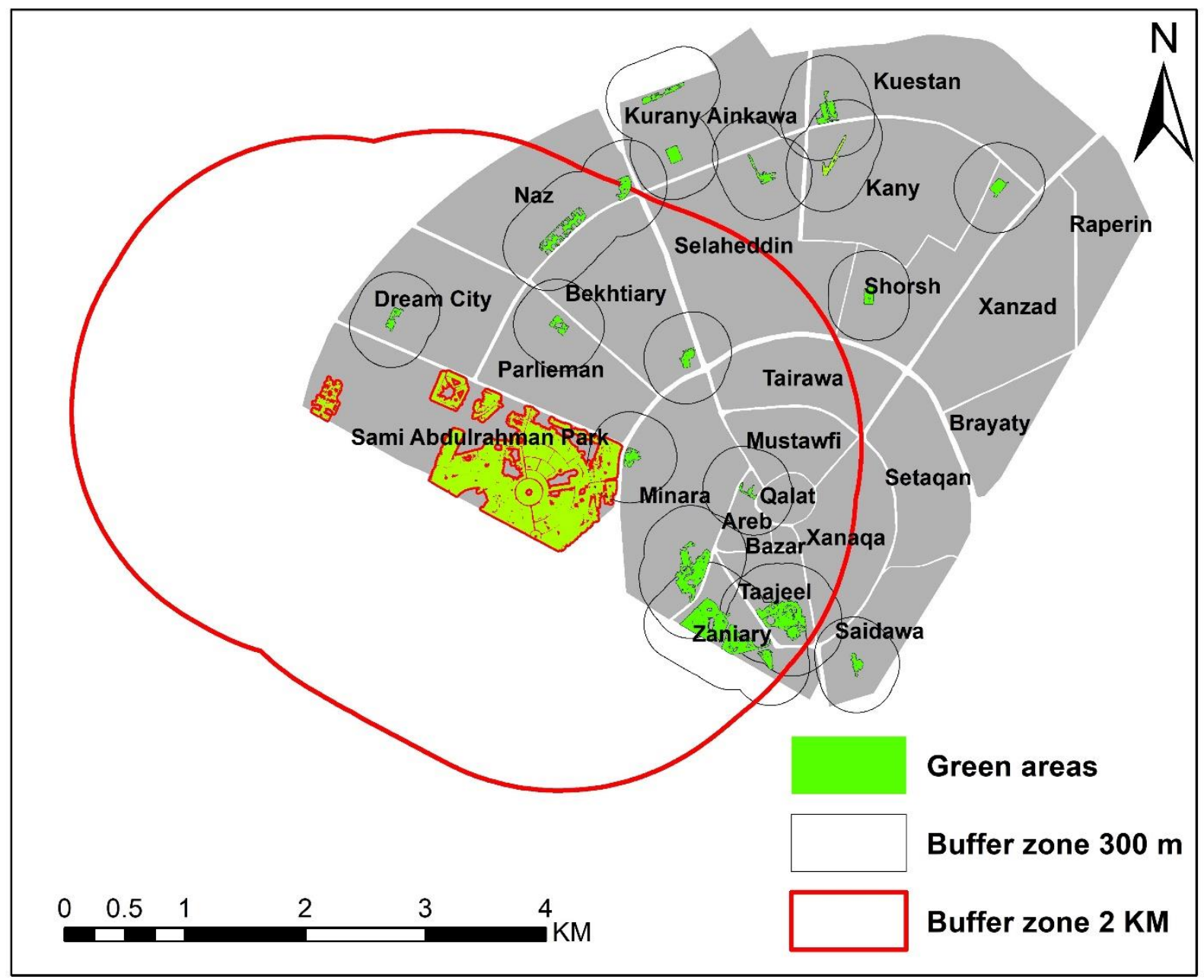

Figure 4-27: Buffer Zone of Green area in the Districts

The most significant results indicate the $42 \%$ of districts have access to $2 \mathrm{~km}$ and more than one $300 \mathrm{~m}$ buffer zone, 7 of them such as Taajeel, Zaniary, Areb, Sami Abdulrahman Park, Minara, Bekhtiary, and Parlieman have 100\% access.

It is important to note that Sami Abdulrahman Park is the only area in the city that provides green areas $>20$ hectares. According to the Accessible Natural Greenspace Standard (ANGSt), all people should have accessible natural green space "of at least two hectares in size, no more than 300 m (five minutes' walk) from home" or "at least one accessible 20hectare site within $2 \mathrm{~km}$ of home". As can be seen from Figure 4-27, Sami Abdulrahman park provided $100 \%$ access to green areas within $2 \mathrm{~km}$ buffer for 11 districts (Bazar, Qalat, Areb, Mustawfi, Bekhtiary, Parlieman, Dream city, Taajeel, Zaniary) and other four districts (Xanaqa, and Selaheddin) has access higher than $50 \%$ to this park. 


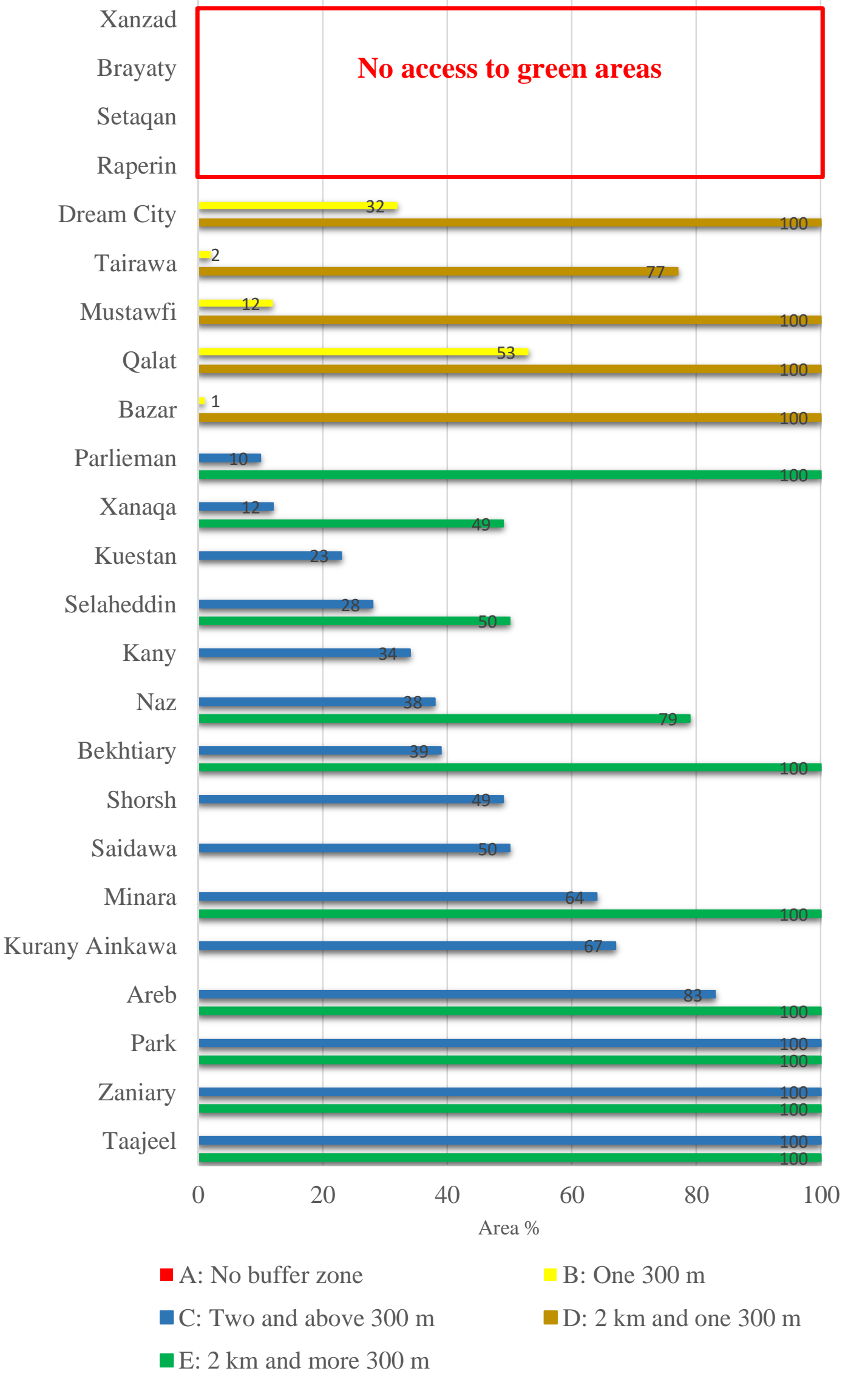

Figure 4-28: Distribution of Districts within the Scales of the Buffer Zones 
Table 4-7: Percentage Districts within the Scale of the Buffer Zones

\begin{tabular}{|cccccc|}
\hline & $\begin{array}{c}\text { A: No } \\
\text { buffer zone }\end{array}$ & $\begin{array}{c}\text { B: One } \\
\mathbf{3 0 0} \mathbf{~ m}\end{array}$ & $\begin{array}{c}\text { C: Two and } \\
\text { above 300 } \mathbf{~ m}\end{array}$ & $\begin{array}{c}\text { D: } \mathbf{2} \mathbf{~ k m} \text { and } \\
\text { one } \mathbf{3 0 0} \mathbf{~ m}\end{array}$ & $\begin{array}{c}\text { E: } \mathbf{2} \text { km and } \\
\text { more } \mathbf{3 0 0} \mathbf{~ m}\end{array}$ \\
\hline Districts & 4 & 5 & 15 & 5 & 10 \\
$\%$ of districts & 17 & 21 & 63 & 21 & 42 \\
\hline
\end{tabular}




\section{Discussion}

Economic growth and rising urbanisation levels are affecting the world climate, and the surface topology in significant ways. As a relevant development, population density, especially in large metropolitan areas, increased sharply all over the world (United Nations, 2014). However, these trends also create many challenges and problems. In order to create favourable living conditions in cities, there would be a need for public spaces, recreational spaces, and green fields or vegetation areas.

Moreover, these facilities and areas should be distributed evenly in line with urban density, and the city population should have easy access to them. Within this context, the detailed measurements of surface cover types in cities and their surrounding areas become a crucial ingredient in the relevant analyses and policy designs. So, the measurement of vegetation area is a key factor in urban development and planning. The surface measurement involves various parameters like the "frequency, cover, density, and biomass" of a particular area (Bonham, 2013), and the assessment of changes is required as well. Remote sensing technologies emerged as the leading way of describing the surface cover types and densities, including the vegetation area (Xie et al., 2008). The current dissertation makes an essential contribution to the literature by using various spatial resolution data at different spatial scales to assess urban vegetation changes in a semiarid region, namely the city of Erbil in Kurdistan, Iraq. Detailed satellite data covering the 1990-2015 period used to derive the spatiotemporal dynamics of green fields, as well as their distribution. In particular, imagery from the MODIS, Landsat, and the Pleiades is used in the construction of vegetation indices and densities.

One crucial and distinguishing property of the current dissertation is that three complementary satellite imagery data sets are used at three spatial scales at the same time to study the spatial and temporal distribution of vegetation area in the city of Erbil and its surroundings. In this way, one can check the robustness of outcome from one method against the others, and thus obtain significant results. Also, the varying resolution of MODIS, Landsat, and the Pleiades provide different perspectives on the same research topic. Usually, the MODIS is more suitable for large-scale mapping, and Landsat is better suited for regional mapping, while the Pleiades provides a local analysis. So, while MODIS and Landsat are suitable to study the spatiotemporal distribution of vegetation for the broader area around the city of Erbil, Pleiades is more suitable to study the vegetation distribution within the city districts. In this way, three different methods produce supportive and complementary evidence. Using these data sets at the same time, it becomes feasible to derive comprehensive and consistent findings at both larger and smaller scales for the vegetation state in the city of Erbil and its 
surroundings, and providing a comparative analysis of relevant results makes the contribution clearer; therefore, the methodological approach also provides an important contribution to the literature.

The most marked observations to emerge from the data comparison for MODIS and Landsat indicate that MODIS is a coarse way to see surface type changes. There was not much change in the figures between 2000 and 2010 (Figure 5-1). It was only in 2015 that MODIS shows some significant increases in the built-up areas of the east and west of the city at the expense of green vegetation.

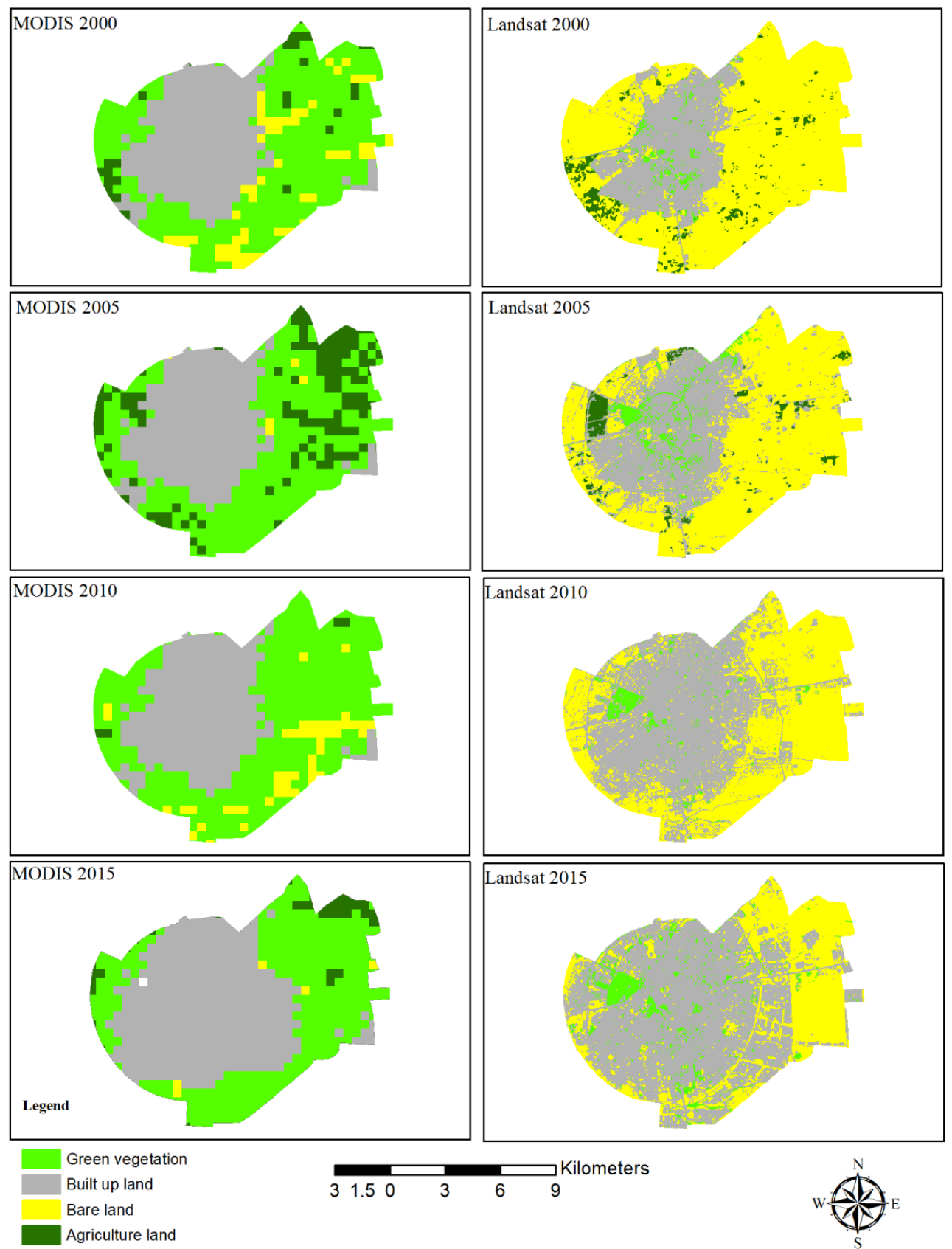

Figure 5-1: Spatial-Temporal Comparison of MODIS and Landsat land cover from 2000 to 2015 
In contrast, Landsat provides more detailed dynamics of surface types over the sample years. It is seen that the built-up area increased continuously in the Landsat result (Figure 5-1). While MODIS is not able to capture green areas within the inner city areas, Landsat shows that vegetation area within the city limits also displayed some increases, especially with the construction of large parks in the latter periods. Another relevant note of agricultural land for 2000 and 2005 tends to be a correlation between MODIS and Landsat. Unfortunately, it was not possible to investigate the significant relationships of MODIS green vegetation and Landsat bare land because MODIS data is yearly, but Landsat data is daily; therefore, bare lands of Landsat is matching to agriculture area of MODIS. So, this comparative analysis shows that MODIS can be useful for larger scales like the city and its surroundings due to high temporal resolution. In comparison, Landsat is better capturing vegetation dynamics at finer but not providing regular data such as MODIS. Also, MODIS is not appropriate for land cover changes detection on a small scale; however, the advantage of MODIS land cover in the current study to distributing MODIS NDVI and EVI inside land cover classes.

The comparison of MODIS and Landsat results can be made more concretely with the graphs in Figure 5-2, which shows the shares of different surface types in both methods.

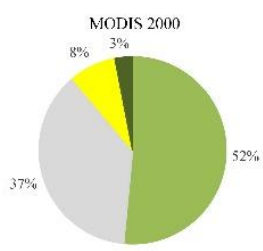

MOTIS 2005
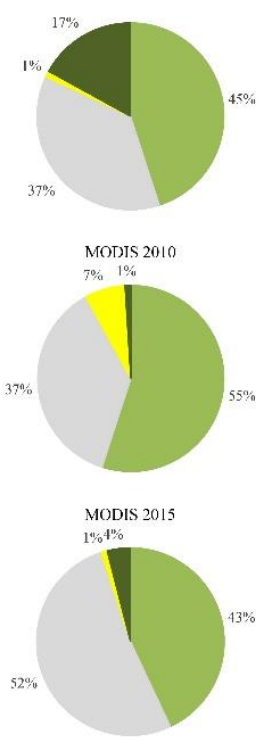

= Green vegetation $\quad$ Built-up land
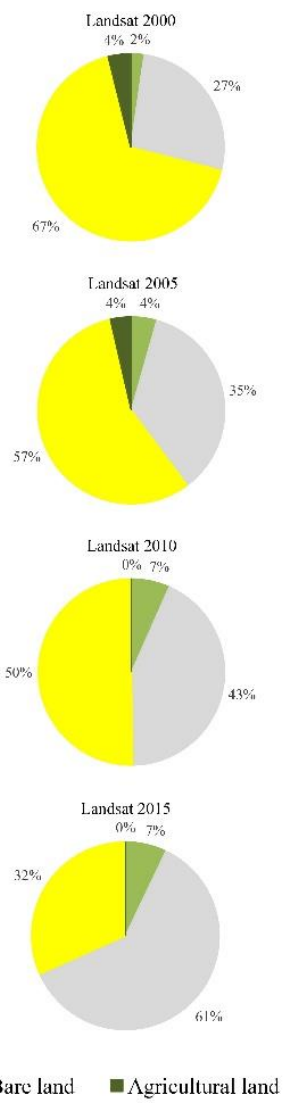

3 
It is seen that MODIS estimated the share of built-up land at $37 \%$ for sample years of 2000, 2005, and 2010. It is was only in 2015 that MODIS estimated the share of built-up land as $52 \%$, which means an increase of $140 \%$.

In contrast, Landsat results show that this increase was smoother, with the built-up land share increasing from $27 \%$ in 2000 , to $35 \%$ in 2005 , to $43 \%$ in 2010 , and $61 \%$ in 2015 that means grew by $225 \%$ compared to 2000 . Agricultural land of MODIS fluctuates between increased and decreased at the bare land expense. While at Landsat gradually reduced at the bare land expense. So, Landsat provides a more accurate picture over time, and the results are different to some extent than MODIS.

In addition to comparing MODIS and Landsat in terms of surface types, one can examine the levels and dynamics of SVIs across these satellite imagery data as well (Figure 5-3). It is seen that in each vegetation index, Landsat has higher values than MODIS over time Landsat. In addition, Landsat-based indices display larger movements, while the MODISbased measures are more stable due to the low density of biomass. For example, in the case of Landsat, NDVI increased from 0.35 in 2005 to above 0.40 in 2010, whereas the same index for MODIS increased slightly from 0.28 to 0.30 only, while they have a similar dynamics in the semiarid urban environments. Therefore, SVIs of Landsat more suitable to estimate the magnitude of biomass due to higher of mean values, and both are applicable to determine the dynamics.

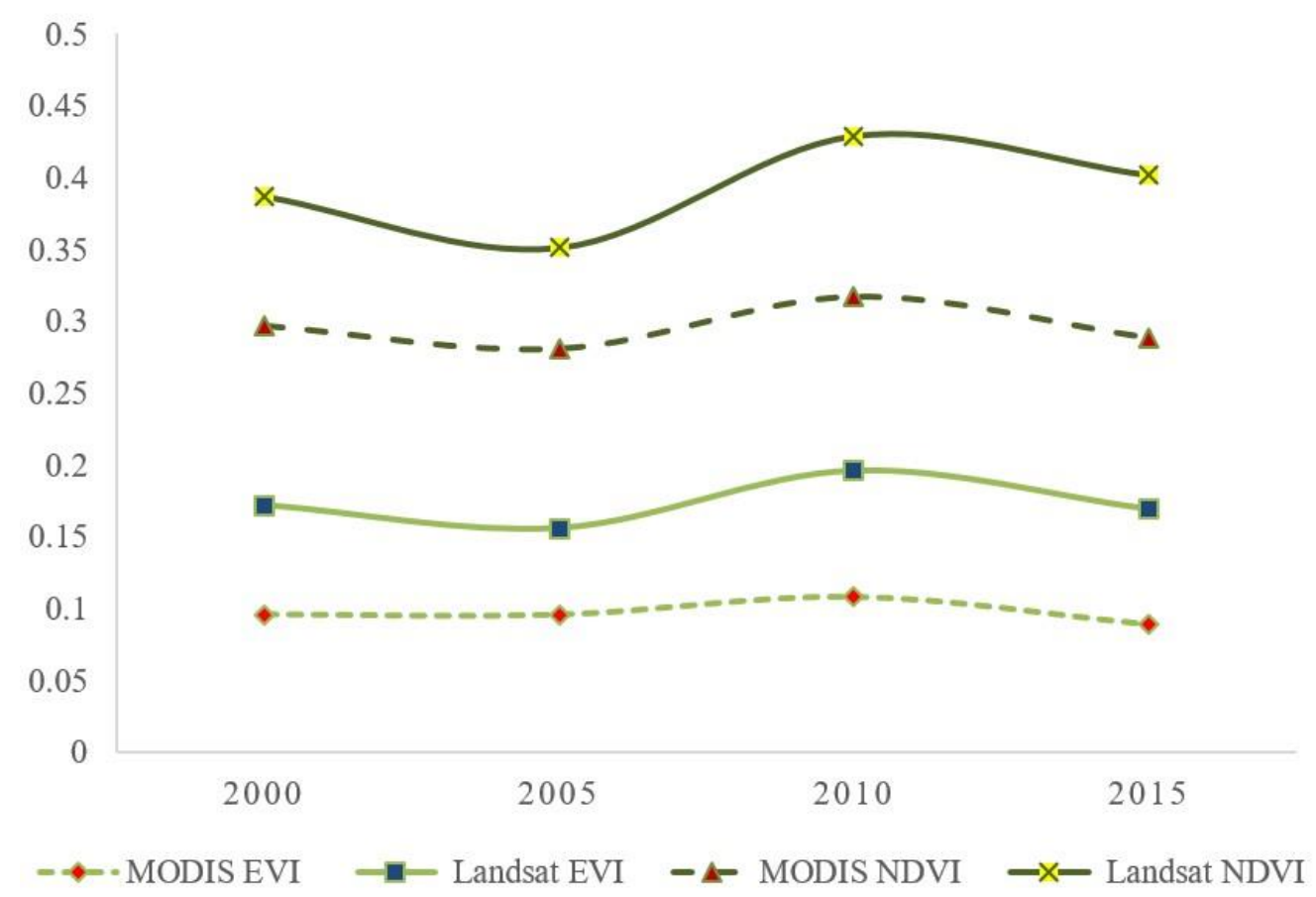

Figure 5-3: Compares Mean NDVI and EVI Values for MODIS and Landsat from (20002015) 
The comparison of the spatial-temporal dynamics of NDVI and EVI measures across MODIS and Landsat from 2000 to 2015 indicates that Landsat has more detailed and finer identification of vegetation levels, however the locations of the vegetation areas similar. Overall, MODIS is useful to display the surface types and vegetation dynamics for the large scales like the city and its surroundings (Figure 5-4, and Figure 5-5).

MODIS EVI 2000

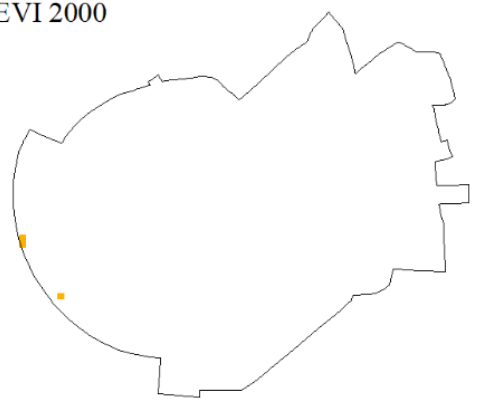

MODIS EVI 2005

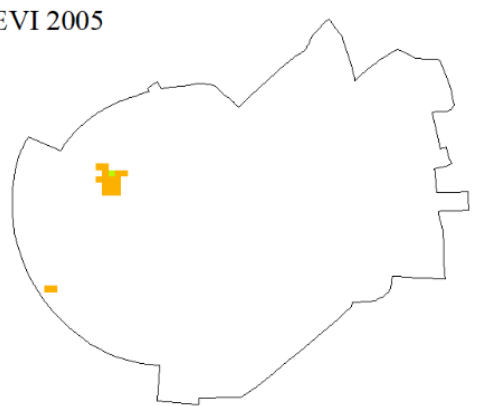

MODIS EVI 2010

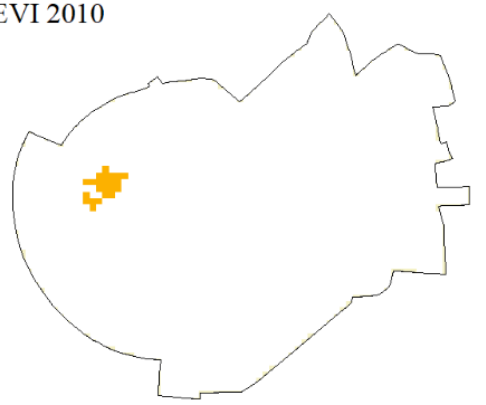

MODIS EVI 2015

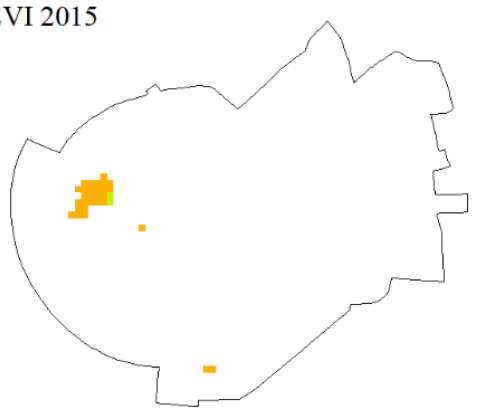

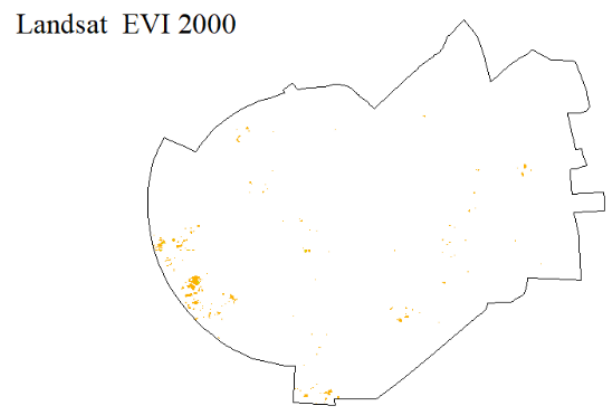

Landsat EVI 2005

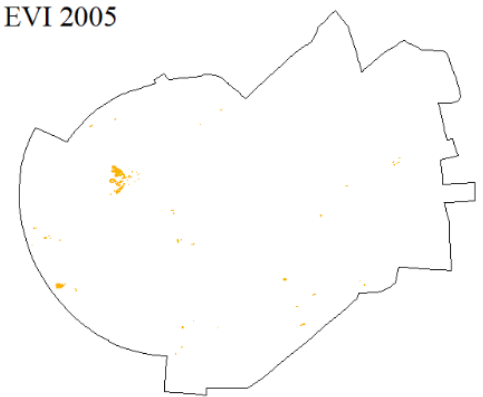

Landsat EVI 2010

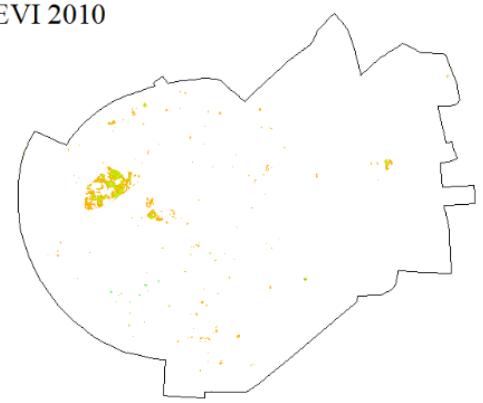

Landsat EVI 2015

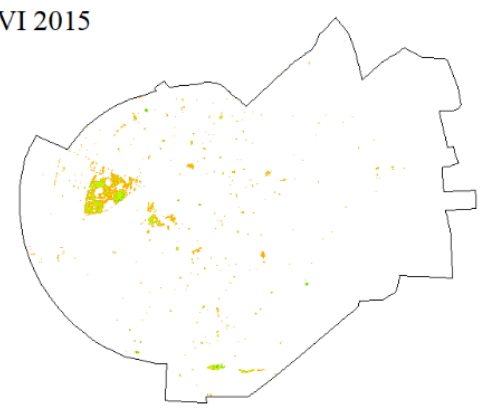

$\square 0-0.25$

$\square 0.25-0.4$

$\square 0.4-0.6$

31.50

3

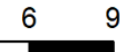

Kilometers

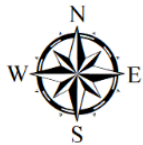

Figure 5-4: Spatial-Temporal Comparison of MODIS and Landsat EVI (2000-2015) 
MODIS NDVI 2000

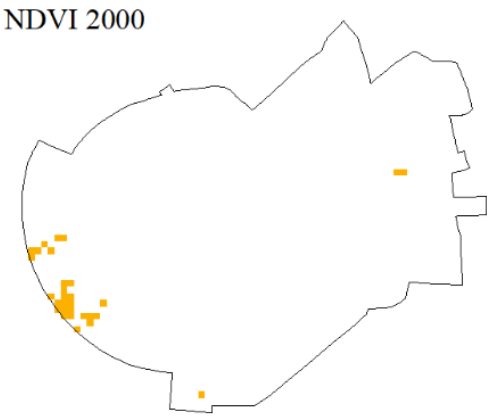

MODIS NDVI 2005

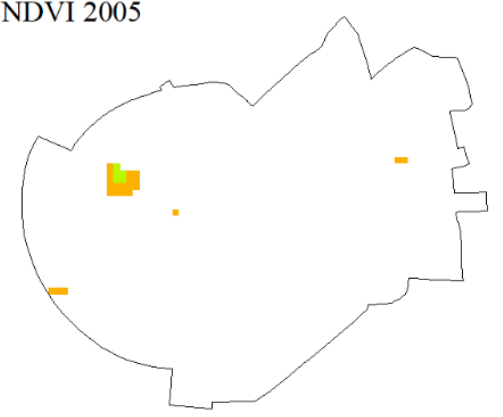

MODIS NDVI 2010

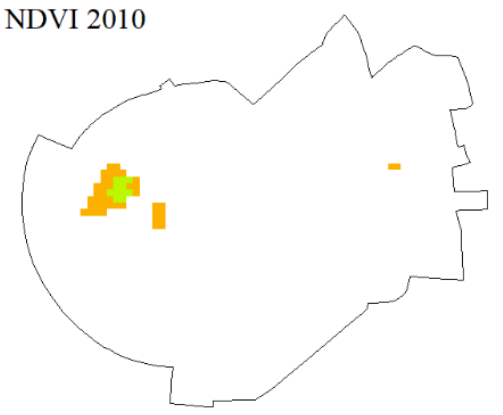

MODIS NDVI 2015

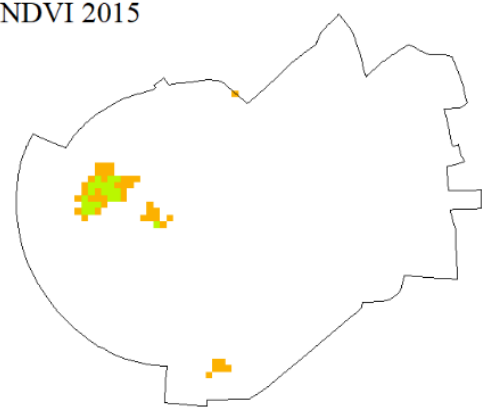

Landsat NDVI 2000

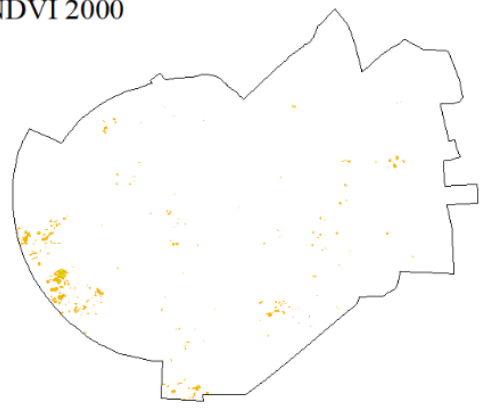

Landsat NDVI 2005

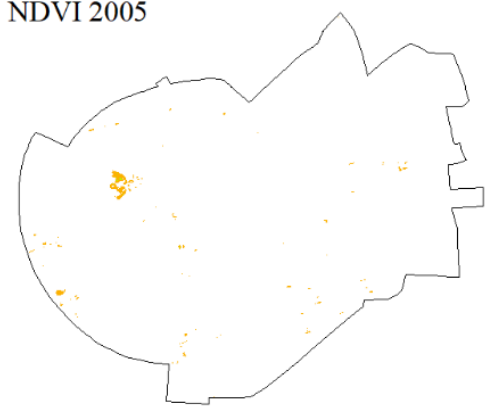

Landsat NDVI 2010

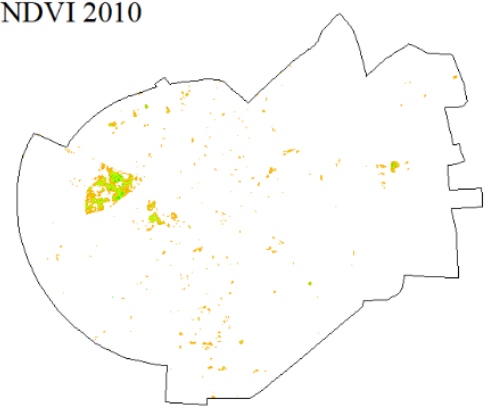

Landsat NDVI 2015

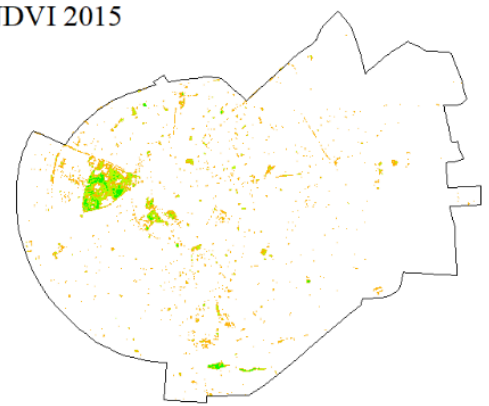

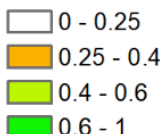

31.50

3

69

Kilometers

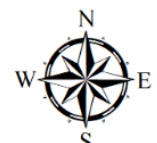

Figure 5-5: Spatial-Temporal Comparison of MODIS and Landsat NDVI (2000-2015)

After comparing MODIS and Landsat, one can also make a comparison between Landsat and Pleiades results. Figure 5-6 shows that the Pleiades has much finer documentation of surface types as it can focus on smaller scales more effectively.

In contrast, Landsat has more coarse identification of land uses. The Pleiades can identify small spots of green areas within the urban lands and around streets, where the average 
size of paths was 0.01 hectare and for Landsat was 0.94 hectare. So, there are many tiny green areas in the map for the Pleiades, while such areas were usually identified on Landsat images as a built-up place. When comparing the distribution of green areas of LSMA and Pleiades, also different; red colour referred in LSMA and blue in the Pleiades (Figure 5-6).
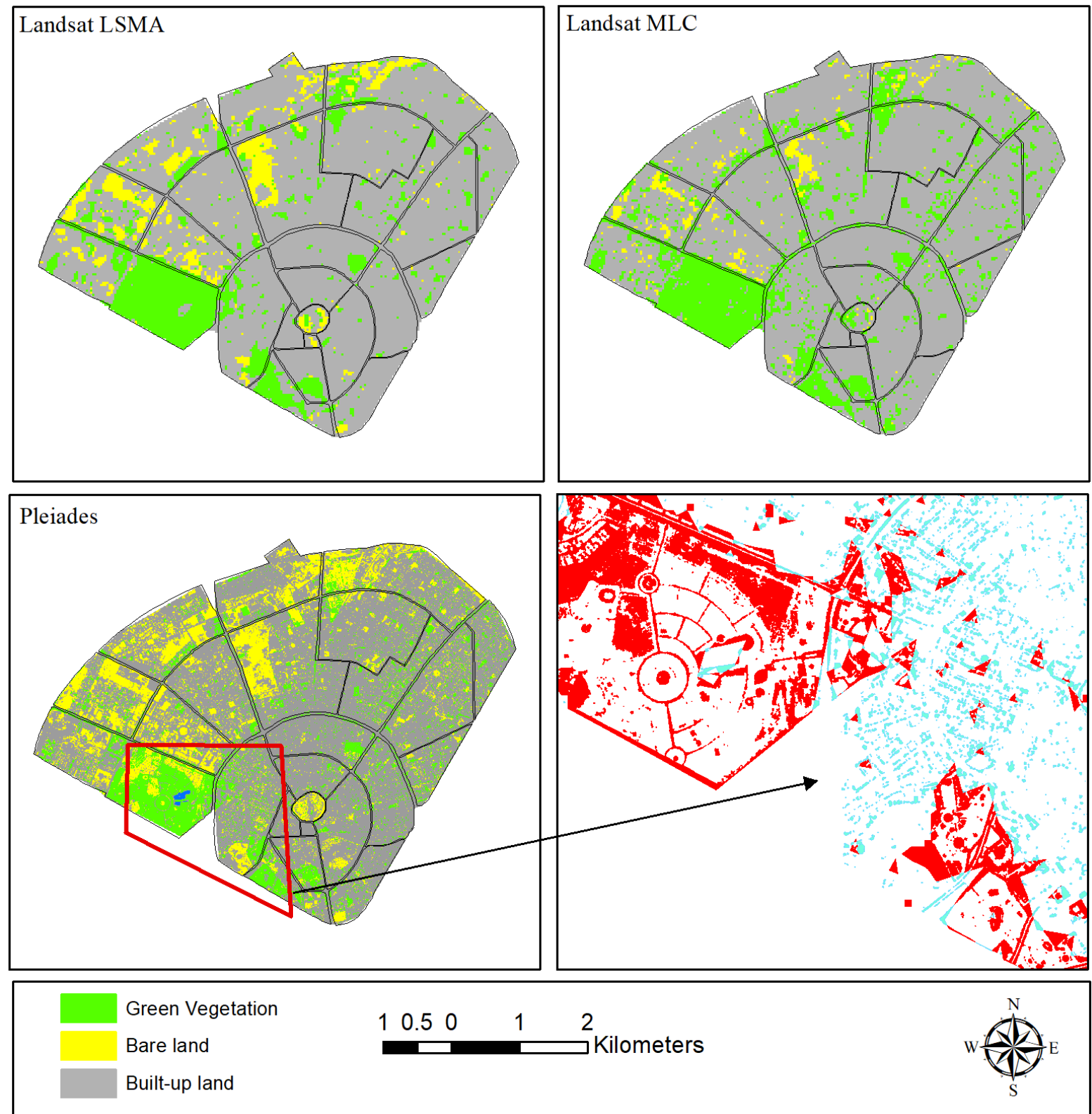

Figure 5-6: Spatial Comparison of Landsat MLC, LSMA, and Pleiades Land Uses in 2015

Statistical comparison of Landsat MLC, LSMA, and Pleiades land cover area for 2015 involve the same proportion of vegetation area for Landsat LSMA and the Pleiades $14 \%$. On the other hand, the share of bare land for LSMA $8 \%$ more accurate than the share of MLC 3\%, while the urban area was similar. Our results have several similarities with Tang et al. (2012), which indicates the results of LSMA more accurately than the MLC result comparing with the 
Pleiades (Figure 5-7). Meanwhile, the spatial distribution of green spaces in the districts differs; for example, the share of the city's largest green area, Sami Abdulrahman Park are 32\%, $40 \%$ and, $46 \%$ for the Pleiades, Landsat LSMA and MLC, respectively.

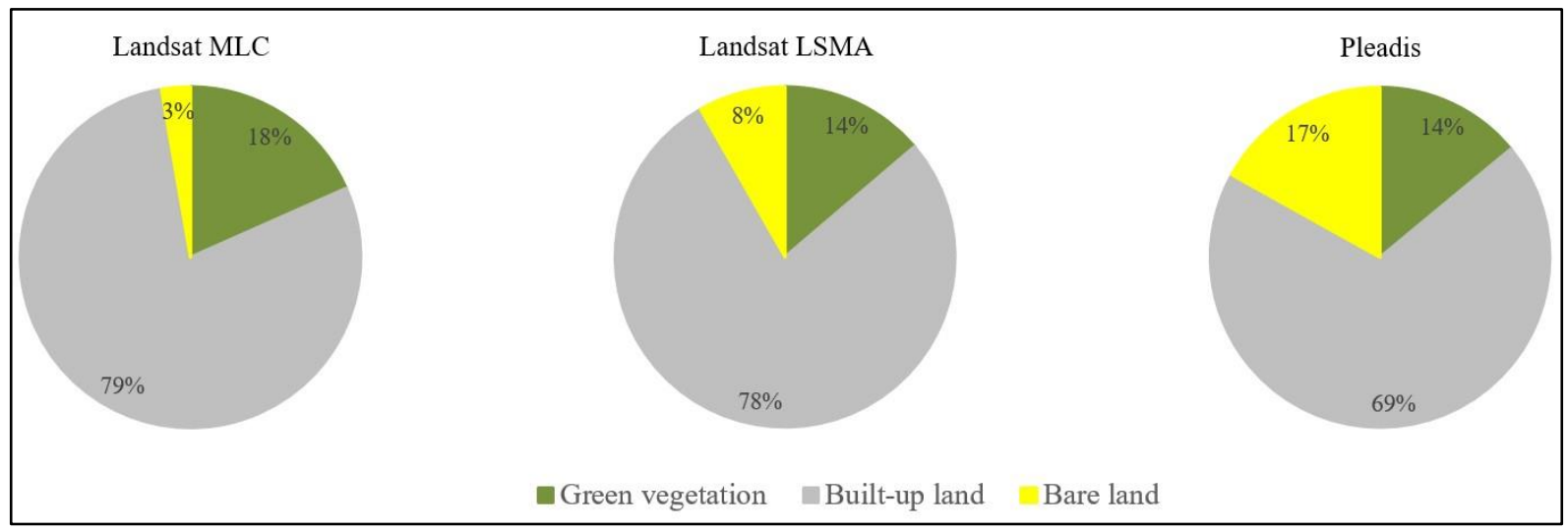

Figure 5-7: Land Use Shares across Landsat MLC, LSMA, and the Pleiades in 2015

Finally, one can compare three satellite imagery data at the same time, in addition to bivariate comparisons. In this context, Figure 5-8 shows the min, maximum, and average values of NDVI measure with MODIS, Landsat, and the Pleiades. It is seen that for this vegetation index, MODIS and Landsat do not produce different average values, with both estimating an index value of around 0.14 .

In contrast, Pleiades has a higher average value with 0.16 . In addition, the difference between the minimum and maximum values widens from MODIS to Landsat to the Pleiades. These results imply that the Pleiades has much more reliable and robust identification when studying smaller scales like the city districts.

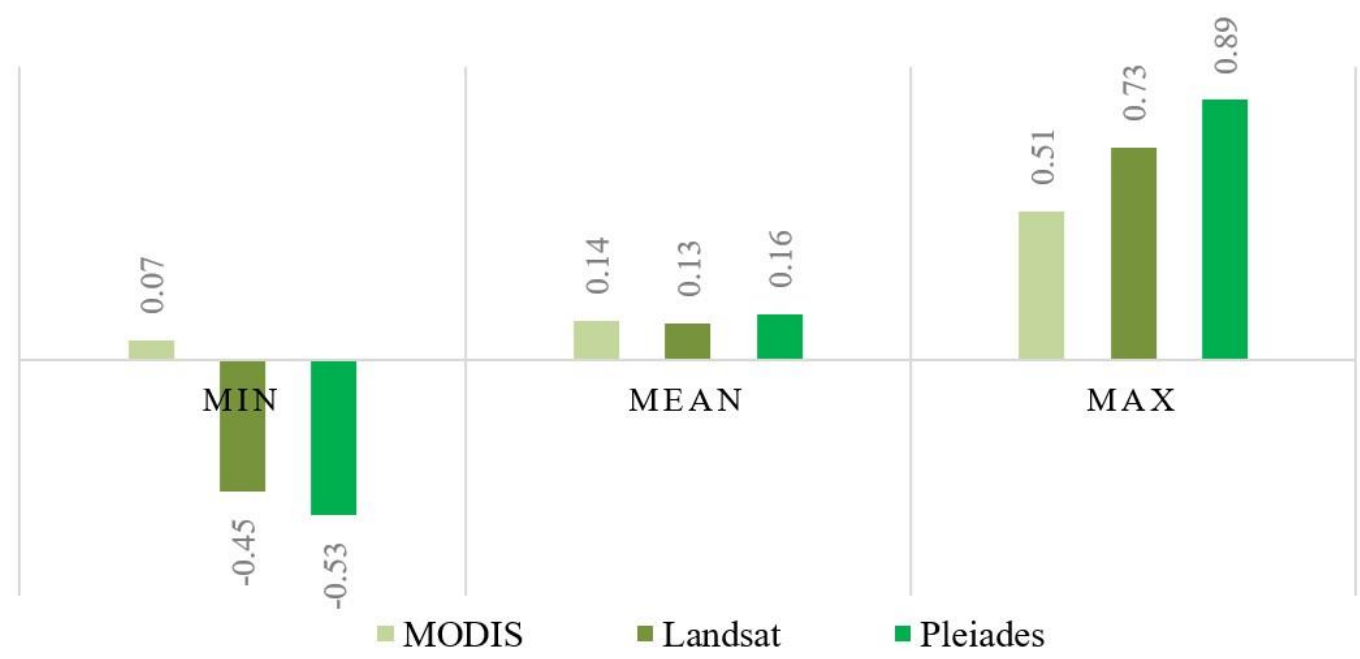

Figure 5-8: Comparison of MODIS, Landsat, and Pleiades NDVI in 2015 
Similar three-way comparisons can be made for spatial distribution as well. Figure 5-9 shows the spatial maps of MODIS, Landsat, and Pleiades NDVI for 2015. It is seen that MODIS provides a very coarse map since it does not fit to study such small scales. It is only able to identify around Abdulrahman Park and a few other places. When one moves to Landsat, the map becomes much clearer with more details. However, Landsat also fails to identify small green fields within urban areas. So, Figure 5-9 shows that studying the spatial distribution of vegetation areas, Pleiades gives much accurate documentation.

It is difficult to map in an urban landscape considering the small footprints of various features such as trees, parks, clusters of buildings, as well as roads. Mertes et al. (2015) stated that urban areas tend to be heterogeneous considering both material composition and configuration, and with the new expansion, they are often highly variable between locations. However, vegetation indices help obtain features of green space from complex urban areas.
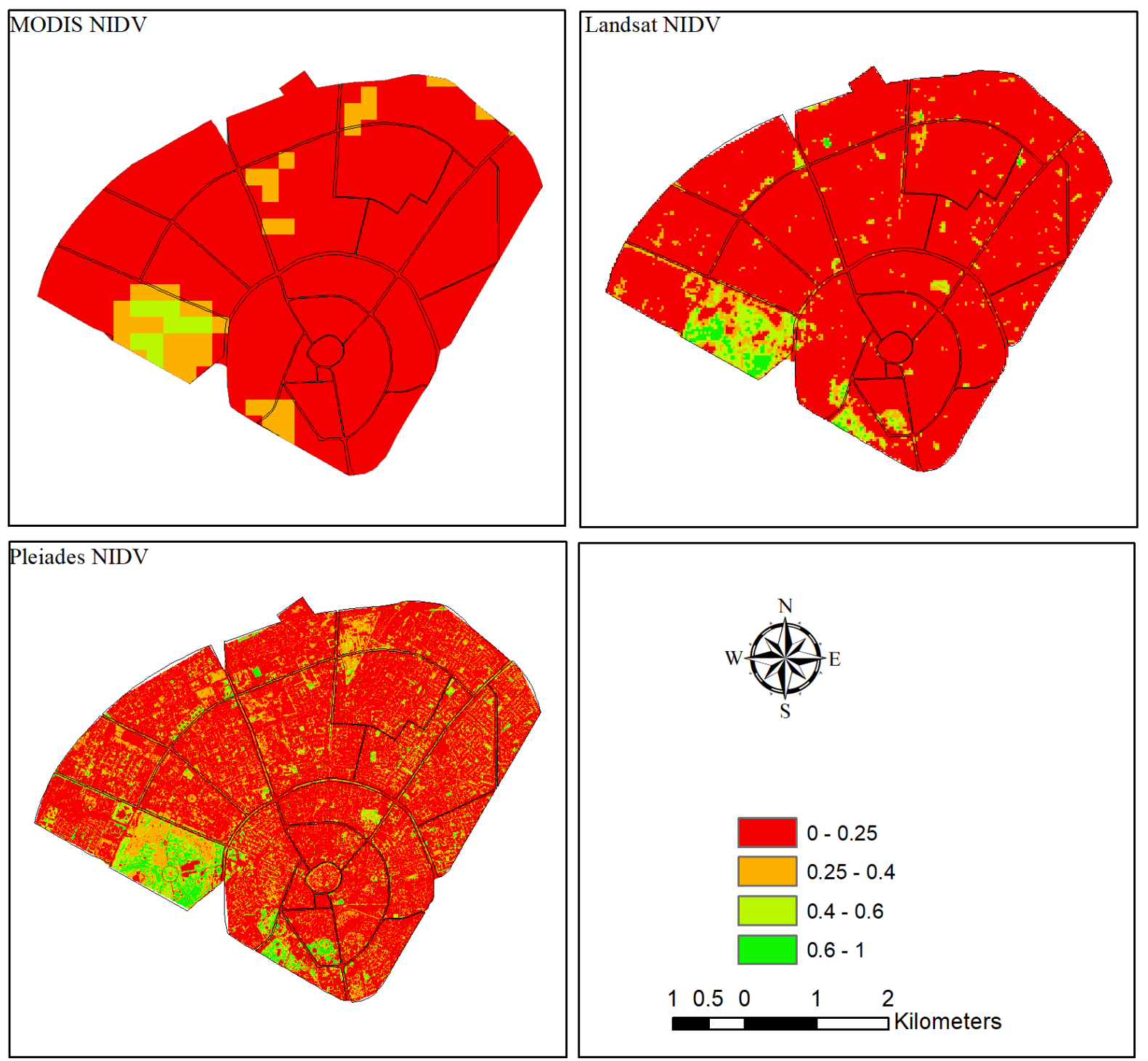

Figure 5-9: Spatial comparison of MODIS, Landsat and Pleiades NDVI in 2015 
Lunetta et al. (2006) and Zoran et al. (2013) examined that vegetation indices of MODIS suitable for urban areas with a low density of biomass. Overall, MODIS data remains able to provide valuable information on the general SVIs dynamics over time and space in the semi-arid urban areas. However, the information is at broader levels with little fine details. Then, the results from Landsat and Pleiades provides supporting evidence on further details. 


\section{Conclusion}

With economic development and rising urbanisation levels, city life experiences significant changes. Higher incomes and population densities lead to rises in demand for residential and commercial property along with a need for more effective infrastructure and transportation networks. Faced with such strong trends, ensuring the efficiency of cities and improving their economies of scale (or the agglomeration economies) would be necessary to create beneficial living conditions. In contrast, when these demands are not satisfied in proper ways, and if the city development progresses in a chaotic and uncoordinated fashion, then cities can become significant sources of environmental, economic, and social problems. Therefore, analysing the economic, demographic, social, and geographic/topographic dynamics of cities and urban areas is of the utmost importance of public officials and city managers. In this broad context, the vegetation area emerges as one of the most important dimensions for the favourable living conditions in cities. The lack of enough vegetation and green areas or their uneven distribution can create many problems for the city residents and worsen the living conditions. For example, some climate change consequences of limited green area, or the urban heat island impact of uneven vegetation distribution are among the important problems discussed in the literature review.

Remote sensing of urban area and greenery provides information on human growth spatial and temporal patterns that are useful to understand social, political, economic, climate, and ecological variations. Based on such essential points, the current dissertation examines the temporal and spatial vegetation dynamics in the city of Erbil and its surroundings. The primary methodological approach of the study is the use of remote sensing techniques by employing satellite data from three different sources, like MODIS, Landsat, and the Pleiades. In this way, three different data sources and three different scales are combined in a comparative to construct robust vegetation indices and to classify the surface cover into different types. This multi-method approach is an essential advantage of the current study, and it is the first step towards enhancing our knowledge of urban ecology in the city of Erbil. Within this context, the main aim of this research is to utilise different remote sensing data and approaches at different spatial resolutions (from large to small) to study and analyse the spatial and temporal patterns of the vegetation cover in the city of Erbil, Iraqi Kurdistan. Based on the relevant data, factors that lead to the changes in the vegetation indices also discussed, and better information to understand how the environmental and urban changes influence vegetation cover and urban ecology obtained. 
The results from three different methods are supportive of and complementary with each other. In the analysis of MODIS satellite imagery, as stated in the introduction, our main objective was to investigate the spatiotemporal variation of urban vegetation cover in the city and its surroundings and examine its relation to climate conditions. The primary target variable in the data analysis is the vegetation index, measured by EVI and NDVI variables. They show that over time the vegetation indices displayed some volatilities. For example, 2003 and 2015 were relatively green years, while 2008 was a mainly dry year. Also, the evolution of vegetation within a year displayed clear patterns. The spring months were the greenest periods, while the summer and autumn months had the lowers vegetation levels. Taken as a whole, it is clear that there is an expansion in the urban areas' spatial distribution in Erbil as well as its surrounding bare ground. Hence, in the past 16 years, urban growth has replaced the vegetation area. When the relationship of these vegetation dynamics with other factors examined, it found that rainfall and humidity are the main factors determining the vegetation pattern. The impact of temperature found to be relatively limited. The evidence from this study suggests that using MODIS for city environment analysis is beneficial to provide phenological information at various spatial and temporal resolutions.

Compared to the MODIS satellite imagery data, Landsat produces more detailed results at the regional level and more computationally intensive, due to higher spatial resolution, and providing a longer-term record of data. A set of six cloud-free Landsat images were adopted in the summer months to study the spatiotemporal variation of urban greenness cover in the city limits and examine the role of urban expansion. Sample of years starting from 1990 to 2015 at five-year intervals. To classify the land cover types at the pixel level, the linear spectral mixture analysis (LSMA), and the maximum likelihood classification (MLC) methods are employed.

The results from Landsat satellite imagery data show that land cover types displayed a significant change in the sample years covering the period of 1990-2015. This development is closely related to the rising population and the increasing urbanisation rates in the city of Erbil. The rising share of build-up land happened at the expense of bare land and agricultural land. On the other hand, vegetation area displayed significant volatilities over the sample period of 1990-2015. Up to 2005, there was a significant decline in the vegetation area due to the strong rise of urbanisation. Then, the municipality involved in the construction of large parks in the city. These parks were instrumental in the rise of vegetation area in the city limits. So, when the initial year of 1990 and the final year of 2015, the relevant vegetation indices show small variations and remained unchanged compared to other rates of land use growth. 
Overall, the Landsat imagery data indicates a significant change in the level and composition of green areas in Erbil.

Similar to MODIS imagery data, Landsat SVIs (EVI and NDVI) were examined from 1990 to 2015 . The results indicate that the biomass of vegetation remains low. The mean of EVI and NDVI started at the highest value in 1990 and decreased gradually to dip in 2005, then increased gradually to 2015. Overall, vegetation indices showed a gradually decreasing trend from 1990 to 2015. This finding is consistent with the above results, which show that biomass of green vegetation and agricultural land declined significantly, with the decline coming from the disappearance of agricultural land.

As part of the methodological approach, the high spatial resolution of Pleiades satellite imagery data with $0.5 \mathrm{~m}$ was used to provide a detailed analysis of urban greenness distribution for particular city districts in 2015 and examine the access of city dwellers to green areas. An essential advantage of this method is that it can construct very detailed land surface types and vegetation indices within the city districts. The results show that the Sami Abdulrahman Park stands out as the greenest area in the city, while other areas have small and dispersed green areas. In addition, the area of vegetation distributed unequally; it found that some districts have very high vegetation areas, while half of the regions have very limited or almost no green areas. These indicate the lack of vegetation cover in the city of Erbil as compared with the international criterions of green areas in cities. The spatial distribution confirms the previous finding that green vegetation is distributed very unevenly across districts. Consequently, this finding considering as a significant point in terms of justifying the study objectives. May have impacted the ecosystem function, biodiversity, and climatic variables.

Overall, as discussed above, the three methods, which used in a complementary way, produce valuable data on the spatial and temporal distribution of surface cover types and vegetation indices in the city of Erbil and its surroundings. In general terms, all results indicate that built-up land increased significantly since 1990, while vegetation within the city limits displayed a volatile pattern. It declined significantly until 2005 with the strong process of urbanisation, but then the construction of large parks increased the vegetation share back to initial levels. However, the spatial picture turned into a very uneven vegetation distribution with significant portions of the city having very limited access to green areas. The Pleiades best obtains such detailed documentation compared to MODIS and Landsat. Therefore, the current dissertation produces significant consequences for city planning and ecological sustainability purposes. 
In Iraq's semi-arid areas, especially Erbil, vegetation patterns can be significantly affected and influenced by anthropogenic activity. Human environmental change has triggered a spatial-temporal transition from native plant species to controlled monocultures for agricultural or urban purposes. Due to seasonal vegetation and rained crop production, the relationship between urban and suburban ecosystems is weak. Therefore, local governments must strive to apply green sustainable development policies as well as climate change strategies to reduce vegetation loss and related impacts such as biodiversity loss and climate change.

Finally, the analysis of the dissertation succeeds in successfully answering the research questions. The evaluation of urban vegetation changes on different scales in the semi-arid region between 2000 and 2015 successfully conducted using three satellite imagery satellites. The results indicated that satellite images like MODIS are better at the documentation of larger scales, and they can become too coarse for identification of vegetation distribution and dynamics within smaller scales. In contrast, Landsat improves the documentation of surface types and dynamics significantly compared to MODIS. The relevant comparisons show that MODIS can stay silent over long periods with limited change in the shares of land use due to its coarse identification at smaller scales. However, Landsat is much successful in identifying vegetation distribution and dynamics. As a further step, if one aims to study very small scales, like the areas within the city limits, Pleiades is much better as it is able even to capture tiny green fields within urban areas. These outcomes add to a growing body of literature on the evaluation of urban ecology. However, Our investigations into this area are still in progress and seem likely to confirm our hypothesis. The most important limitation lies in spatialtemporal resolution, so using more modern and fine-detailed satellite imagery can improve the vegetation documentation to a large extent. Therefore the new-generation satellites that offer a higher spatial and temporal resolution, such as Sentinel-2, more appropriate for future research to provide more detailed accounts of vegetation. 


\section{ACKNOWLEDGEMENTS}

My deep gratitude and thanks for the kind assistance and guidance of my supervisor, Dr. Ferenc Kovács and Dr. Zalán Tobak, both through the courses and the writing of this dissertation. Their critical comments have been of great value to me.

I pay tribute to Prof. Dr. Gábor Mezősi whose help and guidance through the courses I greatly appreciate.

I also wish to express my deep indebtedness to the staff of the Department of Physical Geography and Geoinformatics of the University of Szeged.

My deep thanks also go to all my colleagues in the department and in Szeged whose help in providing me with most of the sources has been of great support to me.

Most sincere thanks and gratitude are due to family for their persistent aid, compassion and patience all through the courses and the preparation of this work.

Finally, I am greatly and deeply indebted to and thankful for Stipendium Hungaricum family for the financial support that enabled me to fulfil my work. 


\section{References}

Abdullah, H. (2012). The use of Landsat 5 TM imagery to detect urban expansion and its impact on land surface temperatures in the city of Erbil, Iraqi Kurdistan. MSc Diploma Work, University of Leicester, p.67.

Adler-Golden, S. M., Matthew, M. W., Bernstein, L. S., Levine, R. Y., Berk, A., Richtsmeier, S. C., Acharya, G.P. Anderson, G. Felde, J. Gardner, M. Hoke, L.S. Jeong, B. Pukall, J. Mello, A. Ratkowski and H. Burke. (1999). Atmospheric correction for shortwave spectral imagery based on MODTRAN4. Imaging Spectrometry V, 3753, 61-69.

Ahern, J., Cilliers, S., \& Niemelä, J. (2014). The concept of ecosystem services in adaptive urban planning and design: A framework for supporting innovation. Landscape and Urban Planning, 125, 254-259.

Ahmad, F. (2012). Detection of change in vegetation cover using multi-spectral and multitemporal information for District Sargodha, Pakistan. Sociedade \& Natureza, 24(3), $557-571$.

Anchang, J. Y., Ananga, E. O., \& Pu, R. (2016). An efficient unsupervised index based approach for mapping urban vegetation from IKONOS imagery. International Journal of Applied Earth Observation and Geoinformation, 50, 211-220.

Arnfield, A. J. (2003). Two decades of urban climate research: a review of turbulence, exchanges of energy and water, and the urban heat island. International Journal of Climatology: A Journal of the Royal Meteorological Society, 23(1), 1-26.

Ayanu, Y. Z., Conrad, C., Nauss, T., Wegmann, M., \& Koellner, T. (2012). Quantifying and mapping ecosystem services supplies and demands: a review of remote sensing applications. Environmental Science \& Technology, 46(16), 8529-8541.

Bajgiran, P. R., Shimizu, Y., Hosoi, F., \& Omasa, K. (2009). MODIS vegetation and water indices for drought assessment in semi-arid ecosystems of Iran. Journal of Agricultural Meteorology, 65(4), 349-355.

Balik, G., Aktaş, E., Önaç, A. K., \& Birişçi, T. (2017). Vegetation Cover Change of Çeşme Alaçatı Wind Power Plant Using Normalized Difference Vegetation Index (NDVI). Journal of International Environmental Application and Science, 12(3), 204-211.

Belgiu, M., Drăguct, L., \& Strobl, J. (2014). Quantitative evaluation of variations in rule-based classifications of land cover in urban neighbourhoods using WorldView-2 imagery. ISPRS Journal of Photogrammetry and Remote Sensing, 87, 205-215.

Benediktsson, J. A., Pesaresi, M., \& Amason, K. (2003). Classification and feature extraction for remote sensing images from urban areas based on morphological transformations. IEEE Transactions on Geoscience and Remote Sensing, 41(9), 1940-1949.

Bhandari, A. K., Kumar, A., \& Singh, G. K. (2012). Feature Extraction using Normalized Difference Vegetation Index (NDVI): A Case Study of Jabalpur City. Procedia Technology, 6, 612-621.

Blanusa, T., Garratt, M., Cathcart-James, M., Hunt, L., \& Cameron, R. W. F. (2019). Urban hedges: A review of plant species and cultivars for ecosystem service delivery in northwest Europe. Urban Forestry \& Urban Greening, 44, 126391.

Bonham, C. D. (2013). Measurements for terrestrial vegetation. John Wiley \& Sons. p.233.

Borak, J. S., Lambin, E. F., \& Strahler, A. H. (2000). The use of temporal metrics for land cover 
change detection at coarse spatial scales. International Journal of Remote Sensing, 21(67), 1415-1432.

Bretz, S., Akbari, H., \& Rosenfeld, A. (1998). Practical issues for using solar-reflective materials to mitigate urban heat islands. Atmospheric Environment, 32(1), 95-101.

Brown, M. E., De Beurs, K. M., \& Marshall, M. (2012). Global phenological response to climate change in crop areas using satellite remote sensing of vegetation, humidity and temperature over 26 years. Remote Sensing of Environment, 126, 174-183.

Buyantuyev, A., Wu, J., \& Gries, C. (2007). Estimating vegetation cover in an urban environment based on Landsat ETM+ imagery: a case study in Phoenix, USA. International Journal of Remote Sensing, 28(2), 269-291.

Cai, G., Ren, H., Yang, L., Zhang, N., Du, M., \& Wu, C. (2019). Detailed urban land use land cover classification at the metropolitan scale using a three-layer classification scheme. Sensors, 19(14), 3120.

Camberlin, P., Martiny, N., Philippon, N., \& Richard, Y. (2007). Determinants of the interannual relationships between remote sensed photosynthetic activity and rainfall in tropical Africa. Remote Sensing of Environment, 106(2), 199-216.

Campbell, J. B., \& Wynne, R. H. (2011). Introduction to remote sensing. Guilford Press. p.670.

Carrus, G., M. Scopelliti, R. Lafortezza, G. Colangelo, F. Ferrini, F. Salbitano, M. Agrimi, L. Portoghesi, P. Semenzato, and G. Sanesi. (2015). Go greener, feel better? The positive effects of biodiversity on the well-being of individuals visiting urban and peri-urban green areas. Landscape and Urban Planning, 134, 221-228.

Chang, C.-I. (2016). Real-time progressive hyperspectral image processing. New York: Springer. p605.

Chanussot, J., Benediktsson, J. A., \& Fauvel, M. (2006). Classification of remote sensing images from urban areas using a fuzzy possibilistic model. IEEE Geoscience and Remote Sensing Letters, 3(1), 40-44.

Chuvieco, E. (2016). Fundamentals of satellite remote sensing: An environmental approach. CRC press. p.468.

Clark, M. L., Aide, T. M., \& Riner, G. (2012). Land change for all municipalities in Latin America and the Caribbean assessed from 250-m MODIS imagery (2001-2010). Remote Sensing of Environment, 126, 84-103.

Colditz, R. R., Conrad, C., Wehrmann, T., Schmidt, M., \& Dech, S. (2006). Generation and assessment of MODIS time series using quality information. IEEE International Symposium on Geoscience and Remote Sensing, 779-782.

Congalton, R. G. (1991). A review of assessing the accuracy of classifications of remotely sensed data. Remote Sensing of Environment, 37(1), 35-46.

Czaplewski, R. L. (2003). Accuracy assessment of maps of forest condition: statistical design and methodological considerations. In Wulder, M. A., \& Franklin, S. E. (Eds), Remote Sensing of Forest Environments Concepts and Case Studies. Springer, Boston, MA. pp.115-140.

Dare, P. M. (2005). Shadow analysis in high-resolution satellite imagery of urban areas. Photogrammetric Engineering \& Remote Sensing, 71(2), 169-177.

Davenport, M. L., \& Nicholson, S. E. (1993). On the relation between rainfall and the Normalized Difference Vegetation Index for diverse vegetation types in East Africa. 
International Journal of Remote Sensing, 14(12), 2369-2389.

De la Vega-Leinert, A. C., Nolasco, M. A., \& Stoll-Kleemann, S. (2012). UNESCO Biosphere Reserves in an Urbanized World. Environment: Science and Policy for Sustainable Development, 54(1), 26-37.

Demetriades-Shah, T. H., Steven, M. D., \& Clark, J. A. (1990). High resolution derivative spectra in remote sensing. Remote Sensing of Environment, 33(1), 55-64.

Dewan, A. M., \& Yamaguchi, Y. (2009). Land use and land cover change in Greater Dhaka, Bangladesh: Using remote sensing to promote sustainable urbanization. Applied Geography, 29(3), 390-401.

El-Kawy, O. R. A., Rød, J. K., Ismail, H. A., \& Suliman, A. S. (2011). Land use and land cover change detection in the western Nile delta of Egypt using remote sensing data. Applied Geography, 31(2), 483-494.

Elmore, A. J., Mustard, J. F., Manning, S. J., \& Lobell, D. B. (2000). Quantifying vegetation change in semiarid environments: precision and accuracy of spectral mixture analysis and the normalized difference vegetation index. Remote Sensing of Environment, 73(1), 87-102.

Esau, I., Miles, V. V, Davy, R., Miles, M. W., \& Kurchatova, A. (2016). Trends in normalized difference vegetation index (NDVI) associated with urban development in northern West Siberia. Atmospheric Chemistry and Physics, 16(15), 9563-9577.

European Commission. (2019). Eurostat Statistics Explained: Territorial typologies. Retrieved from:https://ec.europa.eu/eurostat/statisticsexplained/index.php/Territorial_typologies\#S hare_of_land_area_by_type_of_territory (Accessed 25 October 2019).

Fatiha, B., Abdelkader, A., Latifa, H., \& Mohamed, E. (2013). Spatio temporal analysis of vegetation by vegetation indices from multi-dates satellite images: application to a semi arid area in Algeria. TerraGreen 13 International Conference 2013 - Advancements in Renewable Energy and Clean Environment, 36, 667-675. Energy Procedia, Elsevier.

Fernández-Martinez, M., Garbulsky, M., Peñuelas, J., Peguero, G., \& Espelta, J. M. (2015). Temporal trends in the enhanced vegetation index and spring weather predict seed production in Mediterranean oaks. Plant Ecology, 216(8), 1061-1072.

Friedl, M. A., McIver, D. K., Hodges, J. C. F., Zhang, X. Y., Muchoney, D., Strahler, A. H., Woodcock, C. E., Gopal, S., Schneider, A., Cooper, A., Baccini, A., Gao, F., and Schaaf, C. (2002). Global land cover mapping from MODIS: algorithms and early results. Remote Sensing of Environment, 83(1-2), 287-302.

Gao, X., Huete, A. R., \& Didan, K. (2003). Multisensor comparisons and validation of MODIS vegetation indices at the semiarid Jornada experimental range. IEEE Transactions on Geoscience and Remote Sensing, 41(10), 2368-2381.

Grimmond, S. U. E. (2007). Urbanization and global environmental change: local effects of urban warming. Geographical Journal, 173(1), 83-88.

Gupta, K., Kumar, P., Pathan, S. K., \& Sharma, K. P. (2012). Urban neighborhood green index- a measure of green spaces in urban areas. Landscape and Urban Planning, $105(3), 325-335$.

Hameed, H. (2013). Water harvesting in Erbil Governorate, Kurdistan region, Iraq: detection of suitable sites using geographic information system and remote sensing. MSc Diploma Work, University of Lund, p.47. 
Hasan, T. (2006). Geographical Analysis of the Characteristics of the Temperature in the Kurdistan Region of Iraq. MSc Diploma Work, University of Salahaddin, p.85.

Helbich, M. (2019). Spatiotemporal contextual uncertainties in green space exposure measures: Exploring a time series of the normalized difference vegetation indices. International Journal of Environmental Research and Public Health, 16(5), 852.

Henits, L., Jürgens, C., \& Mucsi, L. (2016). Seasonal multitemporal land-cover classification and change detection analysis of Bochum, Germany, using multitemporal Landsat TM data. International Journal of Remote Sensing, 37(15), 3439-3454.

Herold, M., Scepan, J., \& Clarke, K. C. (2002). The use of remote sensing and landscape metrics to describe structures and changes in urban land uses. Environment and Planning A, 34(8), 1443-1458.

Hofmann, P., Strobl, J., \& Nazarkulova, A. (2011). Mapping green spaces in Bishkek-how reliable can spatial analysis be? Remote Sensing, 3(6), 1088-1103.

Huete, A., Didan, K., Miura, T., Rodriguez, E. P., Gao, X., \& Ferreira, L. G. (2002). Overview of the radiometric and biophysical performance of the MODIS vegetation indices. Remote Sensing of Environment, 83(1-2), 195-213.

Hussein, S. O. (2008). construction of geography database for groundwater characteristics qualities in Erbil city. MSc Diploma Work, University of Mosul, p.113.

Hussein, S. O. (2017a). A vegetation cover time series assessment in Erbil, Iraq using vegetation indices derived from MODIS imagery. 7th Hungarian Landscape Ecology Conference, 267-274. Szeged: The Institute of Geography and Geology of the Faculty of Sciences and Informatics of the University of Szeged and the U-GEO Foundation.

Hussein, S. O. (2017b). The geographical evolution of urban greenness in the city of Erbil based on Landsat imagery. 20th HU and 9th HR-HU Geomathematical Congress "Geomathematics in Multidisciplinary Science, 232-239. Pécs, Hungary: Pécs Regional Committee of the Hungarian Academy of Sciences.

Hussein, S. O. (2018). Monitoring urban greenness evolution using multitemporal Landsat imagery in the city of Erbil (Iraq). Central European Geology, 62(1), 15-26.

Hussein, S. O., Kovács, F., \& Tobak, Z. (2017). Spatiotemporal assessment of vegetation indices and land cover for Erbil city and its surrounding using Modis imageries. Journal of Environmental Geography, 10(1-2), 31-39.

Hussein, S. O., Kovács, F., Tobak, Z., \& Abdullah, H. J. (2019). Spatial distribution of vegetation cover in Erbil city districts using high-resolution Pléiades satellite image. Landscape \& Environment, 12(1), 10-22.

Ibrahim, G. R. F. (2013). Urban expansion monitoring utilizing remote sensing tools in Erbil city-Kurdistan region. MSc Diploma Work, Department of Development and Society, Sheffield Hallam University, p.46.

Imhoff, M. L., Zhang, P., Wolfe, R. E., \& Bounoua, L. (2010). Remote sensing of the urban heat island effect across biomes in the continental USA. Remote Sensing of Environment, 114(3), 504-513.

James, P., Banay, R. F., Hart, J. E., \& Laden, F. (2015). A review of the health benefits of greenness. Current Epidemiology Reports, 2(2), 131-142.

Jensen, J. R., \& Hodgson, M. E. (2004). Remote sensing of selected biophysical variables and urban/suburban phenomena. In Brunn, S. D., Cutter, S. L., \& Harrington Jr, J. W. (Eds.) 
Geography and technology. Springer. pp. 109-154.

Ji, L., \& Peters, A. J. (2007). Performance evaluation of spectral vegetation indices using a statistical sensitivity function. Remote Sensing of Environment, 106(1), 59-65.

Kak Ahmed H. A. (2006). Urban Land use changes in Erbil city from 1985-2005. MSc Diploma Work, University of Salahadin, Erbil, p.120.

Kennedy, R. E., Andréfouët, S., Cohen, W. B., Gómez, C., Griffiths, P., Hais, M., Healey, S.P., Helmer, E.H., Hostert, P., Lyons, M.B., Meigs, G.W., Pflugmacher, D., Phinn, S.R., Powell, S.L., Scarth, P., Sen, S., Schroeder, T.A., Schneider, A., Sonnenschein, R., Vogelmann, J.E., Wulder, M.A., Zhu, Z. (2014). Bringing an ecological view of change to Landsat-based remote sensing. Frontiers in Ecology and the Environment, 12(6), 339-346.

Kennedy, R. E., Cohen, W. B., \& Schroeder, T. A. (2007). Trajectory-based change detection for automated characterization of forest disturbance dynamics. Remote Sensing of Environment, 110(3), 370-386.

Khalid, N. (2014). Urban heat island in Erbil city. MSc Diploma Work, Lund University, p.47.

Klompmaker, J. O., Hoek, G.; Bloemsma, L. D., Gehring, U., Strak, M., Wijga, A. H., van den Brink, C., Brunekreef, B., Lebret, E., Janssen, N. A. H. (2018). Green space definition affects associations of green space with overweight and physical activity. Environmental Research, 160, 531-540.

Koedsin, W., \& Huete, A. (2015). Mapping rubber tree stand age using Pléiades Satellite Imagery: A case study in Talang district, Phuket, Thailand. Engineering Journal, 19(4), $45-56$.

Kong, F., \& Nakagoshi, N. (2006). Spatial-temporal gradient analysis of urban green spaces in Jinan, China. Landscape and Urban Planning, 78(3), 147-164.

Kong, F., \& Nakagoshin, N. (2005). Changes of urban green spaces and their driving gorces: a case Study of Jinan city, China. Journal of International Development and Cooperation, 11(2), 97-109.

Köppen, W., Volken, E., \& Brönnimann, S. (2011). The thermal zones of the earth according to the duration of hot, moderate and cold periods and to the impact of heat on the organic world (Translated from: Die Wärmezonen der Erde, nach der Dauer der heissen, gemässigten und kalten Zeit und nach der Wirku). Meteorologische Zeitschrift, 20(3), 351-360.

KRG. (2015). Ministry of Interior. Erbil Governorate, Plannig and GIS Office.

KRG. (2016). Ministry of agriculture and water resources. Department of Information Technology.

Kustas, W. P., Norman, J. M., Anderson, M. C., \& French, A. N. (2003). Estimating subpixel surface temperatures and energy fluxes from the vegetation index-radiometric temperature relationship. Remote Sensing of Environment, 85(4), 429-440.

Lanorte, A., Lasaponara, R., Lovallo, M., \& Telesca, L. (2014). Fisher Shannon information plane analysis of SPOT/VEGETATION Normalized Difference Vegetation Index (NDVI) time series to characterize vegetation recovery after fire disturbance. International Journal of Applied Earth Observation and Geoinformation, 26, 441-446.

Li, F., Han, L., Liujun, Z., Yinyou, H., \& Song, G. (2016). Urban vegetation mapping based on the hj-1 ndvi reconstrction. International Archives of the Photogrammetry, Remote Sensing \& Spatial Information Sciences, 41.

Li, F., Song, G., Liujun, Z., Yanan, Z., \& Di, L. (2017). Urban vegetation phenology analysis using 
high spatio-temporal NDVI time series. Urban Forestry \& Urban Greening, 25, 43-57.

Li, H., Zheng, L., Lei, Y., LI, C., \& Zhou, K. (2007). Comparison of NDVI and EVI based on EOS/MODIS data. Progress in Geography, 26, 26-32.

Lindgren, D. T. (1985). Land use/land cover: inventory and change. In Land use planning and remote sensing (pp. 101-115). Springer.

Liu, T., \& Yang, X. (2013). Mapping vegetation in an urban area with stratified classification and multiple endmember spectral mixture analysis. Remote Sensing of Environment, 133, 251-264.

Liu, Y., Wang, Y., Peng, J., Du, Y., Liu, X., Li, S., \& Zhang, D. (2015). Correlations between urbanization and vegetation degradation across the world's metropolises using DMSP/OLS nighttime light data. Remote Sensing, 7(2), 2067-2088.

Liu, Z., He, C., Zhou, Y., \& Wu, J. (2014). How much of the world's land has been urbanized, really? A hierarchical framework for avoiding confusion. Landscape Ecology, 29(5), 763-771.

Lo, C. P., Quattrochi, D. A., \& Luvall, J. C. (1997). Application of high-resolution thermal infrared remote sensing and GIS to assess the urban heat island effect. International Journal of Remote Sensing, 18(2), 287-304.

Lunetta, R. S., Knight, J. F., Ediriwickrema, J., Lyon, J. G., \& Worthy, L. D. (2006). Landcover change detection using multi-temporal MODIS NDVI data. Remote Sensing of Environment, 105(2), 142-154.

Maas, J., Verheij, R. A., Spreeuwenberg, P., \& Groenewegen, P. P. (2008). Physical activity as a possible mechanism behind the relationship between green space and health: a multilevel analysis. BMC Public Health, 8(1), 206.

Mallick, J., Kant, Y., \& Bharath, B. D. (2008). Estimation of land surface temperature over Delhi using Landsat-7 ETM+. J. Ind. Geophys. Union, 12(3), 131-140.

Martin, M. E., Newman, S. D., Aber, J. D., \& Congalton, R. G. (1998). Determining forest species composition using high spectral resolution remote sensing data. Remote Sensing of Environment, 65(3), 249-254.

Martínez, B., \& Gilabert, M. A. (2009). Vegetation dynamics from NDVI time series analysis using the wavelet transform. Remote Sensing of Environment, 113(9), 1823-1842.

McMorris, O., Villeneuve, P. J., Su, J., \& Jerrett, M. (2015). Urban greenness and physical activity in a national survey of Canadians. Environmental Research, 137, 94-100.

Melaas, E. K., Wang, J. A., Miller, D. L., \& Friedl, M. A. (2016). Interactions between urban vegetation and surface urban heat islands: a case study in the Boston metropolitan region. Environmental Research Letters, 11(5), 54020.

Mertes, C. M., Schneider, A., Sulla-Menashe, D., Tatem, A. J., \& Tan, B. (2015). Detecting change in urban areas at continental scales with MODIS data. Remote Sensing of Environment, 158, 331-347.

Ministry of Planning. (2014). Central Statistical Organization, Iraq. Retrieved from http://cosit.gov.iq.

Moskal, L. M., Styers, D. M., \& Halabisky, M. (2011). Monitoring urban tree cover using object-based image analysis and public domain remotely sensed data. Remote Sensing, $3(10), 2243-2262$. 
Mucsi, L., Liska, C. M., Henits, L., Tobak, Z., Csendes, B., \& Nagy, L. (2017). The evaluation and application of an urban land cover map with image data fusion and laboratory measurements. Hungarian Geographical Bulletin, 66(2), 145-156.

Mustafa, Y. T., Habeeb, H. N., Stein, A., \& Sulaiman, F. Y. (2015). Identification and mapping of tree species in urban areas using Worldview-2 imagery. ISPRS Annals of Photogrammetry, Remote Sensing \& Spatial Information Sciences, 2, 175-181.

Myint, S. W. (2006). Urban vegetation mapping using sub-pixel analysis and expert system rules: a critical approach. International Journal of Remote Sensing, 27(13), 2645-2665.

Nicholson, S. E., Davenport, M. L., \& Malo, A. R. (1990). A comparison of the vegetation response to rainfall in the Sahel and East Africa, using normalized difference vegetation index from NOAA AVHRR. Climatic Change, 17(2-3), 209-241.

Noor, N. M., Abdullah, A., \& Manzahani, M. N. H. (2013). Land cover change detection analysis on urban green area loss using GIS and remote sensing techniques. Planning Malaysia Journal, 11(3), 125-138.

Omer, I. A. H. (1998). Urban hydrology of Erbil city reign. Doctoral Dissertation, University of Baghdad, p.95.

Pataki, D. E., Bowling, D. R., Ehleringer, J. R., \& Zobitz, J. M. (2006). High resolution atmospheric monitoring of urban carbon dioxide sources. Geophysical Research Letters, $33(3), 1-5$.

Rafiee, R., Salman Mahiny, A., \& Khorasani, N. (2009). Assessment of changes in urban green spaces of Mashad city using satellite data. International Journal of Applied Earth Observation and Geoinformation, 11(6), 431-438.

Rakonczai, J. (2018). Global and Geopolitical Environmental Challenges. Corvinus University of Budapest. p.298.

Rasul, A. (2016). Remote Sensing of Surface Urban Cool and Heat Island Dynamics in Erbil, Iraq, between 1992 and 2013. Doctoral Dissertation, University of Leicester, p.146.

Rasul, A., Balzter, H., \& Smith, C. (2015). Spatial variation of the daytime Surface Urban Cool Island during the dry season in Erbil, Iraqi Kurdistan, from Landsat 8. Urban Climate, 14, 176-186.

Rasul, A., Balzter, H., \& Smith, C. (2016). Diurnal and seasonal variation of surface urban cool and heat islands in the semi-arid city of Erbil, Iraq. Climate, 4(3), 42.

Rasul, A., Balzter, H., \& Smith, C. (2017). Applying a normalized ratio scale technique to assess influences of urban expansion on land surface temperature of the semi-arid city of Erbil. International Journal of Remote Sensing, 38(13), 3960-3980.

Rawat, J. S., \& Kumar, M. (2015). Monitoring land use/cover change using remote sensing and GIS techniques: A case study of Hawalbagh block, district Almora, Uttarakhand, India. The Egyptian Journal of Remote Sensing and Space Science, 18(1), 77-84.

Ritchie, H., \& Roser, M. (2018). Urbanization. Our World in Data. Retrieved from https://ourworldindata.org/urbanization (Accessed 20 August 2019)

Sadowski, F. G., Sturdevant, J. A., \& Rowntree, R. A. (1987). Testing the consistency for mapping urban vegetation with high-altitude aerial photographs and Landsat MSS data. Remote Sensing of Environment, 21(2), 129-141.

Sakamoto, T., Van Nguyen, N., Kotera, A., Ohno, H., Ishitsuka, N., \& Yokozawa, M. (2007). Detecting temporal changes in the extent of annual flooding within the Cambodia and the 
Vietnamese Mekong Delta from MODIS time-series imagery. Remote Sensing of Environment, 109(3), 295-313.

Salehi, B., Zhang, Y., Zhong, M., \& Dey, V. (2012). Object-based classification of urban areas using VHR imagery and height points ancillary data. Remote Sensing, 4(8), 2256-2276.

Salimi Kouchi, H., Sahebi, M. R., Abkar, A. A., \& Valadan Zoej, M. J. (2013). Fractional vegetation cover estimation in urban environments. ISPRS-International Archives of the Photogrammetry, Remote Sensing and Spatial Information Sciences, (3), 357-360.

Sandholt, I., Rasmussen, K., \& Andersen, J. (2002). A simple interpretation of the surface temperature/vegetation index space for assessment of surface moisture status. Remote Sensing of Environment, 79(2-3), 213-224.

Santos, P., \& Negri, A. J. (1997). A comparison of the normalized difference vegetation index and rainfall for the Amazon and northeastern Brazil. Journal of Applied Meteorology, 36(7), 958-965.

Satellite Overview Geoimage. (2019). Retrieved November 21, 2019, from https://www.geoimage.com.au/satellites/satellite-overview

Schneider, A. (2012). Monitoring land cover change in urban and peri-urban areas using dense time stacks of Landsat satellite data and a data mining approach. Remote Sensing of Environment, 124, 689-704.

Scholz, T., Hof, A., \& Schmitt, T. (2018). Cooling effects and regulating ecosystem services provided by urban trees-novel analysis approaches using urban tree cadastre data. Sustainability, 10(3), 712.

Schucknecht, A., Erasmi, S., Niemeyer, I., \& Matschullat, J. (2013). Assessing vegetation variability and trends in north-eastern Brazil using AVHRR and MODIS NDVI time series. European Journal of Remote Sensing, 46(1), 40-59.

Senanayake, I. P., Welivitiya, W., \& Nadeeka, P. M. (2013). Urban green spaces analysis for development planning in Colombo, Sri Lanka, utilizing THEOS satellite imagery-A remote sensing and GIS approach. Urban Forestry \& Urban Greening, 12(3), 307-314.

Sertel, E., \& Akay, S. S. (2015). High resolution mapping of urban areas using SPOT-5 images and ancillary data. International Journal of Environment and Geoinformatics, 2(2), 63-76.

Small, C., \& Miller, R. B. (2000). Spatiotemporal monitoring of urban vegetation. In: Proceedings of International Symposium on Remote Sensing of Environment, 2-5. Capetown, South Africa.

Solecki, W. D., Rosenzweig, C., Parshall, L., Pope, G., Clark, M., Cox, J., \& Wiencke, M. (2005). Mitigation of the heat island effect in urban New Jersey. Global Environmental Change Part B: Environmental Hazards, 6(1), 39-49.

Somers, B., Asner, G. P., Tits, L., \& Coppin, P. (2011). Endmember variability in Spectral Mixture Analysis: A review. Remote Sensing of Environment, 115(7), 1603-1616.

Stabler, L. B., Martin, C. A., \& Brazel, A. J. (2005). Microclimates in a desert city were related to land use and vegetation index. Urban Forestry \& Urban Greening, 3(3-4), 137-147.

Sun, J., Yang, J., Zhang, C., Yun, W., \& Qu, J. (2013). Automatic remotely sensed image classification in a grid environment based on the maximum likelihood method. Mathematical and Computer Modelling, 58(3-4), 573-581.

Tang, J., Chen, F., \& Schwartz, S. S. (2012). Assessing spatiotemporal variations of 
greenness in the Baltimore-Washington corridor area. Landscape and Urban Planning, 105(3), 296-306.

Tavares, P. A., Beltrão, N., Guimarães, U. S., Teodoro, A., \& Gonçalves, P. (2019). Urban Ecosystem Services Quantification through Remote Sensing Approach: A Systematic Review. Environments, 6(5), 51.

Tooke, T. R., Coops, N. C., Goodwin, N. R., \& Voogt, J. A. (2009). Extracting urban vegetation characteristics using spectral mixture analysis and decision tree classifications. Remote Sensing of Environment, 113(2), 398-407.

Tredici, P. Del. (2010). Spontaneous Urban Vegetation: Reflections of Change in a Globalized World. Nature and Culture, 5(3), 299-315.

Tzoulas, K., Korpela, K., Venn, S., Yli-Pelkonen, V., Kaźmierczak, A., Niemela, J., \& James, P. (2007). Promoting ecosystem and human health in urban areas using Green Infrastructure: A literature review. Landscape and Urban Planning, 81(3), 167-178.

Unger, J., Lelovics, E., \& Gál, T. (2014). Local Climate Zone mapping using GIS methods in Szeged. Hungarian Geographical Bulletin, 63(1), 29-41.

United Nations. (2014). World urbanization prospects: The 2014 revision, highlights. New York: United Nations. p.493.

United Nations World Urbanization Prospects. (2018). World Urbanization Prospects: The 2018 Revision. In Department of Economic and Social Affairs, Population Division. Retrieved from https://esa.un.org/unpd/wup/ (Accessed 23 August 2019)

USGS. (2016). Vegetation Indices 16 - Day L3 Global 250m. Retrieved from https://lpdaac.usgs.gov/dataset_discovery/modis/modis_products_table/mod13q1, (Accessed 19 October 2016)

van den Bosch, M., \& Ode Sang. (2017). Urban natural environments as nature-based solutions for improved public health - A systematic review of reviews. Environmental Research, 158(November 2016), 373-384.

Walton, J. T. (2008). Difficulties with estimating city-wide urban forest cover change from national, remotely-sensed tree canopy maps. Urban Ecosystems, 11(1), 81-90.

Weng, Q., Lu, D., \& Schubring, J. (2004). Estimation of land surface temperature-vegetation abundance relationship for urban heat island studies. Remote Sensing of Environment, 89(4), 467-483.

Wikimedia Commons. (2016). Retrieved February 26, 2020, from https://commons.wikimedia.org/wiki/Main_Page

Wilson, J. S., Clay, M., Martin, E., Stuckey, D., \& Vedder-Risch, K. (2003). Evaluating environmental influences of zoning in urban ecosystems with remote sensing. Remote Sensing of Environment, 86(3), 303-321.

$\mathrm{Wu}, \mathrm{J}$. (2014). Urban ecology and sustainability: The state-of-the-science and future directions. Landscape and Urban Planning, 125, 209-221.

Xiao, X., Zhang, J., Yan, H., Wu, W., \& Biradar, C. (2009). Land surface phenology convergence of satellite and $\mathrm{CO} 2$ eddy flux observations. In Noormets, A. (Ed.), Phenology of Ecosystem Processes: Applications in Global Change Research. New York, NY: Springer. Pp 247-270.

Xie, Y., Sha, Z., \& Yu, M. (2008). Remote sensing imagery in vegetation mapping: a review. Journal of Plant Ecology, 1(1), 9-23. 
Xue, J., \& Su, B. (2017). Significant remote sensing vegetation indices: A review of developments and applications. Journal of Sensors, 1-17.

Yuan, F., \& Bauer, M. E. (2007). Comparison of impervious surface area and normalized difference vegetation index as indicators of surface urban heat island effects in Landsat imagery. Remote Sensing of Environment, 106(3), 375-386.

Yunhao, C., Peijun, S., Xiaobing, L., Jin, C., \& Jing, L. (2006). A combined approach for estimating vegetation cover in urban/suburban environments from remotely sensed data. Computers \& Geosciences, 32(9), 1299-1309.

Zhang, X., Friedl, M. A., \& Schaaf, C. B. (2006). Global vegetation phenology from Moderate Resolution Imaging Spectroradiometer (MODIS): Evaluation of global patterns and comparison with in situ measurements. Journal of Geophysical Research: Biogeosciences, 111(G4).

Zhang, X., Friedl, M.A., Schaaf, C.B., Strahler, A.H., Hodges, J.C.F., Gao, F., Reed, B.C., Huete, A (2003). Monitoring vegetation phenology using MODIS. Remote Sensing of Environment, 84(3), 471-475.

Zhang, Y., \& Yang, X. (2019). Evaluate the spatio-temporal changes of vegetation and human activities in China's Wulingyuan Natural World Heritage Site. E3S Web of Conferences, 118.

Zhao, J., Chen, S., Jiang, B., Ren, Y., Wang, H., Vause, J., \& Yu, H. (2013). Temporal trend of green space coverage in China and its relationship with urbanization over the last two decades. Science of the Total Environment, 442, 455-465.

Zhou, X., \& Wang, Y.-C. (2011). Spatial-temporal dynamics of urban green space in response to rapid urbanization and greening policies. Landscape and Urban Planning, 100(3), 268-277.

Zoran, M. A., Savastru, R. S., Savastru, D. M., Dida, A. I., \& Ionescu, O. M. (2013). Urban vegetation land covers change detection using multi-temporal MODIS Terra/Aqua data. In Conference on Remote Sensing for Agriculture, Ecosystems, and Hydrology $X V, 8887,888720$. 